\title{
ANÁLISE DOS CUSTOS PRIVADOS E SOCIAIS DA EROSĀO DO SOLO - O CASO DA BACIA DO RIO CORUMBATAI
}

\section{ARIEL ABDERRAMAN ORTIZ LÓPEZ}

\author{
Engenheiro Agrônomo
}

Orientador: Prof. Dr. Ricardo Shirota

\begin{abstract}
Tese apresentada à Escola Superior de Agricultura "Luiz de Queiroz", Universidade de São Paulo, para obtenção do titulo de Doutor em Ciências, Área de Concentração: Economia Aplicada.
\end{abstract}

\section{PIRACICABA}

Estado de São Paulo - Brasil

Novembro - 1997 
Dados Internacionais de catalogação na Publicação (CIP) DIVISÃo DE BIBLIOTECA E DOCUMENTAÇÃO - Campus "Luiz de Queiroz"/USP

Ortiz López, Ariel Abderraman

Análise dos custos privados e sociais da erosão do solo : caso da bacia do Rio Corumbatai / Ariel Abderraman Ortiz López. - Piracicaba, 1997.

$118 \mathrm{p}$.

Tese (doutorado) - Escola Superior de Agricultura Luiz de Queiroz, 1998. Bibliografia.

1. Custo (avaliação) 2. Erosão 3. Perda de produtividade 4. Rio Corumbatai (bacia) I. Titulo 


\title{
ANÁLISE DOS CUSTOS PRIVADOS E SOCIAIS DA EROSÃO DO SOLO - O CASO DA BACIA DO RIO CORUMBATAI
}

\author{
ARIEL ABDERRAMAN ORTIZ LÓPEZ
}

Aprovada em: 02.03.1998

Comissão julgadora:

Prof. Dr. RICARDO SHIROTA

ESALQ/USP

Profa. Dra. ZILDA PAES DE BARROS MATTOS

ESALQ/USP

Prof. Dr. CARLOS JOSE CAETANO BACHA

ESALQ/USP

Prof. Dr. FRANCISCO LOMBARDI NETO

IAC

Prof. Dr. JOÃO FERNANDO MARQUES

EMBRAPA

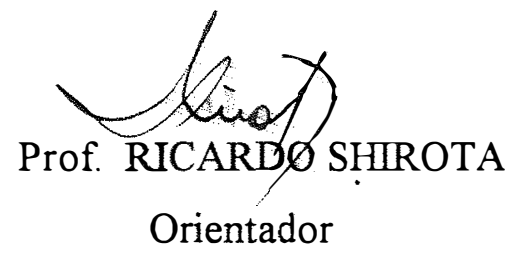




\section{OFEREÇO}

A minha mãe Belarmina, pelo constante incentivo para os estudos

DEDICO

A minha esposa Paula e aos meus filhos Paulo, Astrid e Gerardo 


\section{AGRADECIMENTOS}

É com muita satisfação que agradeço ao Professor Dr. Ricardo Shirota, pela generosa orientação durante a execução desta pesquisa.

Aos Professores Drs. Zilda Paes de Barros Mattos e Carlos José Caetano Bacha, pelas valiosas contribuições indispensáveis para a realização deste trabalho.

Aos Drs. Francisco Lombardi Neto e Pedro Donzeli do Instituto Agronômico de Campinas, pelo apoio na parte referente aos cálculos das perdas de terra por erosão.

Ao Professor Dr. Natálio Koffler da UNESP, por ter permitido o uso dos dados por ele gerados sobre unidades de solo, cobertura e declividades da bacia do rio Corumbatai.

Aos engenheiros José Edgard Camolesi e Elaine do SEMAE, por fornecerem os dados relacionados à estação de tratamento de água Capim Fino.

Aos engenheiros José Roberto e Plínio da usina Costa Pinto, pelo fornecimento dos dados para o cálculo do custo interno da erosão do solo.

Aos colegas do curso pelo, apoio ao longo da minha permanência na ESALQ.

Aos funcionários do DESR, pela colaboração prestada durante o desenvolvimento do programa de estudos.

À Faculdade de Agronomia da Universidade de San Carlos da Guatemala, pelo amplo apoio para a realização do programa de doutorado.

Á CAPES que viabilizou financeiramente a minha permanência no Brasil.

Ao PIRACENA, pelo fornecimento dos dados de uso da terra da bacia do rio Corumbatai em 1978. 


\section{S U M Á R I O}

Página

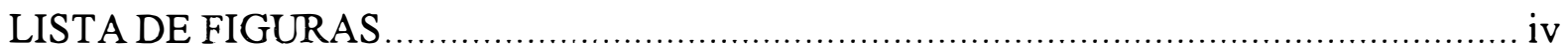

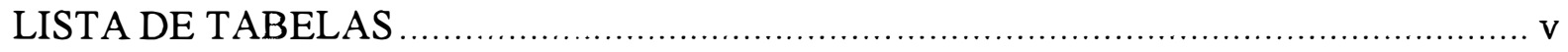

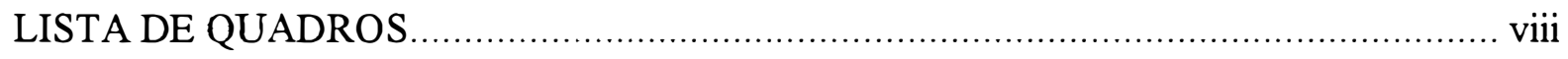

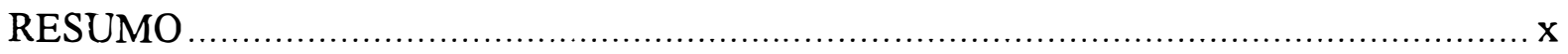

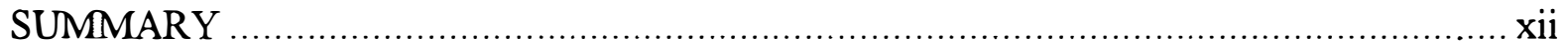

1 INTRODUÇÃO

1.1 A erosão do solo e os seus impactos internos e externos ...................................... 3

1.2 Conseqüências econômicas dos impactos da erosão do solo................................... 8

1.2.1 O custo da perda de produtividade pela erosão do solo .............................. 10

1.2.2 Os custos de tratamento de água devidos à erosão do solo ............................ 12

1.2.3 Os custos internos e externos da erosão do solo ..................................... 13

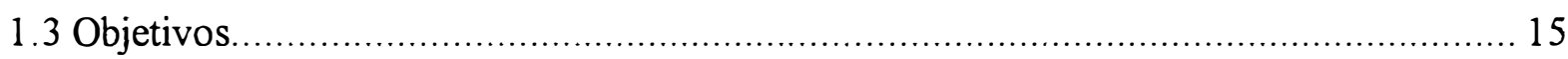

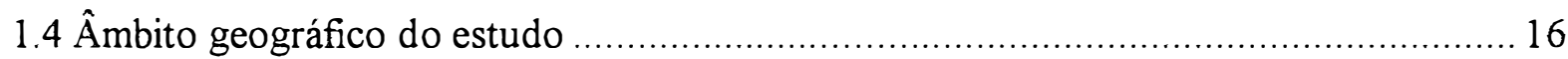

2 CONTEXTO TEÓRICO DA ANÁLISE ECONÔMICA …................................... 19

$2.1 \mathrm{O}$ custo da erosão do solo na unidade produtiva .......................................... 19

2.20 efeito econômico externo da erosão do solo....................................................... 28 


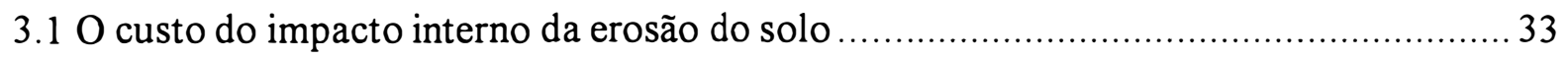

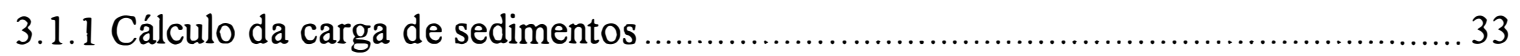

3.1.2 Valor monetário dos nutrientes perdidos junto à carga de sedimentos ................. 35

3.1.3 O custo da perda de produtividade causada pela erosão ………….................... 37

3.1.4 Determinação do custo interno da erosão do solo ............................................ 42

3.1.5 Definição das variáveis básicas e fonte dos dados ........................................... 43

3.2 Impacto da erosão do solo sobre o custo de tratamento de água para

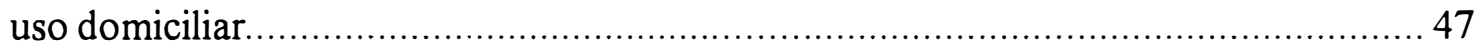

3.2.1 Estimativa da função custo operacional total de tratamento de água .................. 47

3.2.2 Estimativa do custo operacional total mensal de tratamento de água ................... 49

3.2.3 Estimativa do custo operacional adicional para a bacia..................................... 51

3.2.4 Definição das variáveis básicas e fontes dos dados ........................................... 52

3.3 Cálculo do custo total da erosão do solo na bacia ................................................... 55

4 RESULTADOS E DISCUSSÃO

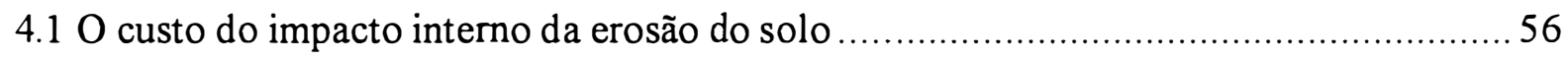

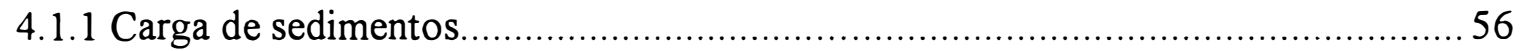

4.1.2 Valor monetário dos nutrientes perdidos junto à carga de sedimentos ................ 58

4.1.3 O custo da perda de produtividade causado pela erosão...................................... 59

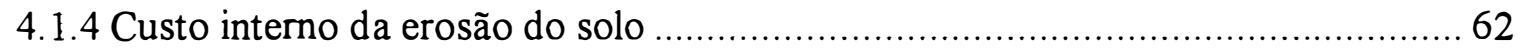

4.2 Impacto da erosão do solo sobre o custo de tratamento de água para uso domiciliar ..... 64

4.2.1 A função de custo operacional total de tratamento de água .................................64

4.2.2 Custo operacional adicional total anual de tratamento de água .............................66

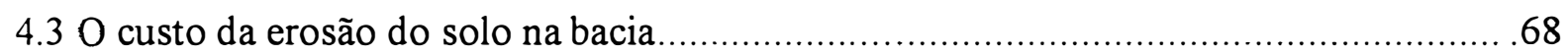

5 CONCLUSÕES

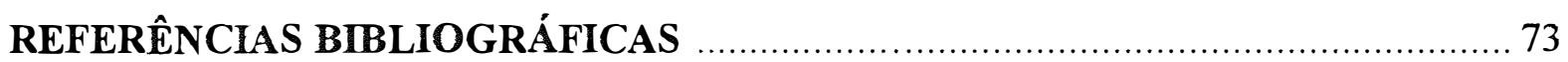


Apêndice 1: DADOS BÁSICOS PARA O CÁLCULO DO

VALOR DOS NUTRIENTES PERDIDOS 82

Apêndice 2: DADO BÁSICOS PARA A DETERMINAÇÃO DO VALOR DA PERDA DE PRODUTIVIDADE 92

Apêndice 3: DADOS DAS ESTAÇÕES DE TRATAMENTO DE ÁGUA E CÁlCULO DO CUSTO ADICIONAL. 98 


\section{I S T A DE FIGURAS}

Figura

Página

1 Localização geográfica da bacia do rio Corumbataí no Estado de São Paulo 16

2 Efeito econômico da depleção da fertilidade do solo pela erosão, sob um sistema de exploração da terra

3 Conseqüência econômica da perda de produtividade causada pela erosão do solo sob um sistema de exploração da terra 22

4 Efeito econômico da erosão do solo na unidade produtiva 25

5 Efeito econômico agregado da erosão do solo e do progresso tecnológico

6 Equilíbrio privado e equilibrio social na presença de externalidades negativas na produção 


\section{IS T A D E T A B E L A S}

Tabela

Página

1 Uso das terras da bacia do rio Corumbatai em 1978 e 1990

18

2 Perdas de terra e carga de sedimentos estimadas e toleráveis na bacia do rio Corumbatai, período 1985-1994

3 Valor das perdas de nutrientes (N, P, K, Ca e Mg) em reais de dezembro de 1995, na bacia do rio Corumbatai para o período 1985-1994

4 Estimativas do efeito das perdas de terra por erosão sobre o rendimento da cana-de-açúcar em solos Podzólico Vermelho-Amarelo da fazenda São Francisco, Latossolo Roxo e Terra Roxa Estruturada da fazenda Santa Rosa II, usina Costa Pinto, safra 1996 60 
5 Perda de produtividade na cultura de cana-de-açúcar causada pela erosão dos solos podzólicos da bacia do rio Corumbatai (em reais de dezembro de 1995), período 1985-1994

6 Custo interno da erosão do solo na bacia do rio Corumbatai (em reais de dezembro de 1995), período 1985-1994

7 Resultados da estimativa das funções de custo operacional de tratamento de água para a ETA 3 (Capim Fino) do SEMAE, Piracicaba

8 Custo operacional adicional de tratamento de água, estimado e tolerável, causado erosão do solo na bacia do rio Corumbatai (em reais de dezembro de 1995), período 1985-1994. 66

9 Custo operacional adicional mensal de tratamento de água por família abastecida na bacia do rio Corumbatai (em reais de dezembro de 1995), período 1985-1994 68

10 Custo da erosão do solo na bacia do rio Corumbatai (em reais de dezembro de 1995), período 1985-1994 69

11 Precipitação pluvial média mensal (em $\mathrm{mm}$ ) e do fator de erosividade da chuva (em MJ.mm/ha.h) dos municipios da bacia do rio Corumbatai, período 1962-1991 83

12 Valores do fator $\mathrm{C}$ para os distintos tipos de uso da terra na bacia do rio Corumbatai 84

13 Valores do fator $\mathrm{P}$ por classe de declividade na bacia do rio Corumbatai 84 
14 Erodibilidade do solo e limites toleráveis de perdas para três das unidades de solopresentes na bacia do rio Corumbatai

15 Preço corrente médio mensal dos fertilizantes, em São Paulo, período 1985-1994 (na moeda correspondente/tonelada). 86

16 Quantidade de nutrientes perdidos nos sedimentos produzidos pela erosão do solo na bacia do rio Corumbatai, 1985 89

17 Equivalente fertilizantes dos nutrientes perdidos na bacia do rio Corumbatai, 1985 90

18 Valor das perdas de nutrientes em termos de fertilizantes equivalentes, na bacia do rio Corumbatai, 1985 91

19 Dados utilizados para a estimativa do impacto da erosão do solo sobre o rendimento da cana-de-açúcar num solo Podzólico Vermelho-Amarelo da fazenda São Francisco, Usina Costa Pinto, safra 1996 93

20 Dados utilizados para a estimativa do impacto da erosão do solo sobre o rendimento da cana-de-açúcar num solo Latossolo Roxo da fazenda Santa RosaII, Usina Costa Pinto, safra 1996 94

21 Dados utilizados para a estimativa do impacto da erosão do solo sobre o rendimento da cana-de-açúcar num solo Terra Roxa Estruturada da fazenda Santa Rosa II, Usina Costa Pinto, safra 1996 95

22 Preço médio anual da cana-de-açúcar na região de Piracicaba, período 1985-1994 96 
23 Dados básicos da ETA 3 de Piracicaba, período 1985-1994 99

24 Dados básicos da ETA 1 de Rio Claro, período 1985-1994 105

25 Dados básicos da ETA 2 de Rio Claro, período 1985-1994 109

26 Preço médio mensal da energía elétrica pago pela ETA 3 de Piracicaba (em reais de dezembro de 1995 por $\mathrm{kw} / \mathrm{h}$ ). 113

27 Preço da mão-de-obra pago pela ETA 3 de Piracicaba (em reais de dezembro de 1995 por mês). 114

28 Estimativa da média mensal do custo operacional de tratamento de água na ETA 3 (em logaritmo neperiano), sem levar em conta a carga de sedimentos, 1985 115

29 Estimativa do custo adicional mensal de tratamento de água causado pela carga de sedimentos na ETA 3, 1985 116

30 Estimativa do custo adicional mensal de tratamento de água nas três ETAs da bacia do rio Corumbatai, 1985 


\section{I S T A D E QUADROS}

Quadro

Página

1 Conseqüências econômicas internas da erosão do solo

2

2 Conseqüências econômicas externas da erosão do solo 2

3 Efeitos da erosão acelerada sobre as características do solo e conseqüências na produção 6

4 Impactos da erosão do solo fora da unidade produtiva agrícola 6 


\title{
ANÁLISE DOS CUSTOS PRIVADOS E SOCIAIS DA EROSÃO DO SOLO - O CASO DA BACIA DO RIO CORUMBATAI
}

\author{
Autor: ARIEL ABDERRAMAN ORTIZ LÓPEZ \\ Orientador: Prof. RICARDO SHIROTA
}

\section{RESUMO}

As conseqüências econômicas da erosão do solo na produção agrícola e os efeitos externos que esta erosão produz são pouco conhecidos no Brasil. Este estudo pretende contribuir ao conhecimento dessas conseqüências, especificamente em termos da perda de produtividade e nutrientes, assim como do custo adicional de tratamento de água para o abastecimento urbano. Os impactos das perdas de terra estimadas foram comparados aos produzidos pelas perdas toleráveis. Relações funcionais entre rendimento de cana-deaçúcar, a principal lavoura da bacia, e diferentes variáveis que afetam a produção foram ajustadas para três unidades de solos, visando determinar o efeito da erosão no rendimento. Uma função translog do custo operacional total de tratamento de água foi também estimada para calcular a parcela do custo causada pela erosão. Os resultados indicam que a erosão está provocando perdas de produtividade nos solos Podzólicos. A produtividade dos Latossolos e da Terra Roxa Estruturada não está sendo atingida pela erosão. A perda de produtividade nos solos Podzólicos é de 18,86 t/ha e eqüivale a R\$ $431,65 / \mathrm{ha}$, em média. Por sua vez, o custo médio por perdas de nutrientes é $\mathrm{R} \$ 26 / \mathrm{ha}$. O custo operacional do tratamento de água causado pela erosão atinge, em média, R\$ 548.318 por ano. Isso implica que cada família abastecida estaria pagando $\mathrm{R} \$ 0,62 / \mathrm{mês}$ a mais por causa da erosão. Conclui-se que, dos componentes do custo interno, o custo gerado pela perda de produtividade (depreciação do capital natural) é maior, apesar de que só acontece em solos Podzólicos. O impacto da erosão do solo nos custos operacionais de tratamento de água é pequeno comparado aos custos internos (apenas 
$3,8 \%$ do custo causado pela erosão do solo na bacia). Finalmente, se as perdas de solo fossem restritas aos seus limites toleráveis, os custos da erosão diminuiriam em $84 \%$. 


\title{
ANALYSIS OF THE PRIVATE AND SOCIAL COSTS OF SOIL EROSION: THE CASE OF THE CORUMBATAI RIVER WATERSHED
}

\author{
Author: ARIEL ABDERRAMAN ORTIZ LÓPEZ \\ Adviser: Prof. RICARDO SHIROTA
}

\section{SUMMARY}

Economic consequences of soil erosion on agricultural production and on the external effects it produces are little known in Brazil. The purpose of this study is to contribute to increasing the knowledge about them, specially in terms of productivity and nutrient losses as well as on additional water treatment costs. Impacts of estimated soil losses were compared to those of tolerable soil losses. Functional relationships between sugar cane yield, the main crop in the watershed, and different variables affecting production were fit for three soil types in order to determine the effect of erosion on yield. A translog total operating water treatment cost function was also estimated to calculate the proportion of cost caused by erosion. Results show that erosion is already causing productivity losses on Typic Paleudult soils but not on Typic Eutrorthox and Rhodic Paleudalf soils. Productivity losses are estimated to be about $18.86 \mathrm{t} / \mathrm{ha}$ with a value of $\mathrm{R} \$ 431.65 / \mathrm{ha}$, on average. Average costs due to nutrient losses amount $\mathrm{R} \$$ $26 /$ ha. Operating water treatment costs caused by erosion are $\mathrm{R} \$ 548,318$ annually. That implies a $\mathrm{R} \$ 0.62 /$ month additional outlay per family due to erosion. The study permits to draw the conclusions that the cost of productivity losses is higher than the one of nutrient 
losses, at the on-site level. The impact of soil erosion on operating water treatment costs is small when compared to on-site costs (only $3.8 \%$ of watershed soil erosion costs). Finally, if soil losses were to be restricted to tolerable limits erosion costs would diminish by $84 \%$. 


\section{INTRODUÇÃO}

A erosão hídrica acelerada do solo ${ }^{1}$ provoca efeitos tanto dentro da unidade produtiva agrícola (efeitos internos) quanto fora dela (efeitos externos). Esses efeitos podem causar conseqüências econômicas importantes como mostram os trabalhos apresentados nos Quadros 1 e 2. No Brasil são poucos os trabalhos de pesquisa sobre os efeitos da erosão do solo e, decorrentemente, as conseqüências econômicas dela são pouco conhecidas.

Este trabalho visa contribuir ao entendimento das consequiências econômicas da erosão hídrica acelerada do solo no Brasil. Para isso, em uma unidade geográfica analisam-se dois impactos internos e um impacto externo. Os impactos internos referemse à determinação dos valores monetários da perda de produtividade do solo e da perda de nutrientes; ou seja, o custo de uso (user cost) das terras agrícolas. Por sua vez, o impacto externo refere-se à estimativa do custo operacional de tratamento de água para o abastecimento urbano causado pela erosão das terras agrícolas. Tanto os impactos internos quanto o impacto externo são comparados aos respectivos valores gerados a partir das perdas toleráveis de solo. Essa comparação permite chegar a uma estimativa, ainda que parcial, do beneficio que poderia ser obtido se a erosão fosse restrita aos seus limites máximos toleráveis.

\footnotetext{
${ }^{1}$ Bennet (1939) indica que pode-se entender o processo de erosão acelerada do solo como sendo a alteração do equilíbrio natural entre perda e regeneração do solo, causada pelo homem, que resulta em uma maior quantidade de solo perdido do que a quantidade regenerada, por unidade de tempo.
} 
Quadro 1. Conseqüiências econômicas internas da erosão do solo.

\begin{tabular}{|c|c|c|c|}
\hline Autor e lugar & Perda de produtividade & Perda de nutrientes & $\begin{array}{l}\text { Redução valor da terra } \\
\text { agrícola }\end{array}$ \\
\hline $\begin{array}{l}\text { Colacicco et al. (1989) } \\
\text { Estados Unidos da América }\end{array}$ & $\begin{array}{l}\text { De US } \$ 0,08 \text { a US } \$ \\
0,66 / t \text { solo erodido }\end{array}$ & $\begin{array}{c}\text { De US\$ } 0,06 \text { a US\$ } \\
0,37 / t \text { solo erodido }\end{array}$ & \\
\hline $\begin{array}{l}\text { Crosson }(1983,1986) \\
\text { Estados Unidos da América }\end{array}$ & US\$ 420 milhões & $\begin{array}{c}\text { De US\$ } 105 \text { a US\$ } 168 \\
\text { milhões }\end{array}$ & \\
\hline $\begin{array}{l}\text { Castro (1987) } \\
\text { Estado de São Paulo, Brasil }\end{array}$ & & US\$ 1,7 bilhão & \\
\hline $\begin{array}{l}\text { Cavalcanti (1995) } \\
\text { Vale do Rio São Francisco, } \\
\text { Brasil }\end{array}$ & & US $\$ 1,4$ bilhão & \\
\hline $\begin{array}{l}\text { Miranowski (1985) } \\
\text { Iowa, Estados Unidos da } \\
\text { América }\end{array}$ & & & $\begin{array}{c}\text { De US\$ } 12 \text { a US\$ } \\
31 / \mathrm{ha} / \mathrm{cm} \text { de solo } \\
\text { erodido }\end{array}$ \\
\hline $\begin{array}{l}\text { Palmquist \& Danielson (1989) } \\
\text { Carolina do Norte, Estados } \\
\text { Unidos da América }\end{array}$ & & & $\begin{array}{c}\text { US\$ } 15,5 / \mathrm{ha} / \mathrm{t} \text { solo } \\
\text { erodido }\end{array}$ \\
\hline
\end{tabular}

Fonte: elaborado pelo autor com base nos estudos citados.

Quadro 2. Conseqüências econômicas externas da erosão do solo.

\begin{tabular}{|lcr|}
\hline \multicolumn{1}{|c|}{ Autor e lugar } & Tratamento de água uso domiciliar & Produção de hidroeletricidade \\
\hline $\begin{array}{l}\text { Sorrenson \& Montoya (1989) } \\
\text { Estado do Paraná, Brasil }\end{array}$ & US\$ 218 mil/ano \\
Holmes (1988) & US\$ 353 milhões/ano \\
Estados Unidos da América & & \\
Southgate \& Macke (1989) & De US\$ 0,5 a US\$ 1 milhão/ano \\
Paute, Equador & De US\$ 64 a US\$ 74 milhões \\
Marques (1996) & \\
\hline Estado de São Paulo, Brasil & \\
\hline
\end{tabular}

Fonte: elaborado pelo autor com base nos estudos citados.

A tese organiza-se em cinco capítulos. O capítulo introdutório apresenta, primeiramente, uma visão geral dos impactos internos e externos da erosão do solo, assim como das suas conseqüências econômicas. Em seguida, apresenta os objetivos do 
estudo e o âmbito geográfico do trabalho. O segundo capítulo refere-se aos fundamentos teóricos que sustentam a metodologia e a discusão dos resultados. O capítulo de metodologia especifica a forma em que os objetivos particulares foram atingidos, define as variáveis utilizadas e as fontes de dados. $\mathrm{O}$ quarto capítulo mostra os resultados e a discussão das estimativas obtidas (custos da erosão provável e da erosão tolerável), comparando-as com as obtidas em outros trabalhos. Finalmente, no quinto capítulo são apresentadas as conclusões do trabalho.

\subsection{A erosão do solo e os seus impactos internos e externos}

Zachar (1982, p. 15-16) define a erosão como sendo “. . . o desgaste do estrato superior do solo - a pedosfera (Grego pedon - solo), ou do material rochoso original - a litosfera (Grego lithos - rocha ou pedra, sphaira - bola) pela ação de matérias de origem exógena, i.e. por fatores geomórficos externos". Esse autor acrescenta que os fatores geomórficos externos incluem a água, a neve, o gelo, o ar (vento), o intemperismo das partículas, os organismos (plantas e animais), e o homem.

A erosão do solo, como um fenômeno natural, tem ocorrido sempre e continuará a ocorrer. No entanto, autores como Beasley (1972) e Dregne (1982) consideram que o homem tem contribuído para a aceleração ${ }^{2}$ do processo erosivo do solo, através do desmatamento e do aproveitamento do solo para o estabelecimento de atividades agrícolas. Segundo Dregne (1982), podem-se identificar três períodos de erosão acelerada do solo na história da humanidade. O primeiro deles ocorreu entre mil e três mil anos atrás e afetou principalmente algumas áreas Mediterrâneas e do Oriente Médio como a Síria, o Líbano e a Mesopotâmia. Esse primeiro período afetou também a China. A aceleração da erosão nesse período foi causada pelo desmatamento, como o que destruiu os "cedros do Líbano", e pela expansão da agricultura pressionada pelo

\footnotetext{
${ }^{2}$ Dregne (1982) considera que a erosão acelerada é o resultado de dois fatores: o manejo impróprio dos solos produtivos e a exploração das terras marginais.
} 
desenvolvimento dos centros urbanos e pela exploração agrícola das montanhas sedimentarias (loessial hills) na China.

O segundo período de erosão acelerada do solo aconteceu durante o século 19 e o início do século 20, atingindo principalmente os países que tiveram ondas de imigração européia expressiva e o estabelecimento de economias voltadas para a exportação de produtos agrícolas. $\mathrm{O}$ fenômeno foi causado, basicamente, porque as populações nativas dos países colonizados foram forçadas a utilizar terras marginais para a agricultura, já que os imigrantes europeus apropriaram-se das melhores terras, como aconteceu, por exemplo, na América Central (especialmente na Guatemala e El Salvador).

O terceiro período de erosão acelerada do solo começou aproximadamente em meados do século 20 e continua ocorrendo até hoje, piorando a cada ano. O fenômeno está associado aos países subdesenvolvidos onde a população e a pressão por terra para agricultura estão aumentando rapidamente. As áreas mais afetadas ficam na América Latina, na África e no Sul da Ásia.

Se por um lado a agricultura acelera o processo de erosão, ela, por outro lado, também contribui para a aceleração do processo de formação do solo. Pimentel et al. (1976) comentam que a formação de uma camada de $2,5 \mathrm{~cm}$ de solo, sob condições naturais, pode demorar entre 300 e 1000 anos (dependendo do tipo e do estado de consolidação do material original). Em contraste, nas terras agrícolas a formação de uma camada do horizonte A da mesma espessura demora em torno de 30 anos para solos de textura grossa (Hall et al., 1982). Essas informações referem-se a regiões temperadas. Em regiões tropicais, esses periodos de tempo podem ser menores.

Esse processo simultâneo de desgaste e formação de solo indica que, do ponto de vista técnico, certa quantidade de solo pode ser perdida sem que isso implique na degradação da sua produtividade. De fato, a essência das definições de tolerância de perda de solo leva embutida a idéia da manutenção da produtividade indefinidamente. Ou 
seja, a perda máxima tolerável de solo, por erosão, que permita a obtenção, de forma econômica, de certos níveis de produtividade, indefinidamente (Schertz, 1983).

Schertz (1983) indica que, aparentemente, a taxa de formação do horizonte A nas terras agrícolas foi um dos principais critérios utilizados para o estabelecimento dos limites toleráveis de perda de solo nos Estados Unidos. No Brasil, o principal critério utilizado na definição dos limites de tolerância das perdas de solo foi o período de tempo necessário para desgastar a camada de solo superficial, sem levar em conta a taxa de formação do solo por fenômenos de intemperismo. Nesse sentido, os limites toleráveis representam a quantidade máxima de solo que pode ser perdida por ano, mantendo-se ainda um certo nível de produtividade (Bertoni \& Lombardi Neto, 1985). Neste estudo pretende-se estimar os beneficios da redução das perdas de solo por erosão até os limites de tolerância, tecnicamente estabelecidos. A avaliação da viabilidade econômica da implementação das medidas para atingir esses limites precisa da estimativa dos custos que elas implicariam. Infelizmente, isto não foi efetuado pois foge dos objetivos deste trabalho.

Nas regiões tropicais do planeta, os principais fatores determinantes da erosão são a água (erosão hídrica) e o vento (erosão eólica). No entanto, esta pesquisa refere-se especificamente à erosão hídrica por ser ela a forma mais importante na área do estudo. Esse tipo de erosão desgasta o solo de formas diferentes, sendo as mais comumente encontradas: a forma laminar, a erosão em sulcos e a erosão em voçorocas. A forma laminar de erosão hídrica remove camadas delgadas e uniformes de solo. Ela é considerada uma das formas mais danosas porque arrasta as partículas mais leves (mais ativas e mais ricas) e é pouco perceptível. Por sua vez, a erosão em sulcos resulta da concentração da enxurrada em determinados pontos do terreno. Já a erosão em forma de voçorocas surge quando grandes enxurradas concentram-se e passam ano após ano num mesmo sulco, ampliando o seu tamanho em extensão e profundidade (Bertoni \& Lombardi Neto, 1985). Neste estudo somente o desgaste laminar do solo foi considerado, 
já que a geração de dados das outras formas de erosão hídrica demanda a prticipação de especialistas no tema.

O Quadro 3 apresenta os principais efeitos da erosão sobre as características do solo, assim como as principais conseqüências na produção.

\section{Quadro 3. Efeitos da erosão acelerada sobre as características do solo e conseqüências na produção.}

Efeitos sobre as características do solo

Perda de nutrientes e matéria orgânica

Alteração da textura

Alteração da estrutura

Queda da taxa de infiltração

Queda da capacidade de retenção de água
Conseqüências na produção

Aumento da necessidade de energia para o cultivo da terra

Diminuição da área disponivel para plantar

Queda da qualidade dos produtos agrícolas

Queda da produtividade

Fonte: elaborado pelo autor com base em Beasley (1972), National Soil Erosion - Soil Productivity Research Planning Comittee (NSESPRPC, 1981) e Christensen \& McElyea (1988).

O Quadro 4 mostra os principais impactos da erosão do solo fora da unidade produtiva.

\section{Quadro 4. Impactos da erosão do solo fora da unidade produtiva agrícola.}

Impactos dentro dos corpos de água (in stream)

Diminuição da capacidade dos corpos d'água

Inviabilização de várias formas de vida aquática

Obstrução da navegação

Aumento do desgaste de equipamentos

Perda de valor para usos recreativos

Diminuição da qualidade da água

Eutroficação
Impactos fora dos corpos de água (off stream)

Aumento do dano das inundações

Aumento das dificuldades de condução da água

Aumento das necessidades de tratamento

Obstrução dos poros da superficie do solo

Aumento do desgaste de equipamentos

Fonte: preparado pelo autor com base em Clark et al. (1985). 
Embora os impactos da erosão do solo na qualidade da água sejam amplamente reconhecidos, McComarck et al. (1982) indicam que existem várias dificuldades para incorporar esses impactos na definição dos limites máximos toleráveis de perdas de solo por erosão. Por exemplo, eles acreditam que a relação entre as taxas de erosão do solo e a qualidade das águas superficiais não é suficientemente conhecida. Adicionalmente, indicam que o controle da erosão do solo para prevenir os impactos externos dependem dos objetivos buscados em relação à qualidade das águas superficiais e, freqüentemente, esses objetivos são específicos para cada bacia. Isso dificultaria a generalização dos critérios para levar em conta os impactos externos na determinação dos valores toleráveis.

Em relação ao impacto externo específico da erosão sobre o tratamento de água para o abastecimento urbano, vários autores - Babbit et al. (1962), Hardenbergh (1964), Azevedo Neto (1966) e Holmes (1988), entre outros - indicam que a complexidade do sistema de tratamento de água para o abastecimento urbano está estreitamente relacionado com a qualidade da água bruta.

A turbidez é um dos parâmetros de qualidade da água. Ela reflete a concentração de elementos em suspensão (argila, areia, silte, sílica, algas, protozoários). Hardenbergh (1964) sugere que a causa principal da turbidez das águas é a erosão do solo que ocorre com maior intensidade em bacias onde o uso predominante da terra é a agricultura. Ele acrescenta que a turbidez da água bruta aumenta nas épocas de chuva, quando a erosão do solo na bacia atinge os seus níveis máximos, tornando-se um fator determinante na escolha do sistema de tratamento que a água necessita.

Um dos sistemas mais simples de tratamento de água é a sedimentação ou decantação que diminui a turbidez da água bruta. No entanto, esse sistema de tratamento é praticável só em casos em que o grau de turbidez da água bruta está perto dos níveis toleráveis para o consumo humano. De maneira geral, a sedimentação é parte de um sistema mais complexo de tratamento. 
Quando a água bruta apresenta níveis de turbidez que não podem ser removidos com o uso unicamente da sedimentação, utiliza-se a coagulação ou floculação e a filtragem. A coagulação requer a adição de reagentes químicos que ajudam a agregação das partículas em suspensão, aumentando os custos operacionais do tratamento em comparação com a simples sedimentação. Além disso, para poder realizar a coagulação é necessária a construção de câmaras de mistura, o que aumenta o custo do investimento. Por sua vez, a filtração da água implica em um aumento nos custos operacionais devido ao consumo de água tratada para a lavagem dos filtros. Ela também aumentaria a necessidade de investimentos na construção dos filtros.

Quando a água bruta apresenta microorganismos nocivos à saúde humana, o sistema de tratamento deve incluir um processo de desinfecção. Esse processo implica na aplicação de substâncias químicas que causam um aumento no custo operacional do tratamento. É preciso também a instalação de equipamentos para a aplicação, aumentando o investimento.

No caso sob estudo, as três estações de tratamento utilizam o sistema convencional de tratamento de água. Esse sistema inclui os processos de coagulação, sedimentação, filtração e desinfecção.

\subsection{Conseqüências econômicas dos impactos da erosão do solo}

É importante estudar os impactos internos e externos, assim como as conseqüências econômicas, da erosão do solo porque a maior parte dos alimentos hoje consumidos pelo homem é obtida na agricultura (das terras cultivadas e das pastagens) ${ }^{3}$. Porém, se por um lado a agricultura moderna tem permitido grandes aumentos na oferta

\footnotetext{
${ }^{3}$ Em 1993, a produção total mundial de alimentos de origem agrícola atingiu 5,3 bilhões de toneladas. Para efeito de comparação, o desembarque total mundial de produtos do mar destinados à alimentação humana foi de 73 milhões de toneladas (anuários FAO de produção v. 48 e de estatísticas de pesca v. 47).
} 
de alimentos, com maior certeza e estabilidade, por outro lado ela tem afetado os sistemas ecológicos naturais e tem criado ambientes artificiais (Tisdell, 1991). Um dos efeitos negativos da agricultura nos sistemas ecológicos naturais é a erosão acelerada do solo. Para complicar o problema, os efeitos da erosão transcendem os limites da unidade de produção agrícola, afetando outros agricultores e/ou atividades econômicas, tanto de produção quanto de consumo (Clark et al. 1985; Colacicco et al. 1989).

O trabalho de Clark et al. (1985) permite perceber o grande volume de informações necessárias para avaliar economicamente os custos externos da erosão acelerada do solo. Provavelmente por isso, a maioria de trabalhos feitos com o propósito de analisar as conseqüências econômicas da erosão do solo referem-se aos impactos dentro da unidade produtiva. Por exemplo, no âmbito internacional, Walker (1982), Hertzler et al. (1985), Gardner \& Barrows (1985), King \& Sinden (1988) e Palmquist \& Danielson (1989) estudaram o efeito da erosão e/ou a conservação do solo sobre o valor das terras agrícolas. Pierce et al. (1984), Kooten van et al. (1989), Dregne (1990) e Xu \& Prato (1995) analisaram os custos da erosão do solo em termos de perda de produtividade. Swanson \& MacCallum(1969), Pope et al. (1983) e Barbier (1990) estudaram o impacto da erosão e da conservação do solo sobre a receita e o lucro do agricultor.

Trabalhos que avaliam os impactos econômicos da erosão do solo fora da unidade produtiva são mais escassos e, normalmente, referem-se a um determinado tipo de impacto ou a um pequeno grupo específico de impactos. Por exemplo, Veloz et al. (1985) e Southgate \& Macke (1989) analisaram os benefícios da conservação do solo em relação à produção de hidroeletricidade. Forster et al. (1987) e Holmes (1988) estudaram o impacto econômico da erosão do solo sobre o tratamento de água para uso doméstico. Crowder (1987) analisou o custo da sedimentação em reservatórios com fins recreativos e para uso doméstico e industrial da água. Robertson \& Colletti (1994) determinaram os impactos econômicos da erosão do solo no uso recreativo do lago formado pelo reservatório Red Rock, em Iowa, Estados Unidos. Por outro lado, a avaliação mais 
abrangente dos impactos econômicos da erosão do solo, incluindo tanto os efeitos dentro da unidade produtiva como os efeitos fora dela, é tratada por um menor número de trabalhos. Entre eles estão Colacicco et al. (1989) e Prato \& Wu (1991).

No caso do Brasil, os poucos trabalhos publicados que abordam o estudo das implicações econômicas da erosão do solo seguem a tendência internacional, dando ênfase na unidade produtiva agrícola. Por exemplo, Kitamura et al. (1982) e Menck (1993) avaliaram economicamente o uso de diferentes sistemas de conservação do solo. Dedecek (1987) e Sparovek et al. (1991) estudaram o efeito da erosão simulada do solo sobre a produtividade da soja e do milho, respectivamente. Castro (1987), Vergara (1991), Bastos Filho (1995) e Cavalcanti (1995) estimaram o valor econômico dos nutrientes perdidos pela erosão do solo. Até hoje, existe uma escassez de trabalhos publicados sobre avaliações econômicas dos impactos externos da erosão do solo. Marques (1995) estudou o custo provocado pelo assoreamento em usinas hidroelétricas a fio d'água no Estado de São Paulo. Sorrenson \& Montoya (1989) apresentam uma estimativa dos custos internos da erosão do solo no Paraná e também mencionam o valor do custo adicional do tratamento de água causado pela erosão do solo nesse Estado em 1984. Bragagnolo (1994) apresenta alguns resultados dos programas de manejo e conservação do solo implementados a partir de 1980 no Estado do Paraná.

\subsubsection{O custo da perda de produtividade pela erosão do solo}

Dentre os trabalhos que abordam o custo da perda de produtividade causada pela erosão do solo, destacam-se os trabalhos de Walker (1982) e Hertzler et al. (1985) que incorporam o conceito de user cost da erosão do solo nas suas estimativas.

O primeiro desses autores desenvolve uma função de dano (damage function) da erosão do solo, que permite obter as seguintes estimativas: (i) o valor da diferença de rendimento entre a prática que deteriora o solo e a prática que o conserva; (ii) a diferença 
dos custos de produção entre as duas práticas indicadas em i; e, (iii) o user cost marginal, incluindo o custo da quantidade adicional de fertilizantes necessária para remediar a queda da fertilidade do solo e a renda futura perdida devido à diminuição do rendimento. Esses cálculos precisaram de informações sobre: os rendimentos esperados tanto da prática convencional de manejo do solo como da prática conservadora do solo; os custos de produção para cada uma dessas práticas; o preço esperado dos produtos; e, o efeito marginal da erosão do solo e da tecnologia sobre o rendimento, através do tempo. O modelo desenvolvido foi aplicado numa área da Palouse mountain nos Estados de Idaho e Washington, Estados Unidos. Os resultados indicam que nos solos de pouca espessura (30 cm de espessura inicial), poderia ser o caso dos solos Podzólicos, o dano da erosão gera incentivo para se adotar práticas conservacionistas, enquanto nos solos mais profundos ( $55 \mathrm{~cm}$ de espessura inicial), poderia ser o caso dos solos Latossolos, a erosão do solo é economicamente racional. Nos solos menos profundos, o valor da função de dano foi negativo a partir do primeiro ano do período analisado (perda de US\$11/ha). Já, nos solos mais profundos, o dano da erosão só aparece no ano 51 (perda de US\$ $0,03 / \mathrm{ha})$.

No estudo conduzido por Hertzler et al. (1985), o user cost da erosão foi dividido em três partes: custo da perda fisica do solo; custo da perda de fósforo; e, custo da perda de potássio. Neste caso, as estimativas foram obtidas com base em informações sobre: o rendimento anual da cultura; a umidade média anual do solo; a profundidade inicial de solo; o estoque de fósforo e potássio; a taxa de erosão do solo; o estoque anual remanescente de fósforo e potássio na camada superficial do solo suscetível à erosão; e, o preço dos fertilizantes fosfatados e potásicos. Estimou-se uma função generalizada de Leontief para calcular o user cost da perda de solo numa bacia do Estado de Iowa, Estados Unidos. Foi determinado que, para um solo susceptível à erosão, o user cost marginal da perda de solo é de aproximadamente US\$70 por $\mathrm{cm}$ de solo perdido por ha, ou seja, menos de US $\$ 0,50$ por tonelada de solo perdido. Isso implica num user cost total anual de US\$20/ha. Os autores desse estudo acrescentam que o valor estimado dos user costs não é grande quando comparado com outros custos e, por isso, podem estar 
sendo negligenciados pelos agricultores que estão produzindo num ambiente econômico complexo.

\subsubsection{Os custos do tratamento de água devidos à erosão do solo}

Forster et al. (1987) e Holmes (1988) analisaram os efeitos da erosão do solo sobre os custos do tratamento da água para uso domiciliar nos Estados Unidos. Em ambos trabalhos foram ajustadas funções Cobb-Douglas. No trabalho de Forster e colaboradores, o custo médio de tratamento de água foi relacionado com variáveis como a quantidade de água potável produzida, o tempo de retenção da água no reservatório, a diminuição da turbidez da água utilizada como insumo e a quantidade de solo erodida. Os resultados indicam que o aumento de $1 \%$ na perda de solo por erosão resulta no acréscimo de $0,4 \%$ no custo médio de tratamento. Estimou-se que uma diminuição da erosão do solo de $25 \%$ provocaria uma redução de US\$ 2,7 milhões no custo de tratamento de água no Estado de Ohio.

Holmes (1988) relacionou o custo operacional e de manutenção total com a quantidade de água potável produzida, a turbidez da água bruta e os preços do trabalho e da eletricidade. Isso para determinar o efeito marginal da turbidez da água bruta sobre o custo de tratamento. Posteriormente, estimou-se o efeito marginal da erosão do solo sobre a turbidez da água bruta para, finalmente, obter o efeito marginal da erosão do solo sobre o custo de tratamento da água. Os resultados indicam que o aumento de $1 \%$ da carga de sedimentos produzida pela erosão do solo causa um acréscimo de $0,05 \%$ nos custos de operação e manutenção. Com esse resultado, estimou-se que, em média, o custo aumenta em US\$ 17,11 por cada mil toneladas de sedimentos. A estimativa do custo adicional causado pelos sedimentos em suspensão na água, para a totalidade dos Estados Unidos, ficou entre US $\$ 35,3$ milhões e US $\$ 661,2$ milhões anuais. 


\subsubsection{Os custos internos e externos da erosão do solo}

Dentre os trabalhos que abordam simultaneamente os efeitos internos e externos da erosão do solo destacam-se Colacicco et al. (1989) e Prato \& Wu (1991), no âmbito internacional; e, Sorrenson \& Montoya (1989) e Bragagnolo (1994) no Brasil.

Colacicco e colaboradores calcularam os custos internos da erosão do solo para dez regiões dos Estados Unidos, utilizando o Erosion Productivity Index Calculator (EPIC) e compararam essas estimativas com as estimativas dos custos externos apresentadas por Clark et al. (1985). A conclusão desse estudo é que em oito das dez regiões pesquisadas os custos externos são maiores que os custos internos. Conclui-se ademais que, no agregado, os custos externos representam quase o dobro do montante dos custos internos (US\$2,2 bilhões contra US\$ 1,2 bilhão em 1982).

Por sua vez o estudo de Prato \& Wu (1991) compara o efeito interno da erosão entre o sistema com preparo convencional e os sistemas: preparo reduzido, redução da taxa de erosão a 1,5 vezes a taxa tolerável (T) e redução da taxa de erosão para $\mathrm{T}(11,2$ t/ha/ano). Eles estimaram também o custo dos danos causados pelos sedimentos na bacia Tom Beall do Estado de Idaho, Estados Unidos. Os resultados desse estudo indicam que o retorno líquido dos produtores agrícolas aumenta em 16\% (de US\$406 para US\$ 473 por hectare) quando o preparo convencional do solo é substituído pelo preparo reduzido. $\mathrm{O}$ retorno líquido aumenta $15,7 \%$ e $11,4 \%$ quando as taxas de erosão $1,5 \mathrm{~T}$ e $\mathrm{T}$ são atingidas. Já, o custo dos danos causados pelos sedimentos atingiu os valores de US\$ 15.418/ano com o preparo convencional do solo, US\$ 6.102 com a adoção de preparo reduzido, US\$ 4.755 com uma taxa de erosão de $1,5 \mathrm{~T}$ e, US\$ 4.702 com a taxa de erosão de T.

O trabalho de Sorrenson \& Montoya (1989) refere-se aos custos da erosão do solo no Estado do Paraná, em 1984. Eles utilizaram o método da reposição dos macronutrientes para chegar à estimativa do custo interno, supondo uma taxa de erosão 
laminar de $20 \mathrm{t} / \mathrm{ha} / \mathrm{ano}$. Ademais, eles apresentam uma estimativa do custo interno da erosão em sulcos e voçorocas. Em relação ao custo externo, eles apresentam unicamente a estimativa do custo adicional do tratamento de água para consumo humano feita pela Companhia de Saneamento do Paraná-SANEPAR, sem a descrição da metodologia utilizada. Os valores estimados são US\$ 242 milhões anuais em macronutrientes perdidos por erosão laminar e US $\$ 34,5$ milhões/ano pela redução da produção devida à erosão em sulcos e voçorocas, fazendo um total de US\$276,5 milhões por ano de custo interno. No caso do custo de tratamento de água, os valores atingem US\$118.572 para a redução da turbidez da água bruta e US\$99.141 em custo de manutenção de equipamentos mais a remoção dos sedimentos depositados nos reservatórios. O custo adicional de tratamento de água atinge US\$217.713.

Bragagnolo (1994), estudando o impacto da redução da erosão do solo através de práticas mecânicas e vegetativas de conservação, encontrou que a produtividade das culturas no Estado do Paraná aumentou entre 10 e 30\%. Esse aumento de produtividade eqüivale a um acréscimo de US\$115,7 milhões na receita anual agregada dos produtores agrícolas. As práticas de conservação do solo também causaram uma diminuição de até 6 vezes na turbidez da água bruta utilizada para o abastecimento urbano, implicando em reduções de até $83 \%$ no custo de tratamento da água.

Em relação aos trabalhos da literatura sobre os custos da perda de produtividade causada pela erosão do solo, percebe-se que a aplicação empírica dos modelos teóricos tem-se vista dificultada pela escassez de dados, principalmente da parte fisico-biológica do fenômeno estudado. Assim, por exemplo, Walker (1982) utiliza uma relação funcional que expressa o rendimento da cultura em função só da espessura da camada superficial do solo. Isso seria válido no caso dos dados serem gerados através de experimentos onde o efeito dos outros fatores que afetam o rendimento é controlado. Se esse não for o caso, pode estar-se cometendo um erro de especificação do modelo que gera estimativas viesadas e ineficientes (Gujarati, 1995). Hertzler et al. (1985) utilizam dados supostos do impacto da erosão na perda de produtividade, assim como para as quantidades de fósforo 
e potássio necessárias para atingir o novo patamar de rendimento por cada polegada de solo erodido.

No caso dos dois trabalhos que avaliam o impacto da erosão do solo sobre os custos de tratamento de água, nota-se que funções da forma Cobb-Douglas são usadas para fazer as estimativas. Ela é uma forma funcional restrita, no sentido de não levar em conta as interações entre os preços dos insumos, nem aquelas entre os preços e a quantidade do produto. Nesse sentido, o uso de uma forma funcional flexível poderia ser mais apropriada. Além disso, o trabalho de Forster et al. (1987) não inclui os preços dos insumos dentre as variáveis explanatórias e Holmes (1988) inclui só os da eletricidade e da mão-de-obra. Adicionalmente, dado que as estimativas desses autores correspondem a várias estações de tratamento, existe a possibilidade de ocorrência de correlação contemporânea. Isso implica que, muito provavelmente, os estimadores dos coeficientes da função custo não sejam eficientes ${ }^{4}$.

\subsection{Objetivos}

O estudo desenvolvido visa, de forma geral, produzir subsídios ao entendimento das conseqüências econômicas da erosão do solo no Brasil. Para tanto, as informações de uma unidade espacial especificamente delimitada são utilizadas.

Já, de forma particular, o estudo pretende:

(i) estimar os custos internos, em termos de perda de produtividade e dos nutrientes perdidos, que a erosão do solo tem provocado para a agricultura;

(ii) determinar o impacto que a erosão do solo tem gerado nos custos de tratamento de água para o abastecimento urbano; e,

(iii) quantificar a magnitude em que os custos causados pela erosão diminuiriam se as perdas de solo fossem restritas aos seus limites toleráveis.

\footnotetext{
${ }^{4}$ Um estimador é eficiente quando não é viesado e possue varianza mínima (Gujarati, 1995, p. 72).
} 


\section{4 Âmbito geográfico do estudo}

A Figura 1 mostra a localização geográfica da bacia do rio Corumbataí no Estado de São Paulo.

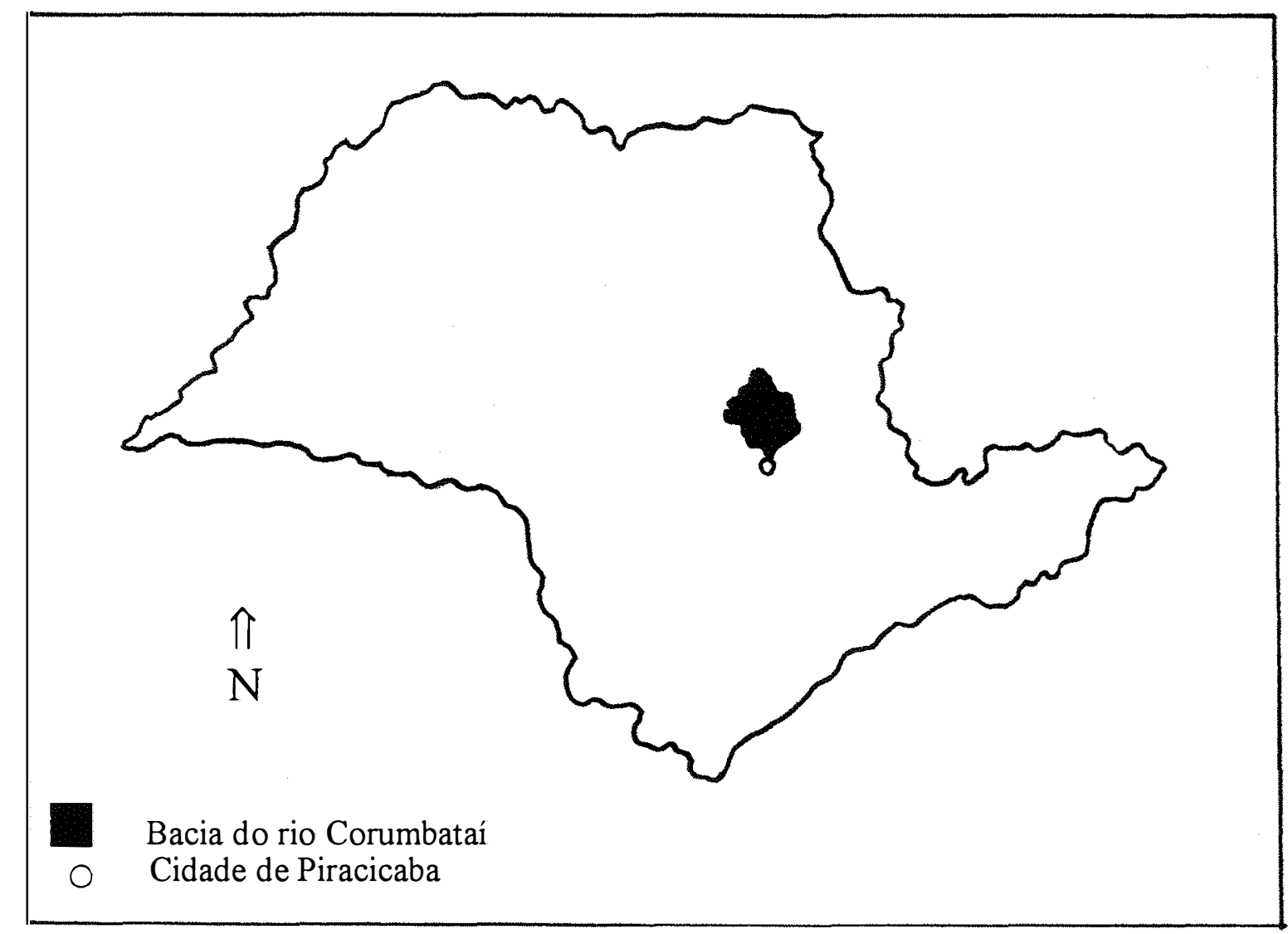

Figura 1- Localização geográfica da bacia do rio Corumbataí no Estado de São Paulo.

Koffler (1993) indica que a bacia do rio Corumbataí localiza-se entre $22^{\circ} 05^{\prime}$ e $22^{\circ}$ $30^{\prime}$ de latitude sul e $47^{\circ} 30^{\prime}$ e $47^{\circ} 50^{\prime}$ de longitude oeste. Ela ocupa uma área aproximada de $1.710 \mathrm{~km}^{2}$, e inclui áreas dos municípios de Analândia, Charqueada, Corumbataí, Ipeúna, Itirapina, Piracicaba, Rio Claro e Santa Gertrudes. Esse autor acrescenta que no período de 1962-91 a precipitação pluviométrica variou de $1393 \mathrm{~mm}$ a $1531 \mathrm{~mm}$ por ano. Por sua vez, Oliveira \& Prado (1984) determinaram que os solos presentes na bacia correspondem às unidades Latossolo (Roxo, Vermelho-Amarelo e Vermelho-Escuro, 
com 31,1\%), Podzólico (Vermelho-Amarelo e Vermelho-Escuro, com 45,5\%), Terra Roxa Estruturada (1,9\%), Brunizem Avermelhado (0,1\%), Cambissolo (0,1\%), Areias Quartzosas (6,7\%), Litólico (13,4\%), Plintossolo (0,7\%), Aluvial (0,1\%) e Hidromórfico $(0,4 \%)$.

A seleção da área de estudo obedece os critérios de: (i) suscetibilidade do solo ao processo erosivo; (ii) presença de culturas indutoras de erosão; e, (iii) proporção da população abastecida por fontes superficiais de água.

Nesse sentido, Kertzman et al. (1995) indicam que das 22 bacias hidrográficas que se localizam no Estado de São Paulo, quatro são consideradas críticas pelo efeito da erosão sobre o recurso água. São elas: Alto Tietê, Piracicaba, Aguapei e Peixe. Dentro de cada uma das quatro bacias criticas, existem sub-bacias criticas ( 16 no total), sendo uma delas a bacia do rio Corumbatai. Nessa bacia os solos apresentam alto potencial de erosão e de produção de sedimentos, decorrente da combinação de solos altamente suscetiveis à erosão, e ocupação com culturas indutoras de processos erosivos.

A Tabela 1 mostra que a ocupação das terras com cana-de-açúcar teve o maior crecimento entre 1978 e 1990. A cultura de cana é a segunda em importância em termos de área ocupada, perdendo só para a pastagem.

Em 1991, aproximadamente $90 \%$ da população humana da bacia era abastecida por fontes superficiais de água (Martins \& Gallo, 1994). Além disso, cerca de 60\% dos habitantes da cidade de Piracicaba utilizam as águas do rio Corumbatai. Três estações de tratamento de água (ETAs) produzem mais de $90 \%$ da água tratada consumida nos municípios da área de influencia da bacia - as ETAs 1 (Ribeirão Claro) e 2 (Corumbatai) da cidade de Rio Claro e a ETA 3 (Capim Fino) da cidade de Piracicaba. 
Tabela 1. Uso das terras da bacia do rio Corumbatai em 1978 e 1990.

\begin{tabular}{lcccc}
\hline \multicolumn{1}{c}{ Uso } & \multicolumn{2}{c}{1978} & & \multicolumn{2}{c}{1990} \\
& Área (000ha) & percentagem & Área (000ha) & percentagem \\
\hline Cana-de-açúcar & 355,3 & 20,8 & 544,6 & 31,8 \\
Culturas anuais & 49,1 & 2,9 & 6,6 & 0,4 \\
Culturas perenes & 38,7 & 2,3 & 36,7 & 2,1 \\
Pastagem & 860,1 & 50,3 & 805,5 & 47,1 \\
Silvicultura & 138,7 & 8,1 & 118,3 & 6,9 \\
Vegetação natural & 234,0 & 13,7 & 104,5 & 6,1 \\
Área urbana e industrial & 23,3 & 1,4 & 59,1 & 3,5 \\
Outros & 11,5 & 0,7 & 35,3 & 2,1 \\
\hline
\end{tabular}

Fonte: Elaborado pelo autor com dados do CENA e de Koffler (1993). 


\section{Contexto teórico da análise econômica}

Neste capítulo apresentam-se os elementos teóricos que orientam o capítulo de metodologia e ajudam na discussão dos resultados do trabalho.

\subsection{0 custo da erosão do solo na unidade produtiva}

Na unidade produtiva os impactos da erosão acelerada começam com a alteração das características fisicas e químicas do solo (textura, estrutura, diminuição da disponibilidade de nutrientes e do teor de matéria orgânica, queda da taxa de infiltração e da capacidade de retenção de água). O reflexo desses impactos é a diminuição progressiva da produtividade potencial ${ }^{6}$ do solo. No entanto, a perda de produtividade potencial não necessariamente significa uma queda do rendimento das culturas. A utilização de tecnologia pode aumentar os rendimentos, mesmo que a erosão esteja reduzindo permanentemente a produtividade natural do solo. Por exemplo, a perda de produtividade devido à menor disponibilidade de nutrientes para as plantas pode ser compensada seja pela adição de fertilizantes ou pelo uso de técnicas apropriadas de manejo (Schertz, 1983). Já uma perda permanente e irreversível de produtividade ocorre quando a erosão reduz a camada efetiva de enraizamento para um nível que restringe os rendimentos das culturas, ou que muda adversamente as propriedades fisicas da camada de enraizamento. Por exemplo, isso ocorre quando a erosão faz com que o material

\footnotetext{
${ }^{6}$ Dregne (1990, p. 432) define a produtividade potencial do solo como "o rendimento que poderia ser obtido se o nível de erosão não tivesse sido danoso".
} 
original fique a $30 \mathrm{~cm}$ ou menos da superficie do solo, ou quando o subsolo fica exposto ou muito próximo da superficie do solo. Ambas as mudanças alteram as relações da água e do ar no solo (Dregne, 1990). Colacicco et al. (1989) indicam que a diminuição da profundidade de enraizamento e a capacidade do solo em reter água para as plantas são os fatores que maior impacto provocam sobre os rendimentos das culturas.

Do ponto de vista econômico, Bunce (1942) indica que a exploração dos recursos do solo, com um determinado estoque de fertilidade natural ${ }^{7}$, pode ser benéfica tanto para o produtor agrícola como para a sociedade. Durante o tempo em que esse estoque for explorado, os custos de produção seriam menores do que seriam se a fertilidade estivesse sendo mantida constante. Isto resultaria em maiores receitas e retornos líquidos ${ }^{8}$ (já que, neste caso, receita líquida é igual a retorno líquido porque não há mudança no valor de capital da terra agrícola) para o produtor, pois a conservação da fertilidade precisa de práticas que requerem investimentos (terraços, barreiras vivas, etc.) ou que penalizam os rendimentos, implicando em aumento dos custos médios.

O exemplo acima é similar ao caso em que o impacto da erosão do solo consiste unicamente na depleção da fertilidade, sem que ocorra a deterioração da produtividade do solo. Graficamente, isso pode ser visualizado na Figura 2.

Nesta figura, para uma determinada parcela de terra, a curva CDE representa a receita líquida (neste caso igual ao retorno líquido) de um sistema de produção que explora a fertilidade natural do solo. A linha ADB corresponde à receita líquida para um sistema que conserva a fertilidade natural do solo. A distância vertical entre ambas depende da magnitude dos custos envolvidos na manutenção da fertilidade natural.

\footnotetext{
${ }^{7}$ Para efeitos deste exemplo, a fertilidade natural do solo é a presença de um excedente de fertilidade (nutrientes e matéria orgânica) que foi acumulado através do tempo, a custo zero para o produtor agrícola (Bunce 1942, p. 70 e 71 ).

${ }^{8}$ Bunce (1942, p. 11) define a receita líquida da terra como a receita bruta da unidade produtiva menos todos os custos de produção (incluindo os retornos ao capital e ao trabalho, assim como o valor dos produtos produzidos e consumidos na unidade produtiva e o valor da moradia). Por sua vez, o retorno líquido é definido como a receita líquida menos ou mais qualquer mudança no valor de capital da terra agrícola resultante de um sistema de exploração ou de melhora dela.
} 


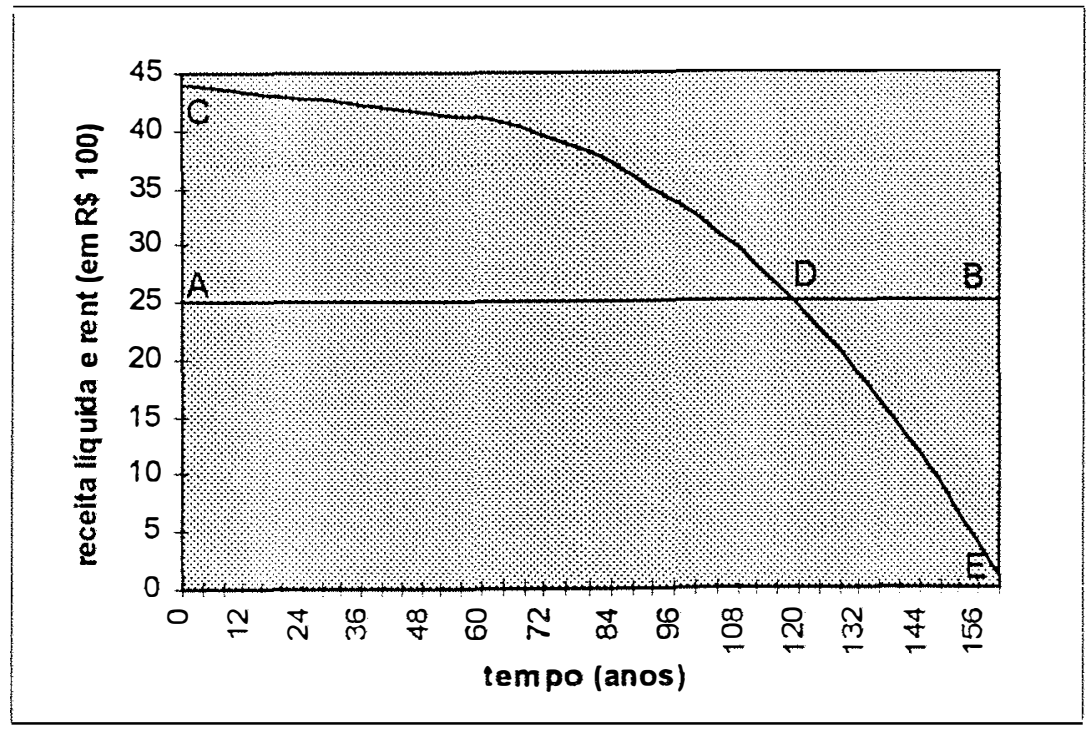

Fonte: adaptada de Bunce (1942, p. 72).

Figura 2 - Efeito econômico da depleção da fertilidade do solo pela erosão, sob um sistema de exploração da terra.

Observa-se que durante o primeiro período de tempo (até o ponto D), é econômico utilizar o sistema de exploração do solo porque a receita líquida desse sistema é maior que a receita líquida do sistema de conservação. A área $\mathrm{ACD}$ eqüivale ao ganho gerado pelo sistema de exploração. Além do ponto D, o sistema de exploração gerará perdas para o produtor. Teoricamente, o sistema de conservação deveria ser adotado a partir do ponto $\mathrm{D}$, onde as receitas líquidas dos dois sistemas são iguais.

Quando o sistema de exploração do solo diminui a fertilidade natural e causa também a redução da produtividade, as conseqüências econômicas para o produtor são maiores. Aparecem retornos líquidos menores que a receita líquida e, consequentemente, o rent ${ }^{9}$ e o valor da terra a ele associado decrescem anualmente (ver Figura 3 ).

\footnotetext{
${ }^{9}$ Bunce (1942, p. 12) define o rent da terra como "o retorno líquido (incluindo o capital irrecuperável aplicado à terra e não separável dela) sob u m sistema de conservação".
} 


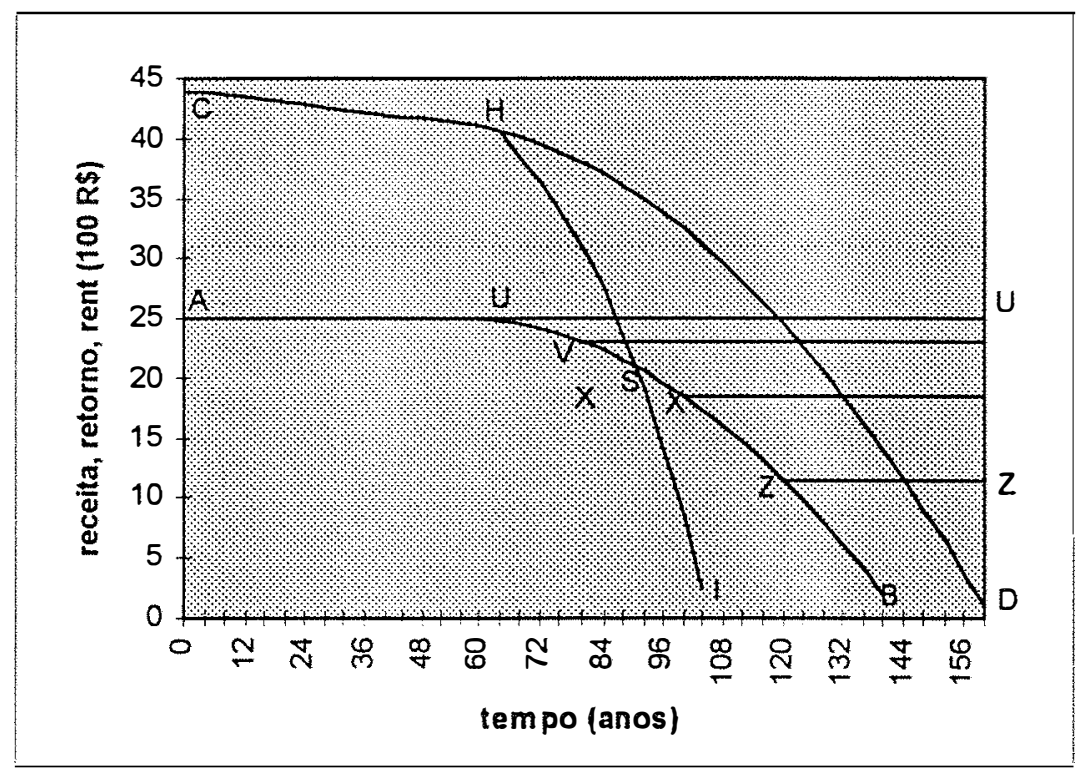

Fonte: adaptada de Bunce (1942, p. 81)

Figura 3 - Conseqüência econômica da perda de produtividade causada pela erosão do solo sob um sistema de exploração da terra.

A curva $\mathrm{CHD}$ da Figura 3 representa a evolução da receita líquida, ao longo do tempo, associada com um sistema de exploração que deteriora a produtividade da terra. A partir dela é calculada uma curva de retorno líquido $\mathrm{CHI}$ que representa a receita líquida menos a perda de valor de capital da terra, considerando uma taxa de juros $\mathrm{i}$.

A linha AUU representa o retorno líquido de um sistema que conserva a produtividade da terra (o rent). Se o sistema que deteriora a produtividade da terra for adotado, os rents (retornos líquidos do sistema com conservação) diminuiriam a cada ano, a partir do ponto $\mathrm{H}$ (ponto em que a deterioração da produtividade da terra começa se manifestar). Consequentemente nesse sistema, ao contrário da curva de rent para o sistema de conservação, o nível da curva do rent (paralela ao eixo das abcissas) será menor ao longo do tempo. Ter-se-á uma série de linhas paralelas (UU a ZZ) representando rents (ou retornos líquidos) sob sistemas de conservação, iniciados em pontos sucessivos no tempo. O conjunto de pontos, onde cada um determina um nivel diferente de rent em um ponto no tempo, será a curva de declividade negativa AUB. 
Até o ponto U não ocorre diminuição permanente da produtividade do solo, mesmo produzindo sob o sistema de exploração. Isso implica que durante esse periodo de tempo o sistema de exploração é bem mais lucrativo que o sistema de conservação. No entanto, a partir do ponto U o sistema de exploração começa a afetar as características do solo, determinando uma queda permanente da produtividade. Como conseqüência disso, o retorno líquido começa a ser menor que a receita líquida e o rent começa a diminuir. O rent continuará diminuindo a uma taxa crescente até desaparecer $(r e n t=0)$, se o produtor não adotar o sistema de conservação. A taxa crescente de redução do rent se refletirá cada vez mais na diferença entre a receita liquida $(\mathrm{CHD})$ e o retorno liquido (CHI).

Para o produtor será econômico adotar o sistema de conservação no ponto em que o retorno líquido do sistema de exploração se iguala ao rent (ponto S na Figura 3). Continuar produzindo no sistema de exploração além desse ponto significaria que o retorno líquido seria menor que o rent que poderia ser obtido, se o sistema de conservação fosse adotado. No entanto, a receita liquida ( $\mathrm{CHD}$ ) continua sendo maior que o rent e isso demonstra a importância de se subtrair a perda de capital. Quando o produtor não percebe a perda de capital, ou quando ele pode transferir essa perda para outra pessoa ou grupo, continuará operando no sistema de exploração original (Bunce, 1942)

O conceito de queda do rent das terras agricolas pode ser apresentado através do conceito de user cost que Randall (1987) explica da seguinte maneira: "o consumo no período 1 ocorre às expensas da satisfação diminuida em períodos futuros. O user cost de se consumir [um bem] no periodo 1 é definido como o valor da satisfação diminuída [nos periodos futuros]". Já na página 300, esse autor indica que, por definição, o user cost marginal (MUC) é "o custo de oportunidade futuro gerado como conseqüência do uso atual [de uma unidade de um recurso]". Ele acrescenta que, no caso da extração de recursos exauriveis, o MUC representa ou reflete o rent do recurso que está sendo extraido. 
A deterioração do recurso solo pela erosão acelerada, que ocorre sob um sistema agrícola de exploração da terra, permite se fazer uma analogia com um recurso exaurível. A deterioração implica na perda da parte do solo que constitui um recurso fundo ${ }^{10}$, até a sua eventual exaustão causando a queda do rent das terras agrícolas ao longo do tempo. A diminuição do rent como conseqüência do "consumo" do solo seria refletida por um MUC crescente ao longo do tempo, ou seja, a contínua ampliação da diferença entre a receita líquida e o retorno líquido (respectivamente as curvas $\mathrm{CHD}$ e $\mathrm{CHI}$, na Figura 3).

Bunce (1942) e Colacicco et al. (1989) indicam que, do ponto de vista econômico, os danos da erosão do solo na produtividade podem ser de dois tipos: danos permanentes (o caso representado na Figura 3) e danos temporários (o caso representado na Figura 2). Os danos permanentes ocorrem quando o potencial produtivo é afetado pela redução da profundidade de enraizamento e pela perda de capacidade de retenção de água. Isso provoca uma queda permanente do "rent" e, eventualmente, maiores preços do produto para o consumidor. Por sua vez, os danos temporários se referem à alteração do potencial produtivo causada pela perda de nutrientes e outros elementos, que podem ser repostos a um custo igual ou menor que o custo da sua conservação. Neste caso, não ocorre redução permanente da produtividade nem do "rent" das terras agrícolas.

Quando esses danos temporários e permanentes são analisados na unidade produtiva individual ou numa área cuja produção não é significativa na oferta agregada, os preços de mercado dos produtos agrícolas não são afetados. Pressupondo tecnologia e preços dos insumos constantes, a Figura 4 mostra como esses danos afetam o custo médio de produção e o custo marginal de produção.

\footnotetext{
${ }^{10}$ Bunce (1942, p. 7) indica que o solo apresenta características de vários tipos de recursos naturais: de recurso biológico porque nele se desenvolve vida microbiana que contribui à sua produtividade; de recurso fluxo que são certos nutrientes e formas de materia orgânica que se movimentam no solo; e, de recurso fundo que são as partículas minerais que são exauriveis sob um sistema agrícola de exploração.
} 


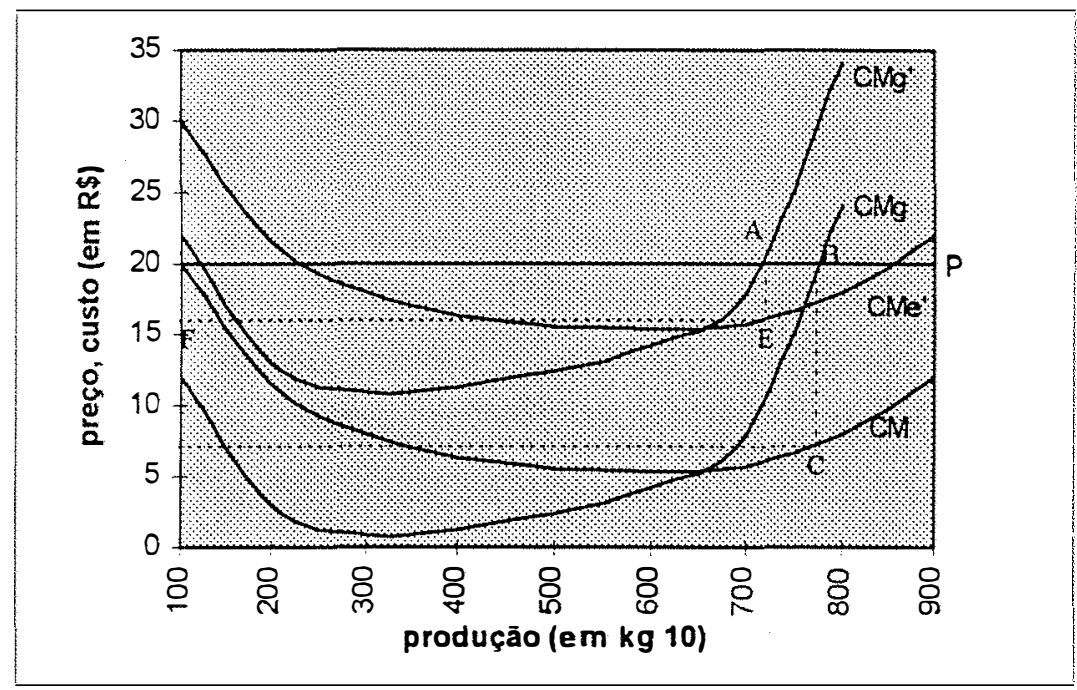

Figura 4 - Efeito econômico da erosão do solo na unidade produtiva.

Nessa figura, o preço hipotético do produto é R\$ 20 (representado pela linha P). A curva CMe mostra o custo médio total no período inicial e a curva $\mathrm{CMg}$ se refere ao custo marginal inicial. O efeito da queda de produtividade causada pela erosão será um aumento dos custos médio e marginal ${ }^{11}$ para $\mathrm{CMe}^{\prime}$ e $\mathrm{CMg}^{\prime}$, respectivamente. Como conseqüência desse aumento dos custos médio e marginal, a receita líquida do produtor diminuirá aproximadamente da área 20BCD para a área 20AEF.

Entretanto, o efeito agregado da erosão do solo sobre a receita líquida do produtor pode ser positivo. Esse é o caso se a demanda pelos produtos agrícolas fôr inelástica. Nesse caso, supondo um mercado competitivo, o aumento percentual do preço, devido à redução da oferta causada pelo acréscimo nos custos de produção, será maior que a diminuição na quantidade demandada. Assim, o aumento da receita agrícola agregada pode ser maior que o acréscimo dos custos por erosão. Não obstante, a redução do bem-estar do consumidor será maior que o possível efeito líquido positivo para os

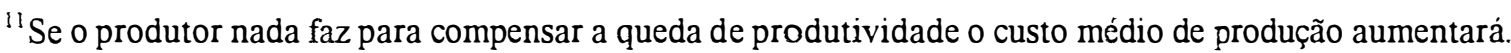
Se o produtor tentar manter a produtividade original, aumentando a quantidade de insumos ou investindo em práticas de controle da erosão, também ocorrerá um acréscimo nos custos de produção.
} 
produtores agrícolas. Isso faz com que a sociedade perca com a erosão (Colacicco et al. 1989).

No entanto, existem outros fatores, além das perdas de produtividade induzidas pela erosão do solo, que afetam a oferta de bens agrícolas. Crosson et al. (1985) indicam que os outros fatores importantes no deslocamento da oferta são as variações no preço dos fatores de produção e o progresso tecnológico. O efeito da perda de produtividade causada pela erosão do solo pode, por exemplo, ser contrabalançado, de forma mais que proporcional, pelo efeito do progresso tecnológico. Em outras palavras, os aumentos de produtividade, devido a utilização de novas tecnologias mascaram o efeito da erosão, como mostram Krauss et al. (1985).

Crosson et al. (1985) comentam que o deslocamento da oferta pelo efeito da erosão pode ocorrer tanto pela redução da produtividade como pelo aumento dos custos de produção, no caso dos produtores invistirem em práticas para o controle da erosão. Eles discutem, teoricamente, o efeito agregado da erosão do solo nos custos de produção e nos preços dos produtos agrícolas, através do tempo, levando em conta a perda de produtividade por erosão e o progresso tecnológico. Essa discussão pode ser visualizada na Figura 5.

Nessa figura as linhas da demanda atual e a demanda futura são representadas respectivamente por D e D'. A linha S corresponde à oferta atual. S'é a linha de oferta futura supondo que a tecnologia permanece constante em relação ao ponto inicial, mostrando, portanto, o efeito da erosão do solo sobre a oferta inicial. A linha S"inclui os efeitos da erosão e a compensação, mais que proporcional, do progresso tecnológico. S" 'é a linha da oferta futura se a erosão não afetasse a produtividade, ela mostra o efeito positivo do progresso tecnológico.

No ponto inicial da análise, o preço e a quantidade de equilíbrio são respectivamente $\mathrm{P}_{0}$ e $\mathrm{Q}_{0}$. No futuro, se a tecnologia e o preço dos fatores permanecerem 
constantes, o preço de equilibrio aumentaria para $\mathrm{P}^{\prime}$. Da diferença entre $\mathrm{P}_{0}$ e $\mathrm{P}^{\prime}$, o deslocamento (aumento) da demanda representa a distância $\mathrm{P}_{0}$ para $\mathrm{P}$ e o efeito da erosão sobre a produtividade representa a distância restante ( $\mathrm{P}$ para $\mathrm{P}$ '). Tem-se que, se a diferença entre $\mathrm{P}$ e P'(receita adicional para o produtor) for maior que a diferença entre as linhas S e S' (custo adicional para o produtor), a receita líquida do produtor aumentaria como consequeência da perda de produtividade gerada pela erosão do solo. Isso dependerá da elasticidade-preço da demanda e da oferta.

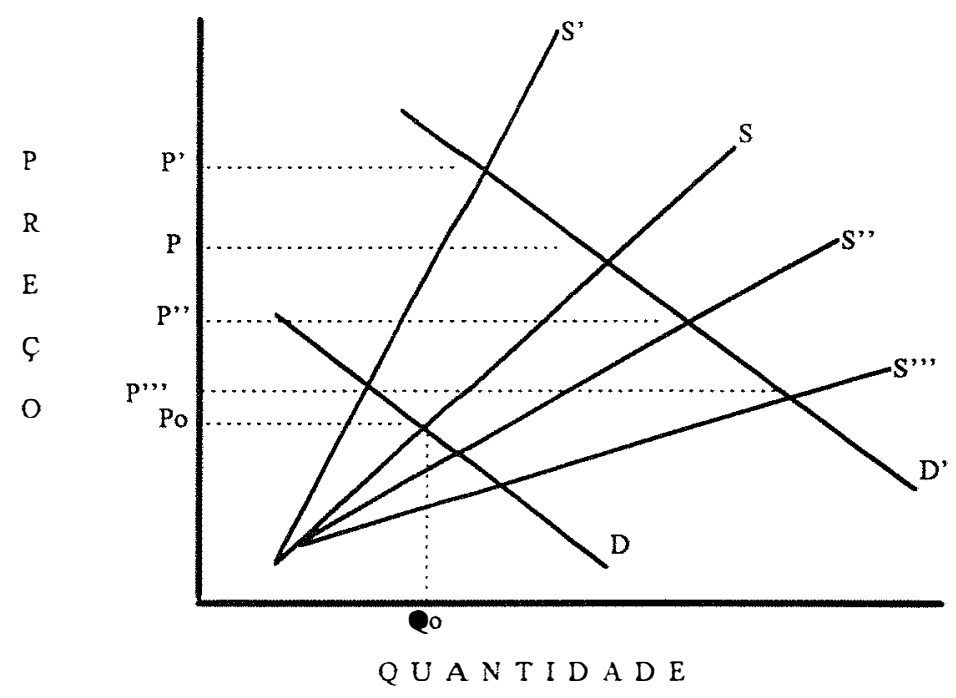

Fonte: adaptada de Crosson et al. (1985, p. 485).

Figura 5 - Efeito econômico agregado da erosão do solo e do progresso tecnológico.

Por outro lado, se o progresso tecnológico consegue contrabalançar o efeito da erosão, de forma mais que proporcional, o equilibrio seria atingido ao preço P'. Com isso, ocorreria um aumento do preço de $\mathrm{P}_{0}$ para $\mathrm{P}$ ". Não obstante, esse aumento seria bem menor que no caso anterior, ocorrendo o mascaramento do efeito da erosão por parte do efeito do progresso técnico. Neste caso, a receita do produtor aumentaria tanto pelo acréscimo do preço (de $\mathrm{P}_{0}$ para $\mathrm{P}^{\prime \prime}$ ), como pela redução do custo de produção (de $\mathrm{S}$ para S"). 
Finalmente, se a erosão não causasse perda de produtividade, o equilíbrio futuro se daria a um preço P"'. O progresso tecnológico diminuiria os custos de produção, deslocando a oferta de S para S"". Esse deslocamento da oferta seria suficiente para contrabalançar, quase na mesma proporção, o deslocamento da demanda, e isso

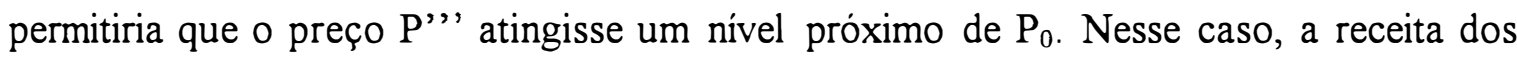
agricultores aumentaria, principalmente, via diminuição do custo de produção, já que o aumento do preço recebido pelo produto permaneceria quase constante.

\section{$2.2 \mathrm{O}$ efeito econômico externo da erosão do solo}

Entre os inúmeros impactos da erosão do solo fora da unidade produtiva, possivelmente o principal seja a poluição da água. Freqüentemente, o processo erosivo hídrico arrasta partículas de solo e poluentes químicos a ele associados (nutrientes e agrotóxicos) até os corpos de água (córregos, rios, reservatórios, lagos, etc.).

Clark et al. (1985) indicam que os principais impactos fora da unidade produtiva, mas dentro dos corpos de água, incluem: a perda de valor desses corpos para usos como a recreação; o aumento dos custos de manutenção das usinas hidroelétricas; a diminuição da viabilidade de várias formas de vida aquática (pela destruição de suas fontes de alimento, esconderijos e lugares para aninhar); o assoreamento das vias de navegação; a redução da capacidade de condução e armazenamento de água dos cursos e reservatórios; e, a mudança da estrutura e ecologia dos cursos e corpos de água. Por sua vez, os principais impactos fora dos corpos de água referem-se ao aumento dos custos de bombeamento, condução e tratamento de água e o aumento da magnitude das inundações.

Esses impactos externos têm implicações econômicas principalmente na forma de diminuição de utilidade de um ou mais indivíduos ou do aumento dos custos de produção de uma ou mais firmas. Segundo Mishan (1971), o termo externalidade (ou efeito 
externo) é comumente definido em função da resposta da produção de uma firma ou da utilidade de uma pessoa à atividade de outras firmas e/ou outras pessoas. Salienta-se que o efeito deve ser direto, ou seja, através de elementos ou variáveis embutidas nas respectivas funções de produção e de utilidade das firmas ou dos individuos afetados.

Esse autor apresenta uma forma matemática de se representar o efeito externo. A função de utilidade de um indivíduo $i$ é representada por $U_{1}=F_{i}\left(\mathrm{x}_{i 1}, \mathrm{x}_{i 2}, \ldots, \mathrm{x}_{i m}, \mathrm{x}_{j n}\right)$. Onde $U_{i}$ seria o nivel de satisfação do indivíduo $i ; F_{i}$ (.) é a função que representa a satisfação do indivíduo $i$; os $\mathrm{x}_{i k}$ são as quantidades dos bens $\mathrm{x}_{1}, \mathrm{x}_{2}, \ldots, \mathrm{x}_{m}$ utilizadas e sob o controle do indivíduo $i$; e, $\mathrm{x}_{j n}$ seria a quantidade do bem $\mathrm{N}$ utilizado pelo indivíduo $i$ mas fora do seu controle (utilizado pelo indivíduo $j$ ou produzido pela firma $j$ ). $F_{i}$ pode também ser identificada como a função de produção de uma indústria ou firma. Nesse caso os $\mathrm{x}_{i k}$ seriam as quantidades dos insumos utilizados controlados por ela e o $\mathrm{x}_{j n}$ seria a quantidade de insumo ou produto de outra firma ou outra indústria fora do controle da firma $i . F_{i}$ pode também ser vista como a função custo total indireto da firma $i$, onde esse custo depende tanto das quantidades produzidas dos bens $\mathrm{x}_{i k}$ como da quantidade do bem $\mathrm{N}$ produzido pela firma $j$ cuja produção gera o efeito externo para a firma $i$.

Um ponto enfatizado na literatura sobre externalidades (Mishan, 1971; Randall, 1987) é que o efeito externo produzido não é, em geral, uma criação deliberada ou intencional, mas corresponde a um subproduto incidental de uma atividade desejada pela sociedade. Nesse contexto, a produção agrícola é uma atividade desejada pela sociedade. No entanto, ela gera, como subproduto, a erosão acelerada do solo, que por sua vez se torna uma fonte de poluição dos corpos de água via sedimentos e elementos químicos arrastados. Essa poluição constitui uma externalidade negativa da agricultura, por exemplo, para as firmas encarregadas do tratamento de água para o abastecimento urbano. A poluição da água gerada pela erosão do solo afeta diretamente o processo de produção de água potável, aumentando a quantidade de insumos a serem utilizados e, com isso, aumenta o custo de produção. 
O sistema econômico de mercado competitivo pode falhar na alocação eficiente dos recursos quando existem interações, entre firmas e indivíduos, que não são adequadamente refletidas nos preços de mercado (Nicholson, 1985). Randall (1987) identifica cinco fontes de falha de mercado: a existência de bens e recursos não exclusíveis; a existência de bens, serviços e amenidades não rivais no consumo; a existência de bens congestionáveis; a ocorrência de monopólio; e, a existência de externalidades não compensadas.

Neste estudo aborda-se especificamente o caso de extenalidade em que a poluição da água pela erosão do solo (sedimentos em suspensão, residuos de pesticidas, fertilizantes, matéria orgânica, etc.) é gerada junto à atividade desejada de produção agrícola. A produção agrícola geralmente se encontra sujeita a um sistema bem especificado de direitos de propriedade e de estrutura de preços, mas o seu subproduto "poluição" não é desejado e nem incorporado nos mercados.

Esses efeitos externos de poluição da água representam custos adicionais para a sociedade, em diferentes formas. Por exemplo: aumento no custo de tratamento de água para o consumo humano, que se traduz em um maior preço pago pelo serviço de água potável; maiores custos na geração de hidroeletricidade; maiores custos ou menor utilidade da recreação, etc.

Nesse sentido, os custos globais da produção agrícola que provoca efeitos externos por erosão são maiores que os custos privados. A Figura 6 mostra essa situação. A linha D representa a demanda por produtos agrícolas (o beneficio marginal social). A linha CMP mostra o custo marginal privado (oferta atual de mercado) e a linha CMS é o custo marginal social (oferta desejada pela sociedade). O ponto de equilibrio 'privado' seria $\mathrm{A}$, representado por uma produção $\mathrm{Y}$ e um preço $\mathrm{P}$. Por sua vez, o ponto de equilibrio 'social' seria $B$, com a produção $Y$ ' e o preço $P$ '. Do ponto de vista social existe uma alocação ineficiente de recursos no ponto $\mathrm{A}$, porque recursos a mais estão sendo utilizados para se produzir Y quando Y' seria a quantidade socialmente ótima. 
A diferença entre CMS e CMP é o custo adicional com que a sociedade se defronta devido aos efeitos externos que a produção agrícola gera ${ }^{12}$.

A estimação dos custos internos e externos da erosão é um subsídio importante na formulação de políticas públicas e programas visando a conservação do solo. Isso porque a decisão de implementar ou não os programas freqüentemente é baseada na comparação de beneficios e custos.

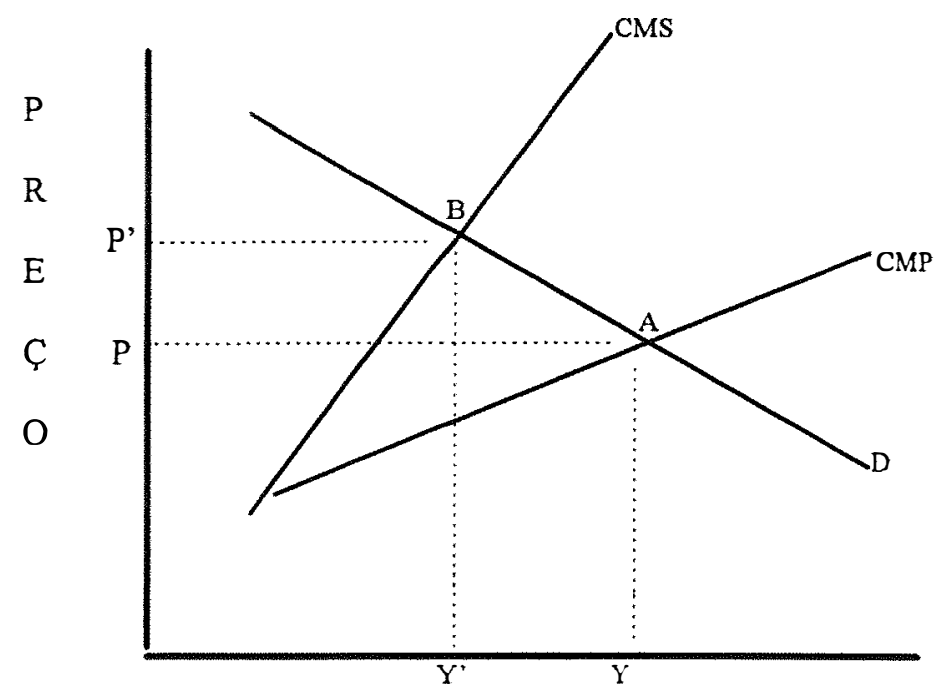

Q A N T I D A D E

Figura 6 - Equilíbrio privado e equilíbrio social na presença de externalidades negativas na produção.

Bunce (1942) sugere que a ação da sociedade, através da formulação de políticas públicas, visando a conservação é desejável quando: (i) a conservação é economicamente vantajosa para o produtor agrícola individual, mas ele não a adota. Nesse sentido, políticas públicas visando a conservação são desejáveis porque a implementação delas aumentaria os retornos líquidos do indivíduo e da sociedade. (ii) a conservação não é

\footnotetext{
${ }^{12}$ Se o preço de todos os fatores é determinado em mercados de concorrência perfeita. o cálculo do custo social pode ser feito diretamente. Caso contrário, ajustes devem ser realizados para transformar os preços observados em preços sombra.
} 
economicamente vantajosa para o produtor, mas sim para a sociedade. Nesse caso a justificativa econômica é que sem a implantação das políticas, os retornos líquidos sociais seriam menores que os retornos líquidos privados. (iii) fins intangíveis tornam-se objetivos sociais apoiados pela maioria das pessoas através dos mecanismos políticos existentes. Nesse sentido, apesar de a valoração econômica ser difícil, supõe-se que a utilidade da sociedade aumentaria com a implantação das políticas, inclusive se os indivíduos afetados forem compensados. 


\section{METODOLOGIA}

O capítulo de metodologia divide-se em duas partes. A primeira parte descreve a forma em que o custo interno causado pela erosão do solo foi obtido. A segunda apresenta o procedimento utilizado para o cálculo do impacto da erosão do solo sobre os custos de tratamento de água para o abastecimento urbano.

\subsection{0 custo do impacto interno da erosão do solo}

O custo do impacto interno resultante da erosão acelerada do solo na bacia do rio Corumbatai foi determinado em três fases. Na primeira, estima-se a carga de sedimentos produzida pela erosão. Na segunda fase, o valor monetário dos nutrientes perdidos junto aos sedimentos é calculado. Finalmente, na terceira fase, estima-se o valor da queda do rendimento da cana-de-açúcar provocada pela erosão.

\subsubsection{Cálculo da carga de sedimentos}

O cálculo da carga de sedimentos partiu da estimativa das perdas de terra causadas pela erosão hídrica laminar através da Equação Universal de Perdas de Solo (EUPS) (Wischmeier \& Smith, 1978):

$$
A=R \times K \times L \times S \times C \times P
$$

onde:

$A$ é a perda estimada de solo por erosão, em toneladas por hectare; 
$R$ é o fator de erosividade da chuva, em $\mathrm{MJ} / \mathrm{ha}: \mathrm{mm} / \mathrm{h}$;

$K$ é o fator de erodibilidade do solo, em $\mathrm{t} / \mathrm{ha} / \mathrm{MJ} / \mathrm{ha} \cdot \mathrm{mm} / \mathrm{h}$;

$L$ é o comprimento de rampa;

$S$ é o declive médio;

$C$ é o fator uso e manejo do solo; e,

$P$ é o fator de prática conservacionista.

As estimativas das perdas de terra por erosão foram utilizadas na obtenção da carga de sedimentos (quantidade de solo erodido que atinge os corpos superficiais de água da bacia). Para isso, utilizaram-se as fórmulas sugeridas por Renfro (1975), citado por Chaves (1995):

$$
S D R=\frac{1}{\sqrt[5]{A B}}
$$

onde:

$S D R$ é a proporção das perdas de solo que atingem os corpos de água (sediment delivery ratio); $\mathrm{e}$,

$A B$ é a área da bacia em milhas quadradas (a área da bacia foi utilizada em milhas quadradas porque a fórmula não foi ainda calibrada para as condições do Brasil).

A equação para o cálculo da carga de sedimentos é:

$$
Y=S D R \cdot A
$$

onde:

$Y$ é a carga de sedimentos, em toneladas por hectare;

$S D R$ é o sediment delivery ratio; $\mathrm{e}$,

$A$ é a perda estimada de terra por erosão obtida através da EUPS, em toneladas por hectare. 


\subsubsection{Valor monetário dos nutrientes perdidos junto à carga de sedimentos}

Com base nas informações sobre o teor dos principais nutrientes (nitrogênio, $\mathrm{N}$; potássio, K; Cálcio, Ca; e Magnésio, $\mathrm{Mg}$ ) do horizonte superficial dos solos predominantes na bacia (Podzólico Vermelho-Amarelo, Latossolo Vermelho-Amarelo e Terra Roxa Estruturada), tomados de Oliveira \& Prado (1984), obtiveram-se os valores do teor médio de nutrientes para os solos da bacia, assim:

$$
T M N_{j}=\frac{\sum_{i=1}^{3} A B_{i} \cdot T N_{j i}}{\sum_{i=1}^{3} A B_{i}} ; j=1,2, \ldots, 3
$$

onde:

$T M N_{j}$ é o teor médio do $j$-ésimo nutriente dos solos da bacia, em percentagem;

$A B_{i}$ é a área da bacia ocupada pelo $i$-ésimo tipo de solo, em ha;

$T N_{j i}$ é o teor do $j$-ésimo nutriente no $i$-ésimo tipo de solo, em percentagem;

$j=1$ é nitrogênio;

$j=2$ é potássio; e,

$j=3$ é cálcio + magnêsio.

O teor médio de fósforo $(\mathrm{P})$ corresponde à média dos solos do Estado de São Paulo (Bellinazzi Junior et al., 1981), visto que as informações para esse nutriente não se encontram em Oliveira \& Prado (1984).

A quantidade perdida de nutrientes junto à carga de sedimentos foi estimada assim

$$
Q N P_{j}=Y . A B \cdot T M N_{j} ; \quad j=1,2, \ldots, 4
$$

onde:

$Q N P_{j}$ é a quantidade perdida do $j$-ésimo nutriente, em toneladas;

$Y$ é a carga de sedimentos, em toneladas por hectare;

$A B$ é a área da bacia em hectares; $\mathrm{e}$, 
$T M N_{j}$ é o teor médio do $j$-ésimo nutriente, em percentagem;

As quantidades equivalentes dos fertilizantes e corretivos mais comumente utilizados na região (sulfato de amônia para $\mathrm{N}$, superfosfato simples para $\mathrm{P}$, cloreto de potássio para $\mathrm{K}$ e calcário dolomítico para $\mathrm{Ca}+\mathrm{Mg}$ ) foram estimadas com a fórmula:

$$
Q E F_{j k}=\frac{Q N P_{J}}{T N F_{j k}} ; \quad j=1,2, \ldots, 4 \mathrm{e} k=1,2, \ldots, 4
$$

onde:

$Q E F_{j k}$ é a quantidade do $j$-ésimo nutriente perdido, em unidades equivalentes do $k$-ésimo fertilizante, em toneladas;

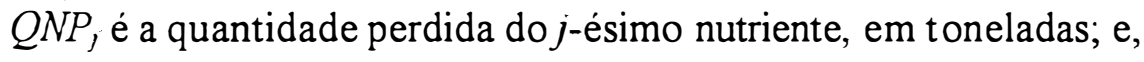
$T N F_{j k}$ é o teor do $j$-ésimo nutriente no $k$-ésimo fertilizante, em percentagem.

$k=1$ é sulfato de amônia;

$k=2$ é superfosfato simples;

$k=3$ é cloreto de potássio; $\mathrm{e}$,

$k=4$ é calcário dolomítico.

Finalmente, o valor monetário total dos nutrientes perdidos, em termos equivalentes de fertilizantes, foi calculado utilizando-se a seguinte fórmula:

$$
V M N=\sum_{k=1}^{4} P_{k} \cdot Q E F_{k}
$$

onde:

IMN é o valor monetário agregado dos fertilizantes, em reais de dezembro de 1995;

$P_{k}$ é o preço do $k$-ésimo fertilizante, em reais de dezembro de 1995; e, $Q E F_{k}$ é a quantidade do $k$-ésimo fertilizante ou corretivo, em toneladas. 


\subsection{3 $O$ custo da perda de produtividade causada pela erosão}

O rendimento de uma cultura é a expressão da interação do potencial genético com o ambiente. Pimentel et al. (1976) indicam que a produção agrícola é afetada por fatores como a variedade, as características do solo (teor de nutrientes, estrutura, espessura da camada superficial e drenagem), a temperatura e a umidade do ambiente e o dano por pragas e doenças.

Nesse sentido, o modelo teórico do rendimento de uma cultura em um ponto no tempo poderia ser expresso através da seguinte relação:

$$
y=f(V, N, E, S, D, T, U, P, H)
$$

onde:

$y$ é a produção por unidade de área;

$V$ é a variedade da cultura;

$N$ é a quantidade de nutrientes disponível no solo;

$E$ é a estrutura da camada superficial do solo;

$S$ é a espessura da camada superficial do solo;

$D$ é a drenagem do solo;

$T$ é a temperatura do ambiente;

$U$ é a umidade do ambiente;

$P$ é o dano causado por pragas; $\mathrm{e}$,

$H$ é o dano causado por doenças.

Neste estudo, para constatar se a produtividade do solo está sendo afetada pela erosão implicando em queda do rent das terras agrícolas (ponto $\mathrm{H}$ da Figura 3), estimativas do efeito da erosão sobre o rendimento foram feitas especificamente para a cultura de cana-de-açúcar. Isso porque da área da bacia ocupada com lavouras em 1990, 93\% correspondia a cana. Apesar da maior parte da área da bacia ser ocupada com pastagens, não se estudou o efeito da erosão sobre o rendimento delas já que, geralmente, as perdas de solo por erosão em áreas com pastagens não ultrapassam os limites 
toleráveis de perdas $^{13}$. Isso significa que muito provavelmente não exista efeito significativo da erosão sobre a produtividade das pastagens.

A estimação empírica da eq. (8) foi simplificada, visto que só foi possível se contar com dados sobre rendimento de cana, variedades, idade do canavial, espaçamento, quantidades adicionadas de nutrientes e perdas de terra por erosão. Porém, ainda que simples, os modelos empíricos podem captar uma parte importante da variabilidade do rendimento. Isso porque, por exemplo, o efeito do dano por pragas e doenças é absorvido pelas variedades $^{14}$. O efeito de várias das características do solo é levado em conta pelas perdas de solo por erosão. Finalmente, na medida que os dados representam um corte no tempo (cross-section), o efeito do clima (temperatura e umidade) pode ser considerado constante para $o$ ano em que as informações foram geradas.

Contou-se com dados para três das unidades de solo existentes na bacia (Podzólico Vermelho-Amarelo, PV; Latossolo Roxo, LR e Terra Roxa Estruturada, TE), essas três unidades de solo representam, no conjunto, o 78,5\% da área da bacia. Para o PV foram obtidas 25 observações da fazenda São Francisco da Usina Costa Pinto, todas elas mostrando perdas de solo acima do limite tolerável (9,17 t/ha em média). Entretanto, das 35 observações disponiveis para o Latossolo Roxo, 30 apresentaram valores abaixo do limite tolerável ( $13 \mathrm{t} / \mathrm{ha}$ ) de perdas de solo por erosão. No caso dos dados da Terra Roxa Estruturada, contou-se com 19 observações cujas perdas de solo não superavam o limite tolerável (13,4 t/ha em média) e 10 observações com perdas acima do limite tolerável. As observações dos solos Latossolo Roxo e Terra Roxa Estruturada foram obtidas da fazenda Santa Rosa II da Usina Costa Pinto. Das três unidades de solo estudados, supõe-se que só no Podzólico Vermelho-Amarelo poderá aparecer um efeito significativo da erosão sobre o rendimento da cana-de-açúcar. Isso porque os Latossolos

\footnotetext{
${ }^{13}$ As perdas de solo por erosão estimadas para as áreas com pastagens da bacia do rio Corumbatai são, em média, 10,5 t/ha. Esse valor praticamente coincide com o valor médio das perdas toleráveis.

${ }^{14}$ João Américo Beltrame, Usina Costa Pinto, comunicação pessoal, 20/05/97.
} 
e as Terras Roxas Estruturadas geralmente apresentam espessuras que não restringem o crescimento das raízes e a retenção de umidade.

A função estimada para o solo Podzólico Vermelho-Amarelo simplificou-se $\operatorname{para}^{15}$ :

$$
\begin{aligned}
R P 96=\alpha_{0}+ & \alpha_{1} A+\alpha_{2} A^{2}+\alpha_{3} I 96+\alpha_{4} I 96^{2}+\alpha_{5} N 95+\alpha_{6} N 95^{2}+\alpha_{7} K 95+\alpha_{8} K 95^{2} \\
& +\alpha_{9} D+\varepsilon ;
\end{aligned}
$$

onde:

RP96 é o rendimento de cana-de-açúcar da safra de 1996, no solo Podzólico

Vermelho-Amarelo, em toneladas por hectare;

$A$ é a perda estimada de terra, em toneladas por hectare;

I96 é a idade do canavial em 1996, em anos;

N95 é a quantidade de nitrogênio aplicada em 1995, em quilogramas por hectare;

K95 é a quantidade de potássio aplicada em 1995, em quilogramas por hectare;

$D$ é a variável dummy para diferenciar o efeito de variedade RB 78-5148;

$\alpha_{0}$ a $\alpha_{9}$ são os parâmetros a estimar; e,

$\varepsilon$ é o erro.

Neste caso não existe efeito do espaçamento porque os dados usados vem de uma área onde o espaçamento era constante.

Para o caso dos Latossolos Roxos, a relação estimada foi:

$$
\begin{gathered}
R L 96=\phi_{0}+\phi_{1} A+\phi_{2} A^{2}+\phi_{3} I 96+\phi_{4} I 96^{2}+\phi_{5} N 95+\phi_{6} N 95^{2}+\phi_{7} K 95+\phi_{8} K 95^{2} \\
+\phi_{9} D_{1}+\phi_{10} D_{2}+\phi_{11} D_{3}+\phi_{12} D_{4}+\varepsilon ;
\end{gathered}
$$

is Optou-se pela forma quadráticas diante da suposição da presença de rendimentos marginais decrescentes e pela facilidade de manipulação matemática. A estimação das funções foi feita utilizando o procedimento de regressão passo a passo já que, neste caso, considerou-se mais importante a significancia do coeficiente estimado do que um alto $\mathrm{R}$ quadrado. 
onde:

RL96 é o rendimento da cana-de-açúcar da safra 1996 no Latossolo Roxo, em toneladas por hectare;

$A$ é a perda estimada de terra, em toneladas por hectare;

I96 é a idade do canavial em 1996, em anos;

N95 é a quantidade de nitrogênio aplicada em 1995, em quilogramas por hectare;

K95 é a quantidade de potássio aplicada em 1995, em quilogramas por hectare;

$D_{1}$ a $D_{4}$ são variáveis dummy para as variedades SP 79-1011, SP 71-6163, RB

72-454 e SP 79-2312, respectivamente;

$\phi_{0}$ a $\phi_{12}$ são os parâmetros a serem estimados; e,

$\varepsilon$ é o erro.

No caso da eq. (10), não foi considerado o espaçamento já que este era homogêneo na área onde os dados foram obtidos.

Por sua vez, o modelo estimado para o solo Terra Roxa Estruturada foi:

$$
\begin{aligned}
R T 96=\theta_{0} & +\theta_{1} A+\theta_{2} A^{2}+\theta_{3} I 96+\theta_{4} I 96^{2}+\theta_{5} N 95+\theta_{6} N 95^{2}+\theta_{7} K 95+\theta_{8} K 95^{2} \\
& +\theta_{9} D_{1}+\theta_{10} D_{2}+\theta_{11} D_{3}+\theta_{12} D_{4}+\theta_{13} D_{5}+\varepsilon
\end{aligned}
$$

onde:

RT96 é o rendimento da cana-de-açúcar da safra 1996, no solo Terra Roxa

Estruturada, em toneladas por hectare;

$A$ é perda estimada de terra, em toneladas por hectare;

I96 é a idade do canavial em 1996, em anos;

N95 é a quantidade de nitrogênio aplicada em 1995, em quilogramas por hectare;

K95 é a quantidade de potássio aplicada em 1995, em quilogramas por hectare;

$D_{1}$ a $D_{5}$ são variáveis dummy para as variedades SP 71-1406, RB 76-5418, SP

71-6163, SP 79-2312 e RB 72-454, respectivamente;

$\theta_{0}$ a $\theta_{13}$ são os parâmetros a serem estimados; e, 
$\varepsilon$ é o erro.

No caso da eq. (11), não foi considerado o espaçamento já que este era homogêneo na área onde os dados foram obtidos.

A perda de produtividade para cada tipo de solo foi obtida utilizando-se a seguinte fórmula:

$$
Q P_{i}=\frac{\partial R M_{i}}{\partial A_{i}}\left(\overline{A_{i}}-\overline{P T_{i}}\right) ; \quad i=1, \ldots, 3
$$

onde:

$Q P_{i}$ é a perda de produtividade da cana-de-açúcar no $i$-ésimo tipo de solo, em toneladas por hectare;

$\frac{\partial R M_{i}}{\partial A_{i}}$ é a variação do rendimento da cana-de-açúcar causada por uma variação unitária da perda estimada de solo no $i$-ésimo tipo de solo, em toneladas por hectare;

$\overline{A_{i}}$ é a perda média estimada de terra do $i$-ésimo tipo de solo, em toneladas por hectare;

$\overline{P T_{i}}$ é a perda tolerável média de terra do $i$-ésimo tipo de solo, em toneladas por hectare;

$i=1$ representa os solos Podzólicos;

$i=2$ representa os solos Latossolo; e,

$i=3$ representa os solos Terra Roxa Extruturada.

Finalmente, o valor monetário anual da perda de produtividade da cana-de-açúcar foi determinado de acordo com a fórmula ${ }^{16}$ :

${ }^{16}$ A extrapolação do cálculo feito com rendimentos de cana-de-açúcar de 1996 para o periodo de 1985 a 1990 faz-se supondo que a queda de produtividade devida a erosão do solo é constante. Isso porque (i) os parâmetros dos fatores da EUPS utilizados para calcular as perdas de terra são médias de 30 anos; e, (ii) supondo tecnologia constante, o fator clima faria mudar o rendimento da cana de um ano para outro. Não obstante, dado que a área da bacia é relativamente pequena, para um mesmo 


$$
V Q P_{l}=\sum_{i=1}^{3}\left(Q P_{i} . A C_{i l} . P C_{l}\right) ; \quad l=1,2, \ldots, 10
$$

onde:

$V Q P_{l}$ é o valor monetário da perda de produtividade da cana-de-açúcar, no $l$ ésimo ano, em reais de dezembro de 1995;

$Q P_{i}$ é a queda de produtividade da cana-de-açúcar no $i$-ésimo tipo de solo, em toneladas por hectare;

$A C_{i l}$ é a área da bacia plantada com cana-de-açúcar no $i$-ésimo tipo de solo durante o $l$-ésimo ano, em hectares;

$P C_{l}$ é o preço bruto da cana-de-açúcar ao produtor, na região de Piracicaba, no $l$ ésimo ano, em reais de dezembro de 1995 por tonelada; e,

$l=1$ é $1985 \ldots l=10$ é 1994.

\subsubsection{Determinação do custo interno da erosão do solo}

O custo interno da erosão do solo foi calculado somando o custo da perda de produtividade e o custo da perda de nutrientes, assim:

$$
C I A_{l}=I M N_{l}+V Q P_{l}
$$

onde:

$C I A_{l}$ é o custo interno agregado da erosão do solo no $l$-ésimo ano, em reais de dezembro de 1995;

$V M N_{l}$ é o valor monetário da perda de nutrientes no $l$-ésimo ano, em reais de dezembro de 1995; e,

$V Q P_{l}$ é o valor da perda de produtividade causada pela erosão do solo no $l$-ésimo ano, em reais de dezembro de 1995. 


\subsubsection{Definição das variáveis básicas e fonte dos dados}

Nesta seção definem-se as variáveis utilizadas no estudo e que dizem respeito ao efeito interno da erosão do solo. Tratam-se das variáveis cujos dados foram obtidos de outras fontes citadas a seguir e a partir das quais os cálculos desta parte do estudo foram desenvolvidos.

\subsubsection{Fator erosividade da chuva $(\mathbf{R})$}

O fator de erosividade da chuva utilizado neste trabalho é definido pela fórmula (Lombardi Neto \& Moldenhauer, 1992):

$$
\mathrm{R}_{i}=89,823\left(\mathrm{r}_{i}^{2} / \mathrm{P}_{i}\right)^{0,759}
$$

onde:

$\mathrm{R}_{i}$ é o fator de erosividade da chuva para o $i$-ésimo município dentro da bacia, em Megajoule/hectare . milímetro/hora (MJ/ha . mm/h);

$\mathrm{r}_{i}^{2}$ é o quadrado da precipitação média mensal para o $i$-ésimo município dentro da bacia, em milímetros; e,

$\mathrm{P}_{i}$ é a precipitação média anual para o $i$-ésimo município dentro da bacia, em milimetros.

Os valores utilizados para calcular o fator $\mathrm{R}$ aparecem na Tabela 11 (apêndice 1).

\subsubsection{Fator erodibilidade do solo (K)}

Define-se como a perda de solo por unidade de índice de erosão da chuva. Expressa-se em tonelada hora por Megajoule milímetro (t.h/MJ.mm) (Bertoni \& Lombardi Neto, 1992) (Tabela 14, apêndice 1). 


\subsubsection{Fator comprimento e grau de declive (LS)}

É definido como a perda estimada de solo por unidade de área em um declive qualquer em relação às perdas de solo de uma parcela de $25 \mathrm{~m}$ de comprimento com $9 \%$ de declive. Neste caso ele foi calculado pela fórmula (Bertoni \& Lombardi Neto, 1992):

$$
L S=0,00984 \cdot C^{0,63} \cdot D^{1,18}
$$

onde:

$L S$ é o fator de comprimento e grau de declive ou fator topográfico;

$C$ é o comprimento dos lançantes, em metros; e,

$D$ é o grau de declive dos lançantes, em percentagem.

\subsubsection{Fator uso e manejo do solo (C)}

É a relação esperada entre as perdas de solo de um terreno cultivado em dadas condições e as perdas correspondentes de um terreno mantido continuamente descoberto e cultivado (Bertoni \& Lombardi Neto, 1992). A tabela 12 (apêndice 1) mostra os valores do fator $\mathrm{C}$ utilizados nesta pesquisa.

\subsubsection{Fator prática conservacionista $(P)$}

Define-se como a relação entre as perdas de solo com uma prática conservacionista e as perdas de solo quando a cultura está plantada no sentido do declive $^{17}$ (Bertoni \& Lombardi Neto, 1992). A Tabela 13 (apêndice 1) apresenta os valores do fator $\mathrm{P}$ adotados para este estudo.

\footnotetext{
${ }^{17}$ Os valores dos fatores $\mathrm{R}, \mathrm{K}, \mathrm{C}$ e P para este estudo foram gentilmente calculados pelo Dr. Francisco Lombardi Neto do Instituto Agronômico de Campinas (IAC). Os valores do fator topográfico (LS) foram calculados pelo autor sob a orientação do Dr. Pedro Donzeli do IAC.
} 


\subsubsection{6 Área da bacia (AB)}

É o espaço superficial que ocupa a bacia. Ao longo do trabalho ela é expressa em $\mathrm{km}^{2}$, hectares e milhas quadradas. Ela foi obtida de Koffler (1993) e corresponde a 1.710 $\mathrm{km}^{2}$.

\subsubsection{Perda tolerável de solo por erosão (PT)}

Define-se como a intensidade máxima de erosão do solo que permitirá a um elevado nivel de produtividade manter-se econômica e indefinidamente (Bertoni \& Lombardi Neto, 1992). Os valores dos limites toleráveis de perdas para os distintos tipos de solos da bacia foram fornecidos pelo Dr. Francisco Lombardi Neto do IAC.

\subsubsection{Preço do fertilizante (P)}

É o valor pago para adquirir uma tonelada de fertilizante ou corretivo. É expressa em reais de dezembro de 1995. Os dados foram obtidos do anuário de informações estatísticas da agricultura preparado pelo Instituto de Economia Agrícola de São Paulo.

\subsubsection{Rendimento observado (R)}

O rendimento observado é a quantidade obtida de cana-de-açúcar por unidade de área, expressa em toneladas por hectare (t/ha). Neste caso, o rendimento da safra de 1996 foi utilizado. Os dados foram obtidos na Usina Costa Pinto (ver Tabelas 14, 15 e 16 do apêndice 2). 


\subsubsection{Idade do canavial (I)}

Define-se como o período de tempo que transcorre entre o plantio e a colheita da cana na safra de 1996. Expressa-se em anos. Os dados foram fornecidos pela usina Costa Pinto (ver Tabelas 14, 15 e 16 do apêndice 2).

\subsubsection{1 Área ocupada com cana-de-açúcar (AC)}

Refere-se à extensão de terra que é ocupada com cana-de-açúcar, em cada ano do período estudado, na bacia do rio Corumbataí, assumindo-se uma expansão linear ${ }^{18}$. Ela é expressa em hectares. Os dados foram obtidos a partir dos mapas de uso da terra de 1978, elaborado pelo projeto 'Bacia do Rio Piracicaba - Ciência e Educação para a Melhoria do Meio Ambiente" (Pira Cena) e do mapa de uso da terra de 1990, elaborado pelo Professor Natálio Koffler.

Ela foi calculada assim:

$$
A C_{l}=A C_{l-1}+\left(\frac{A C_{90}-A C_{78}}{12}\right)
$$

onde:

$A C_{l}$ é a área plantada com cana-de-açúcar no $l$-ésimo ano, em hectares;

$A C_{90}$ é a área plantada com cana-de-açúcar em 1990, em hectares; e, $A C_{78}$ é a área plantada com cana-de-açúcar em 1978, em hectares.

\footnotetext{
${ }^{18}$ Apesar dessa pressuposição não ser razoável, ela foi feita devido à falta de informações anuais sobre o uso da terra. Ela determinará que para alguns anos o custo da erosão seja superestimado, enquanto para outros anos ele seja subestimado.
} 


\subsubsection{Preço da cana-de-açúcar recebido pelo produtor $(\mathrm{PC})$}

Define-se como o valor médio anual recebido pelo produtor agrícola, por tonelada de cana-de-açúcar, na região do estudo, em moeda constante de dezembro de 1995 . Os preços, em moeda corrente, foram obtidos da Associação dos Fornecedores de Cana de Piracicaba.

\subsection{Impacto da erosão do solo sobre o custo de tratamento da água para uso domiciliar}

O impacto da erosão do solo sobre o custo de tratamento de água para consumo humano foi determinado em três etapas. Na primeira etapa, foi estimada uma função hedônica não homotética de custo operacional total. Na segunda etapa, obteve-se o custo operacional mensal e médio (por metro cúbico) em função da carga de sedimentos. Finalmente, na terceira etapa, o custo operacional adicional anual causado pela carga de sedimentos foi calculado para a bacia toda.

\subsubsection{Estimativa da função custo operacional total de tratamento de água}

Nesta parte do estudo estimou-se uma função custo onde o custo operacional total de tratamento é a variável dependente e a quantidade distribuída de água tratada, a carga de sedimentos e os preços de energia elétrica, mão-de-obra, sulfato de alumínio, cal e cloro são as variáveis independentes.

Trata-se de uma função custo hedônica não homotética de regressão na forma Translog (Chambers, 1991). Nessa função, inclui-se a carga de sedimentos como uma proxy para captar o efeito externo da erosão do solo sobre o custo de tratamento de 
água, acatando-se assim o apontado por Mishan (1971). A forma geral da função proposta é:

$$
\begin{aligned}
\log C_{t}=\beta_{0}+ & \beta_{1} \log A g_{t}+\frac{1}{2} \beta_{2}\left(\log A g_{t}\right)^{2}+\delta_{0} \log Y_{t}+\frac{1}{2} \delta_{1} \log \left(Y_{t}\right)^{2}+ \\
& \sum_{i=1}^{n} \alpha_{i} \log P_{i t}+\frac{1}{2} \sum_{i=1}^{n} \sum_{j=1}^{m} \phi_{i j} \log P_{i t} \log P_{j t}+ \\
& \sum_{i=1}^{n} \theta_{i} \log P_{i t} \log A g_{t}+\varepsilon_{t, j} \quad t=1, \ldots, 120, \quad i=1,2, \ldots, 5, \\
j= & 1,2, \ldots, 5, \quad i \neq j, \quad i j=j i
\end{aligned}
$$

onde:

$\log C_{t}$ é o logaritmo neperiano do custo operacional de tratamento de água, em reais de dezembro de 1995 , no $t$-ésimo mês;

$\log A g_{t}$ é o logaritmo neperiano da quantidade de água distribuída, em metros cúbicos, no $t$-ésimo mês;

Log $Y_{t}$ é o logaritmo neperiano da carga de sedimentos, em toneladas, no $t$-ésimo mês;

Log $P_{i t}$ é o logaritmo neperiano do preço, em valores reais de dezembro de 1995, do $i$-ésimo insumo no $t$-ésimo mês;

$\beta_{0}$ a $\beta_{2}, \delta_{0}, \delta_{1}, \alpha_{i}, \phi_{i j}, \theta_{i}$ são os parâmetros a serem estimados;

$\varepsilon_{t}$ é o erro associado à $t$-ésima observação;

$i=1$ é o preço do sulfato de alumínio;

$i=2$ é o preço da cal;

$i=3$ é o preço do cloro;

$i=4$ é o preço da eletricidade;

$i=5$ é o preço da mão-de-obra; e,

$t=1$ é o mês de janeiro de $1985, \ldots, t=120$ é o mês de dezembro de 1994 . 
A homogeneidade de grau 1 nos preços dos insumos foi imposta no momento da estimação da eq. (18), através das restrições:

$$
\sum_{i=1}^{n} \alpha i=1 ; \quad \sum_{i=1}^{n} \phi i j=\sum_{j=1}^{n} \phi j i=\sum_{i=1}^{n} \theta i=0
$$

A eq. (18) também foi estimada impondo-se homoteticidade $\left(\theta_{i}=0\right)$. Para se chegar na estimativa das funções do tipo Cobb-Douglas, impôs-se na eq. (18) a condição de homogeneidade de grau constante no produto $\left(\beta_{2}=0\right)$ e, também $\phi_{i j}=0$. Detectou-se colinearidade entre os efeitos quadráticos e lineares da quantidade de água distribuída e a carga de sedimentos. A colinearidade estava causando a não significância dos coeficientes da água distribuída e sinais trocados dos coeficientes da carga de sedimentos. Para contornar o problema, supôs-se que o efeito quadrático dessas variáveis não é significativo no intervalo de valores analisado. Nesse sentido, a função estimada foi uma translog modificada (sem efeitos quadráticos).

Para fazer as estimativas do custo operacional total mensal escolheu-se, dentre os quatro modelos estimados, aquele com maior coeficiente de determinação $\left(\mathrm{R}^{2}\right)$.

\subsubsection{Estimativa do custo operacional total mensal de tratamento de água}

O custo operacional total para cada mês do periodo 1985-1994 foi estimado utilizando a eq. (18) estimada. Para isso, os valores médios anuais de cada variável, exceto da carga de sedimentos, foram substituídos nela assim como os respectivos valores observados da carga de sedimentos:

$$
\log \hat{C}_{t}=\hat{\beta}_{0}+\hat{\beta}_{1} \log \overline{A g_{l}}+\frac{1}{2} \hat{\beta}_{2}\left(\log \overline{A g_{l}}\right)^{2}+\hat{\delta}_{0} \log Y_{t}+\frac{1}{2} \hat{\delta}_{1} \log \left(Y_{t}\right)^{2}+
$$




$$
\begin{aligned}
& \sum_{i=1}^{n} \hat{\alpha}_{i} \log \overline{P_{i t}}+\frac{1}{2} \sum_{i=1}^{n} \sum_{j=1}^{m} \hat{\phi}_{i j} \log \overline{P_{i t}} \log \overline{P_{j t}}+ \\
& \sum_{i=1}^{n} \hat{\theta}_{i} \log \overline{P_{i t}} \log \overline{A g l}, \quad t=1, \ldots, 120, \quad i=1,2, \ldots, 5, \\
& j=1,2, \ldots, 5, \quad i \neq j, \quad i j=j i
\end{aligned}
$$

onde:

$\log \hat{C}_{t l}$ é o logaritmo neperiano do custo operacional de tratamento de água estimado para o $t$-ésimo mês do l-ésimo ano, em reais de dezembro de 1995;

$\log \overline{A g}$ é a média mensal do logaritmo neperiano da quantidade de água distribuída no l-ésimo ano, em metros cúbicos;

$\log Y_{t}$ é o logaritmo neperiano da carga de sedimentos no $t$-ésimo mês, em toneladas; e,

$\bar{P}_{i l}$ é a média mensal do logaritmo neperiano do preço do $i$-ésimo insumo no $l$ ésimo ano, em reais de dezembro de 1995.

A eq. (20) foi também utilizada para calcular o impacto da carga de sedimentos correspondente aos niveis toleráveis de perdas de solo.

O custo operacional adicional por metro cúbico de água distribuída foi obtido através da seguinte fórmula:

$$
\operatorname{COAM}_{t l}=-\frac{\hat{C}_{u l}}{A T_{t l}}-\frac{\hat{C}_{a l}}{A T_{a l}}
$$

onde:

$C O A M_{t l}$ é o custo operacional adicional por metro cúbico de água distribuída no t-ésimo mês do l-ésimo ano, em reais de dezembro de 1995; 
$\hat{C}_{t l}$ é o custo operacional estimado para o $t$-ésimo mês do $l$-ésimo ano, em reais de dezembro de 1995;

$\hat{C}_{a l}$ é o custo operacional do mês de agosto ${ }^{19}$ do l-ésimo ano, em reais de dezembro de 1995;

$A T_{t l}$ é a quantidade de água tratada no $t$-ésimo mês do $l$-ésimo ano; e, $A T_{a l}$ é a quantidade de água tratada no mes de agosto do l-ésimo ano.

\subsubsection{Estimativa do custo operacional adicional para a bacia}

A estimativa do custo operacional adicional mensal das ETAs da cidade de Rio Claro obteve-se com a fórmula:

$$
C_{k t l}=C O A M_{t l} \cdot A g_{k t l}
$$

onde:

$C_{k t l}$ é o custo operacional adicional da $k$-ésima estação de tratamento de água no

$t$-ésimo mês do $l$-ésimo ano, em reais de dezembro de 1995 ;

$C_{\text {COA }}$ é o custo operacional adicional por metro cúbico da ETA 3 de

Piracicaba, no t-ésimo mês do l-ésimo ano; e,

$A g_{k t l}$ é a quantidade de água distribuída pela k-ésima estação de tratamento, no tésimo mês do l-ésimo ano.

O custo operacional adicional mensal para as três estações de tratamento de água foi calculado assim:

$$
C A_{t l}=\sum_{k=1}^{3} C_{k t l}
$$

onde:

$C A_{t l}$ é o custo operacional adicional para as três ETAs, no $t$-ésimo mês do $l$ ésimo ano, em reais de dezembro de 1995; e,

${ }^{19}$ Considerou-se o mês de agosto como ponto de referência pois é nesse mês que ocorre a menor carga de sedimentos gerada pela erosão das terras agrícolas. Assume-se que os sedimentos gerados nesse mês não alteram significativamente a qualidade da água bruta. 
$C_{k t l}$ é o custo operacional adicional da $k$-ésima ETA no $t$-ésimo mês do $l$-ésimo ano, em reais de dezembro de 1995.

Finalmente, o custo operacional adicional anual para a bacia toda foi estimado utilizando a seguinte fórmula:

$$
C A A_{l}=\sum_{t=1}^{11} C A_{t l}
$$

onde:

$C A A_{l}$ é o custo operacional adicional agregado para a bacia toda, no $l$-ésimo ano, em reais de dezembro de 1995; e,

$C A_{t l}$ é o custo operacional adicional agregado através das três ETAs, no $t$-ésimo mês do $l$-ésimo ano.

\subsubsection{Definição das variáveis básicas e fontes dos dados}

A seguir, define-se cada uma das variáveis cujos dados serão utilizados na estimativa do efeito da erosão do solo sobre o custo médio do tratamento de água para consumo humano.

\subsubsection{Custo operacional de tratamento da água (C)}

O custo operacional do tratamento da água é definido como as despesas que a estação de tratamento (ETA) incorre para bombear, conduzir e tratar a água bruta. Ele inclui os custos da eletricidade, dos reagentes utilizados no tratamento da água, da mãode-obra que trabalha na estação e o custo da limpeza dos filtros e dos decantadores. Os dados de custo são mensais e expressos em reais de dezembro de 1995. 


\subsubsection{Quantidade de água tratada distribuída (A)}

Define-se como:

$$
A_{k}=V_{k}-\left(A L_{k}+A D P_{k}\right) ; \quad k=1, \ldots, 3
$$

onde:

$A_{k}$ é a quantidade de água tratada distribuída pela $k$-ésima estação de tratamento, em mil metros cúbicos por mês;

$V_{k}$ é a quantidade de água bruta que entra na $k$-ésima estação de tratamento (vazão), em mil metros cúbicos por mês;

$A L_{k}$ é a quantidade de água utilizada pela $k$-ésima estação para a lavagem dos filtros, floculadores e decantadores, em mil metros cúbicos por mês; $A D P_{k}$ é a quantidade de água das descargas e as perdas da $k$-ésima estação. Esta variável é expressa em mil metros cúbicos por mês;

$k=1$ é a ETA 1 de Rio Claro (Ribeirão Claro);

$k=2$ é a ETA 2 de Rio Claro (Corumbatai); e, $k=3$ é a ETA 3 de Piracicaba (Capim Fino).

\subsubsection{Carga de sedimentos (Y)}

Refere-se à quantidade de sedimentos produzidos pelo processo de erosão do solo nas áreas agrícolas da região estudada, que atinge os cursos superficiais de água. Foi calculada utilizando a eq.(3). 


\subsubsection{Preço médio da eletricidade}

Define-se como a quantidade de dinheiro que a estação de tratamento pagou por quilowatt-hora $(\mathrm{R} \$ / \mathrm{KW} / \mathrm{hr})$ durante o periodo de tempo que o estudo abrange. Os preços, em moeda corrente, foram obtidos dividindo-se o valor das despesas do consumo de energia elétrica pela quantidade consumida por mês na ETA 3 do SEMAE (Tabela 20, apêndice 3).

\subsubsection{Preço da mão-de-obra}

O salário médio mensal dos operários da ETA 3 de Piracicaba foi utilizado como uma proxy da variável preço da mão-de-obra ${ }^{20}$. Ele está expresso em valores constantes de dezembro de 1995 (Tabela 21, apêndice 3).

\subsubsection{Preço dos reagentes}

É a despesa feita pelas estações de tratamento por unidade do reagente (sulfato de alumínio, cal, cloro, flúor e polímero), em reais de dezembro de 1995. Os dados foram obtidos junto ao Serviço Municipal de Água e Esgoto-SEMAE, da cidade de Piracicaba (ver Tabela 17, apêndice 3).

${ }^{20}$ O fato de extrapolar o preço de Piracicaba para Rio Claro pode causar a superestimação dos custos adicionais em Rio Claro, se esses preços fossem maiores em Piracicaba. 


\subsection{Cálculo do custo total da erosão do solo na bacia}

O custo interno foi somado ao custo operacional adicional de tratamento de água para obter uma estimativa do custo que a erosão do solo causou na bacia toda durante o período 1985-1994, assim:

$$
C A T_{l}=C I A_{l}+C A A_{l}
$$

onde:

$C A T_{l}$ é o custo total causado pela erosão do solo na bacia no l-ésimo ano, em reais de dezembro de 1995 ;

$C I A_{l}$ é o custo interno agregado da erosão no l-ésimo ano, em reais de dezembro de 1995; e,

$C A A_{l}$ é o custo operacional adicional do tratamento de água causado pela erosão no l-ésimo ano, em reais de dezembro de 1995.

Algumas das contribuições que o trabalho pretende dar são, no âmbito geral: (i) a utilização de uma forma funcional flexível para a estimação da função custo de tratamento de água e (ii) o uso de um maior número de variáveis explanatórias, com a inclusão dos preços dos reagentes químicos usados no sistema convencional de tratamento de água. Já, no âmbito brasileiro, as contribuições são: (i) mensurar o custo da erosão do solo em termos de perda de produtividade (depreciação do capital natural); (ii) aprimorar a estimativa do custo da perda de nutrientes (calculando-o a partir da carga de sedimentos e não da perda de solo por erosão); (iii) avaliar o impacto direto da erosão sobre o custo de tratamento de água; e, (iv) comparar, dentro de uma mesma unidade geográfica, as conseqüências econômicas da erosão estimada com as da erosão tolerável. 


\section{RESULTADOS E DISCUSSÃO}

\section{1 $O$ custo do impacto interno da erosão do solo}

Nesta seção são apresentados os resultados da determinação da carga de sedimentos, do valor da perda de nutrientes junto à carga de sedimentos, do valor da perda de produtividade e do valor interno dos custos causados pela erosão do solo na bacia.

\subsubsection{Carga de sedimentos}

A Tabela 2 apresenta as estimativas das perdas de terra por erosão, das perdas toleráveis e das suas respectivas cargas de sedimentos para o período 1985-1994. Notase que, em média, as perdas estimadas representam 3,04 vezes as perdas toleráveis, e a carga de sedimentos estimada representa 2,37 vezes a carga de sedimentos produzida pelas perdas toleráveis de solo. Deduz-se, dessa tabela, que se os limites máximos toleráveis de erosão fossem respeitados, ocorreria uma diminuição média anual de 3.794.902 toneladas de terra perdida. Isso implicaria em uma redução média anual na carga de sedimentos da ordem de 769.131 toneladas. Em termos de perdas médias por unidade de superficie (dividindo-se os valores totais por $171.000 \mathrm{ha}$ ), tem-se que as perdas estimadas atingem 32,52 t/ha; as perdas toleráveis são de 10,33 t/ha; a carga de sedimentos produzida pelas perdas estimadas chega a 7,77 t/ha; e, a carga de sedimentos

produzida pelas perdas toleráveis alcança a magnitude de 3,27 t/ha. É claro que os valores estimados representam médias de uma dispersão ampla correspondente às 
diferentes combinações de tipos de solo, cobertura, declividade e comprimento dos lançantes, práticas conservacionistas e intensidade das chuvas. Finalmente, determinouse que o valor médio das perdas estimadas $(32,52 \mathrm{t} / \mathrm{ha})$ é maior que o encontrado nos estudos de Castro (1987) de 8,68 t/ha, Menck (1993) de 21,67 t/ha, Bastos Filho (1995) de $4,75 \mathrm{t} / \mathrm{ha}$ e Cavalcanti (1995) de 6,77 t/ha. Isso pode ser devido ao fato de alguns desses autores, por exemplo Castro e Bastos Filho, terem utilizado as perdas médias por tipo de uso da terra geradas para condições experimentais específicas e as extrapolaram para o Estado todo. Em relação às estimativas de Menck e Cavalcanti, as diferenças se devem às variações nas condições naturais e de uso e manejo das áreas estudadas, lembrando que a bacia do rio Corumbatai é uma das bacias críticas do Estado de São Paulo em termos de susceptibilidade à erosão (Kertzman et al., 1995).

Tabela 2. Perdas de terra e carga de sedimentos estimadas e toleráveis na bacia do rio Corumbatai, período 1985-1994.

\begin{tabular}{rrrrr}
\hline & \multicolumn{2}{c}{ Perdas de terra (toneladas) } & \multicolumn{2}{c}{ Carga de sedimentos (toneladas) } \\
Estimadas & Toleráveis \\
\hline 1985 & 5.057 .388 & 1.765 .724 & 1.253 .503 & 559.539 \\
1986 & 5.124 .617 & 1.765 .724 & 1.270 .168 & 559.539 \\
1987 & 5.191 .721 & 1.765 .724 & 1.286 .802 & 559.539 \\
1988 & 5.258 .887 & 1.765 .724 & 1.303 .447 & 559.539 \\
1989 & 5.326 .054 & 1.765 .724 & 1.320 .087 & 559.539 \\
1990 & 5.393 .220 & 1.765 .724 & 1.336 .812 & 559.539 \\
1991 & 5.470 .216 & 1.765 .724 & 1.355 .827 & 559.539 \\
1992 & 5.527 .555 & 1.765 .724 & 1.370 .038 & 559.539 \\
1993 & 5.594 .718 & 1.765 .724 & 1.386 .685 & 559.539 \\
1994 & 5.661 .887 & 1.765 .724 & 1.403 .332 & 559.539 \\
Total & 55.606 .263 & 17.657 .240 & 13.286 .701 & 5.595 .390 \\
Média & 5.560 .626 & 1.765 .724 & 1.328 .670 & 559.539 \\
\hline
\end{tabular}

Fonte: resultados da pesquisa. 


\subsubsection{Valor monetário dos nutrientes perdidos junto à carga de sedimentos}

A Tabela 3 mostra os valores estimados para as perdas de nutrientes junto à carga de sedimentos (exemplo do cálculo no apêndice 1).

Importante notar nessa tabela que se os limites toleráveis fossem respeitados, os produtores agrícolas da bacia poderiam poupar, em média, $R \$ 15,22 /$ ha por ano em termos de nutrientes. Isso eqüivale a $58 \%$ do valor total perdido $(\mathrm{R} \$ 26,06 / \mathrm{ha})$.

Tabela 3. Valor das perdas de nutrientes ( $\mathrm{N}, \mathrm{P}, \mathrm{K}$, Ca e $\mathrm{Mg}$ ) em reais de dezembro de 1995, na bacia do rio Corumbatai para o período 1985-1994.

\begin{tabular}{cccccc}
\hline Ano & $\begin{array}{c}\text { Valor Perdas } \\
\text { Valor Perdas } \\
\text { Estimadas Total }\end{array}$ & $\begin{array}{c}\text { Estimadas- } \\
\text { Perdas } \\
\text { Toleráveis Total }\end{array}$ & $\begin{array}{c}\text { Valor Perdas } \\
\text { estimadas/ha }\end{array}$ & $\begin{array}{c}\text { Valor Perdas } \\
\text { Estimadas- } \\
\text { Perdas } \\
\text { Toleráveis/ha }\end{array}$ & $\begin{array}{c}\text { Valor das } \\
\text { perdas } \\
\text { estimadas/t de } \\
\text { solo erodido }\end{array}$ \\
\hline 1985 & 5.924 .785 & 3.282 .200 & 34,65 & 19,19 & 1,20 \\
1986 & 4.454 .284 & 2.470 .215 & 26,05 & 14,45 & 0,77 \\
1987 & 3.911 .336 & 2.214 .549 & 22,87 & 12,95 & 0,80 \\
1988 & 5.129 .207 & 3.261 .641 & 30,00 & 19,07 & 0,94 \\
1989 & 4.212 .163 & 2.415 .790 & 24,63 & 14,13 & 0,82 \\
1990 & 5.290 .931 & 3.072 .194 & 30,94 & 17,97 & 0,88 \\
1991 & 3.835 .021 & 2.254 .498 & 22,43 & 13,18 & 0,68 \\
1992 & 4.254 .292 & 2.516 .305 & 24,88 & 14,72 & 0,73 \\
1993 & 3.823 .653 & 2.279 .115 & 22,36 & 13,33 & 0,71 \\
1994 & 3.720 .706 & 2.251 .772 & 21,76 & 13,17 & 0,67 \\
Total & 44.556 .378 & 26.018 .279 & & & 0.82 \\
\hline Média & 4.455 .638 & 2.601 .828 & 26.06 & 15,22 & \\
\hline
\end{tabular}

Fonte: resultados da pesquisa. 
O custo da perda de nutrientes por hectare na bacia do rio Corumbatai é significativamente menor que a calculada por Castro (1987), $R \$ 26,06$ contra $R \$ 193,85$. Isso se deve, em parte, a que as estimativas de Castro foram feitas com base nas perdas de solo e não na carga de sedimentos. O valor das estimativas feitas por Cavalcanti (R\$ 29,59/ha) é similar ao gerado neste trabalho. Não obstante, essa semelhança é causada pelo fato de que a magnitude das perdas de solo estimadas para o Vale do Rio São Francisco é parecida à da carga de sedimentos da bacia do Corumbatai $(6,77$ t/ha vs. 7,77 t/ha, respectivamente). Obviamente, os valores do custo da perda de nutrientes por erosão calculados com base nas perdas de solo estão superestimados.

\subsubsection{O custo da perda de produtividade causado pela erosão}

$\mathrm{Na}$ Tabela 4 aparecem os modelos estimados para a relação funcional entre o rendimento da cana-de-açúcar e a perda de solo por erosão.

Observa-se, nessa tabela, que os sinais dos coeficientes indicam relações inversas entre idade do canavial e rendimento, assim como entre o efeito quadrático das perdas de terra por erosão e rendimento no caso dos solos Podzólicos Vermelho-Amarelos, de acordo com o que era esperado. O teste $\mathrm{F}$ é significativo para $\alpha=0,01 \mathrm{em}$ dois casos e ele é significativo para $\alpha=0,05$ no outro caso. Os valores do $\mathrm{R}$ quadrado indicam que algumas variáveis que podem contribuir na explicação da variação do rendimento ficaram fora dos modelos estimados.

Nota-se que, nos casos dos solos Latossolo Roxo e Terra Roxa Estruturada não existe um efeito significativo da erosão sobre o rendimento. Esse era um resultado esperado, primeiro porque tais tipos de solo são bastante profundos, fornecendo condições adequadas para o desenvolvimento radicular da cana-de-açúcar e para a adequada retenção de umidade e posterior fornecimento às plantas. $\mathrm{O}$ trabalho de Walker (1982) mostra que o impacto da erosão do solo na produtividade das culturas aparece 
mais rapidamente e com maior intensidade em solos pouco profundos do que nos mais profundos.

Em segundo lugar, no caso dos Latossolos Roxos, as perdas estimadas de terra foram menores do que os limites máximos toleráveis (ver Tabela 16, apêndice 2) e, por definição, não se esperam impactos significativos da erosão na produtividade das culturas. No caso da Terra Roxa Estruturada, apesar da maioria das perdas de terra superarem os limites máximos toleráveis, não foram percebidos impactos significativos. Isso pode ser explicado pela grande profundidade desses solos ser suficiente para fornecer o suporte necessário ao desenvolvimento radicular e para a retenção de umidade.

Tabela 4. Estimativas do efeito das perdas de solo por erosão sobre o rendimento da cana-de-açúcar em solos Podzólico Vermelho-Amarelo da fazenda São Francisco, Latossolo Roxo e Terra Roxa Estruturada da fazenda Santa Rosa II, usina Costa Pinto, safra 1996.

\begin{tabular}{lccc}
\hline \multicolumn{1}{c}{ Variável } & $\begin{array}{c}\text { Podzólico Vermelho- } \\
\text { Amarelo }\end{array}$ & Latossolo Roxo & Terra Roxa \\
\hline Intercepto & $139,0676^{*}$ & $142,1619^{*}$ & $86,9435^{*}$ \\
Efeito quadrático das perdas de & & & - \\
solo por erosão & $-0,0197^{* * *}$ & - & - \\
Idade do canavial & $-17,8048^{* *}$ & $-36,3073^{*}$ & - \\
Efeito quadrático da idade & - & $3,2481^{* *}$ & $-52,5785^{*}$ \\
Variedade SP 71-6163 & - & - & $-31,8421^{*}$ \\
Variedade SP 71-1406 & - & - & - \\
Variedade SP 79-1011 & - & $35,1639^{*}$ & $27,20^{*}$ \\
F calculado & $6,84^{* *}$ & $13,45^{*}$ & 0.6518 \\
$\mathrm{R}^{2}$ ajustado & 0.3537 & 0,5234 & \\
\hline
\end{tabular}

Fonte: resultados da pesquisa.

*significativo para $\alpha=0,01$;

** significativo para $\alpha=0,05$;

$* * *$ significativo para $\alpha=0,10$; e,

- não aplicável.

Em resumo, parece ser que nos casos dos solos Latossolo Roxo e Terra Roxa Estruturada o sistema de produção de cana-de-açúcar, na fazenda Santa Rosa II, não 
atingiu ainda o ponto em que o rent dessas terras começa a diminuir (ponto $\mathrm{H}$ da Figura $3)$.

Por sua vez, nos solos Podzólicos Vermelho-Amarelos, o efeito da erosão sobre o rendimento da cana-de-açúcar foi significativo. Deduz-se neste caso que a redução do rendimento da cana-de-açúcar, avaliado na perda tolerável média $(9,17 \mathrm{t} / \mathrm{ha})$, é de 0,3613 toneladas por cada tonelada adicional de terra perdida. Extrapolando esse resultado para os solos Podzólicos da bacia como um todo, determinou-se, utilizando a eq. (12), que a perda de produtividade atingiu $18,86 \mathrm{t} / \mathrm{ha}$ em 1990 . Isso não significa que o rendimento da cana-de-açúcar diminua nessa taxa, pois o progresso técnico mascara o efeito da erosão compensando a perda de produtividade, como mostra o trabalho de Krauss \& Allmaras (1982) (exemplo do cálculo no apêndice 2).

Deve-se salientar que os resultados apresentados na Tabela 4 foram obtidos utilizando-se dados específicos de duas fazendas da usina Costa Pinto. Muito provavelmente a amplitude na variação das perdas de solo e dos rendimentos seria maior ao se considerar os canaviais da bacia toda. Isso abre a possibilidade da existência de efeito significativo da erosão sobre o rendimento inclusive nos Latossolos Roxos e nas Terras Roxas Estruturadas. Pesquisas mais precisas sobre o tema, na mesma área geográfica, precisariam de uma amostragem mais intensa e ampla nas unidades produtoras de cana-de-açúcar.

A Tabela 5 apresenta o valor monetário da perda de produtividade da cana-deaçúcar plantada em solos Podzólicos Vermelho-Amarelos. Infere-se que um sistema de conservação do solo que restrinja as perdas de solo por erosão aos limites máximos toleráveis seria adotado só se o custo de implementá-lo fosse menor que $\mathrm{R} \$ 431,65 /$ ha por ano, em média. Isso, no caso particular de canaviais estabelecidos em solos Podzólicos Vermelho-Amarelos. Equivalentemente, eles teriam incentivos econômicos para adotar qualquer sistema de conservação do solo cujo custo (para conseguir a diminuição de uma $t /$ ha de perdas de solo) não superasse o valor de $\mathrm{R} \$ 8,15$, em média. 
Tabela 5. Perda de produtividade na cultura de cana-de-açúcar causada pela erosão em solos podzólicos da bacia do rio Corumbatai (em reais de dezembro de 1995), período 1985-1994.

\begin{tabular}{ccccc}
\hline & $\begin{array}{c}\text { Área podzólicos } \\
\text { com cana (ha) }\end{array}$ & $\begin{array}{c}\text { Valor total da } \\
\text { perda de } \\
\text { produtividade }\end{array}$ \\
\hline $18 \$)$ & $\begin{array}{c}\text { Valor médio da } \\
\text { perda }\end{array}$ (R\$/ha) & $\begin{array}{c}\text { Valor médio da } \\
\text { perda }(\mathrm{R} \$ / \mathrm{t})\end{array}$ \\
\hline 1985 & 18.966 & 11.105 .323 & 585,54 & 11,06 \\
1986 & 19.684 & 9.934 .785 & 504,71 & 9,53 \\
1987 & 20.401 & 9.830 .485 & 481,86 & 9,10 \\
1988 & 21.119 & 9.849 .876 & 466,40 & 8,81 \\
1989 & 21.836 & 8.964 .029 & 410,52 & 7,75 \\
1990 & 22.556 & 8.598 .327 & 381,20 & 7,20 \\
1991 & 23.274 & 7.803 .491 & 335,29 & 6,33 \\
1992 & 23.988 & 9.119 .052 & 380,15 & 7,18 \\
1993 & 24.706 & 9.260 .640 & 374,83 & 7,08 \\
1994 & 25.423 & 10.067 .808 & 396,01 & 7,48 \\
Total & & 94.533 .816 & & 8,15 \\
Média & 9.453 .382 & 431,65 & \\
\hline
\end{tabular}

Fonte: resultados da pesquisa

\subsubsection{Custo interno da erosão do solo}

A Tabela 6 mostra as estimativas do custo interno pela erosão do solo, na bacia, durante o período estudado. Percebe-se que o valor da perda de produtividade representa $68 \%$ do valor total do impacto interno da erosão do solo na bacia, ou seja, duas vezes o valor da perda de nutrientes. Se o custo interno da erosão é dividido pela área total da bacia, o custo interno médio é de $\mathrm{R} \$ 81,34 /$ ha por ano e de $\mathrm{R} \$ 2,50 / \mathrm{t}$ de solo erodido. Observa-se também que, se os limites máximos toleráveis de erosão fossem respeitados, os custos internos causados pelas perdas de solo seriam reduzidos em R\$ 12.055 .210 (87\%). Em média, esse valor corresponde a $\mathrm{R} \$ 70,50 /$ ha por ano. Isso implica que a implementação de um programa de conservação de solos, na bacia, visando atingir níveis 
de perdas de solo iguais ou menores aos limites máximos toleráveis, deveria ter um custo médio para o produtor menor que $\mathrm{R} \$ 70,50 /$ ha por ano para incentivar a sua adoção.

No caso das áreas com solos Podzólicos o custo interno médio anual atinge R\$ 457,71. É esse o valor que deve ser levado em conta ao momento de considerar a possibilidade de estabelecer programas de conservação de solos nessas áreas.

Tabela 6. Custo interno da erosão do solo na bacia do rio Corumbatai (em reais de dezembro de 1995), período 1985-1994.

\begin{tabular}{ccccccc}
\hline \multirow{2}{*}{ Ano } & \multicolumn{2}{c}{ Custo perda nutrientes } & Custo perda & \multicolumn{2}{c}{ Custo interno } & Custo interno \\
\hline 1985 & 5.924 .785 & 2.642 .585 & 11.105 .323 & 17.030 .108 & 2.642 .585 & 14.387 .523 \\
1986 & 4.454 .284 & 1.984 .069 & 9.934 .785 & 14.389 .069 & 1.984 .069 & 12.405 .000 \\
1987 & 3.911 .336 & 1.696 .787 & 9.830 .485 & 13.741 .821 & 1.696 .787 & 12.045 .034 \\
1988 & 5.129 .207 & 1.867 .566 & 9.849 .876 & 14.979 .083 & 1.867 .566 & 13.111 .517 \\
1989 & 4.212 .163 & 1.796 .373 & 8.964 .029 & 13.176 .192 & 1.796 .373 & 11.379 .819 \\
1990 & 5.290 .931 & 2.218 .737 & 8.598 .327 & 13.889 .258 & 2.218 .737 & 11.670 .521 \\
1991 & 3.835 .021 & 1.580 .523 & 7.803 .491 & 11.638 .512 & 1.580 .523 & 10.057 .989 \\
1992 & 4.254 .292 & 1.737 .987 & 9.119 .052 & 13.373 .344 & 1.737 .987 & 11.635 .357 \\
1993 & 3.823 .653 & 1.544 .538 & 9.260 .640 & 13.084 .293 & 1.544 .538 & 11.539 .755 \\
1994 & 3.720 .706 & 1.468 .934 & 10.067 .808 & 13.788 .514 & 1.468 .934 & 12.319 .580 \\
Total & 44.556 .378 & 18.538 .099 & 94.533 .816 & 139.090 .194 & 18.538 .099 & 120.552 .095 \\
Média & 4.455 .638 & 1.853 .810 & 9.453 .382 & 13.909 .019 & 1.853 .810 & 12.055 .210 \\
\hline \hline
\end{tabular}

Fonte: resultados da pesquisa.

Essa situação ressalta a importância de se contar com informações detalhadas para melhorar a precisão das estimativas de valores monetários, assim como para identificar e priorizar as áreas alvo para a implementação dos programas conservacionistas. Por exemplo, a precisão das estimativas e a identificação de áreas alvo melhorariam se fosse possível contar com mapas de tipos de solo, declividade e cobertura, em nivel de detalhe. Melhor ainda, se os mapas de cobertura do solo estivessem disponíveis para vários períodos durante o ano e para varios anos. Isso 
permitiria o aprimoramento das estimativas do valor do impacto interno da erosão do solo.

Em termos da Figura 3 (p. 22), a perda média anual de produtividade (R\$ 9.456.382) representa a diferença entre as curvas $\mathrm{CHD}$ e $\mathrm{CHI}$.

4.2 Impacto da erosão do solo sobre o custo de tratamento de água para uso domiciliar

Esta seção aborda, inicialmente, os resultados da estimativa dos quatro modelos propostos para a função de custo operacional total. Logo, os valores estimados do custo operacional adicional anual são apresentados.

\subsubsection{A função de custo operacional total de tratamento de água}

A Tabela 7 mostra os resultados da estimação da função custo para a ETA 3 do SEMAE. Apresentam-se estimativas de quatro tipos de funções: o caso geral da função não homogênea e não homotética (NHNH); a função homogênea de grau um nos preços dos insumos (HNH); a função homogênea e homotética $(\mathrm{HH})$; e, finalmente, a função Cobb-Douglas.

Pode-se ver que, para todos os casos, o teste de $\mathrm{F}$ é significativo para $\alpha=0,01$. $\mathrm{O}$ teste de Durbin-Watson indica que não existe autocorrelação nos três primeiros modelos e ele é indefinido no caso do modelo Cobb-Douglas. $\mathrm{O}$ maior valor do $\mathrm{R}$ quadrado corresponde ao modelo HNH e por isso, foi ele o modelo usado para fazer as estimativas do custo operacional mensal e operacional adicional. 
Tabela 7. Resultados da estimativa das funções de custo operacional de tratamento de água para a ETA 3 (Capim Fino) do SEMAE, Piracicaba.

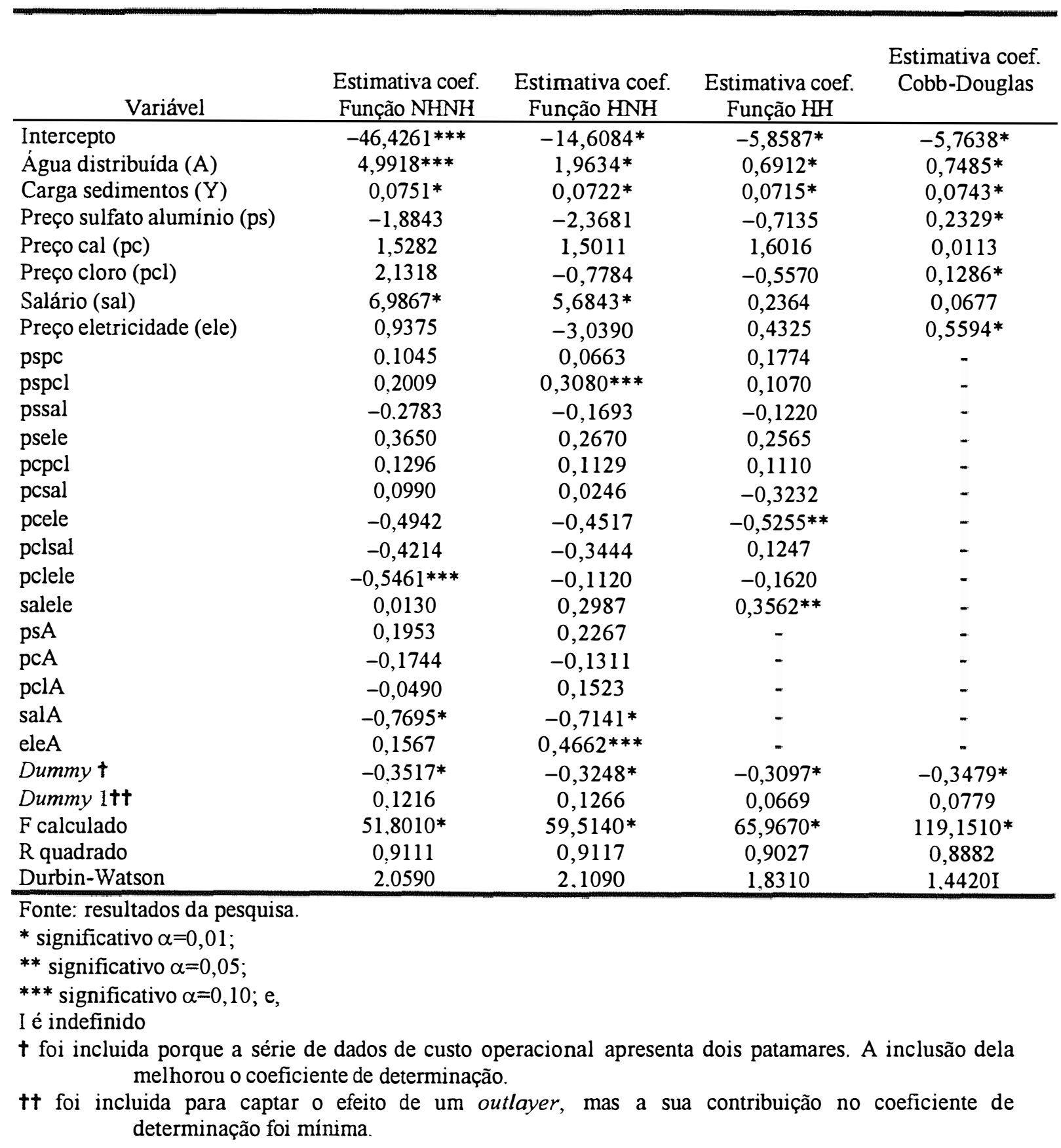




\subsubsection{Custo operacional adicional total anual de tratamento de água}

Os resultados da Tabela 8 mostram que a carga de sedimentos produzida pelas perdas estimadas de solo por erosão representam custos operacionais adicionais de 1,1 vezes aqueles produzidos pelas perdas toleráveis. Isso significa que se os limites máximos toleráveis de perdas de solo fossem respeitados ocorreria uma diminuição de $9,7 \%$ nos custos operacionais adicionais. Essa proporção na redução dos custos operacionais adicionais é menor que a citada por Bragagnolo (1994), de 83\% no Estado do Paraná. Isso provávelmente é devido a alguma diferença na estrutura dos custos utilizada nos estudos.

Tabela 8. Custo operacional adicional de tratamento de água, estimado e tolerável, causado pela erosão do solo na bacia do rio Corumbatai (em reais de dezembro de 1995), período 1985-1994.

\begin{tabular}{ccccc}
\hline Ano & $\begin{array}{c}\text { Custo adicional } \\
\text { estimado (CAE) }\end{array}$ & $\begin{array}{c}\text { Custo adicional } \\
\text { tolerável (CAT) }\end{array}$ & CAE - CAT & $\begin{array}{c}\text { CAE-CAT } \\
(\%)\end{array}$ \\
\hline 1985 & 116.539 & 106.229 & 10.310 & 8,85 \\
1986 & 223.402 & 205.745 & 17.657 & 7,90 \\
1987 & 97.013 & 83.214 & 13.799 & 14,22 \\
1988 & 451.913 & 396.191 & 55.722 & 12,33 \\
1989 & 336.816 & 304.450 & 32.366 & 9,61 \\
1990 & 412.600 & 376.770 & 35.830 & 8,68 \\
1991 & 567.940 & 513.710 & 54.230 & 9,55 \\
1992 & 838.802 & 769.145 & 69.657 & 8,30 \\
1993 & 1.312 .383 & 1.202 .301 & 110.082 & 8,39 \\
1994 & 1.125 .775 & 1.034 .361 & 91.414 & 8,12 \\
Total & 5.483 .183 & 4.992 .116 & 491.067 & 8.96 \\
\hline Média & 548.318 & 499.212 & 49.106 & \\
\hline
\end{tabular}

Fonte: resultados da pesquisa. 
O custo adicional apresentado na Tabela 8 (exemplo do cálculo no apêndice 3) é maior que o citado por Sorrenson \& Montoya (1989), possívelmente devido também a diferenças na estrutura de custos utilizada nos cálculos ${ }^{21}$.

Em média, o custo operacional adicional seria de $\mathrm{R} \$ 3,21 /$ ha por ano e $\mathrm{R} \$ 0,10 / \mathrm{t}$ de solo erodido.

Nota-se também uma tendência crescente do custo operacional adicional causado pela erosão do solo, durante o período estudado.

Na Tabela 9 apresentam-se estimativas do custo operacional adicional mensal de tratamento de água por família abastecida na bacia.

Essas estimativas consideram que $60 \%$ da população da cidade de Piracicaba e $100 \%$ da cidade de Rio Claro foram abastecidas pelas três estações de tratamento de água incluídas no estudo, durante o período 1985-1994. Observa-se que, se o custo operacional adicional de tratamento de água fosse totalmente repassado para as famílias abastecidas, cada uma delas estaria pagando, em média, $\mathrm{R} \$ 0,62$ por mês a mais por causa do impacto da erosão do solo sobre o custo operacional de tratamento de água. Nota-se também a existência de uma tendência crescente no pagamento adicional que cada familia abastecida estaria fazendo. Se a erosão do solo fosse controlada até atingir os seus limites toleráveis, o pagamento adicional mensal de cada família cairia de $\mathrm{R} \$ 0,62$ para $\mathrm{R} \$ 0,57(8 \%)$, em média. O impacto da erosão do solo nos custos de tratamento de água pode ser considerado baixo, como indica também o trabalho de Holmes (1989), quando comparado com outros impactos externos da erosão como o da recreação.

\footnotetext{
${ }^{21}$ Basicamente suspeita-se que nos estudos de Bragagnolo e Sorrenson \& Montoya o custo de tratamento refere-se somente aos reagentes utilizados para reduzir a turbidez, desconsiderando o custo de eletricidade e mão-de-obra (que são os que ocupam a maior parcela do custo operacional de tratamento).
} 
Tabela 9. Custo operacional adicional mensal de tratamento de água por família abastecida na bacia do rio Corumbatai (em reais de dezembro de 1995), período 1985-1994.

\begin{tabular}{cccc}
\hline Ano & $\begin{array}{c}\text { Número de fanúlias } \\
\text { abastecidas* }\end{array}$ & $\begin{array}{c}\text { Custo adicional } \\
\text { mensal/família }\end{array}$ & $\begin{array}{c}\text { Custo adicional } \\
\text { tolerável/família }\end{array}$ \\
\hline 1985 & 63.171 & 0,15 & 0,14 \\
1986 & 65.542 & 0,28 & 0,26 \\
1987 & 66.105 & 0,12 & 0,10 \\
1988 & 66.698 & 0,56 & 0,50 \\
1989 & 67.325 & 0,42 & 0,38 \\
1990 & 71.297 & 0,48 & 0,44 \\
1991 & 72.542 & 0,65 & 0,59 \\
1992 & 74.212 & 0,94 & 0,86 \\
1993 & 78.873 & 1,39 & 1,35 \\
1994 & 80.331 & 1,17 & 1,07 \\
Média & & 0,62 & 0,57 \\
\hline
\end{tabular}

Fonte: resultados da pesquisa.

*Calculado pelo autor com base em informações do Anuário Estatístico do Estado de São Paulo (SEADE).

\subsection{O custo da erosão do solo na bacia}

Dos resultados da Tabela 10 pode-se inferir que o custo interno representa $96,2 \%$ do custo da erosão do solo na bacia. Isso implica que, muito provavelmente, não se justifique a intervenção governamental na implantação de programas de conservação de solos porque possívelmente ela não seja econômica para a sociedade.

A conservação de solos ficaria em mãos dos produtores que a empreenderiam na medida que ela fosse econômica para eles. Por sua vez, o custo estimado representa 6,1 vezes o custo tolerável, significando isto que se os limites máximos toleráveis de perdas de terra fossem respeitados, ocorreria uma redução de $84 \%$ nos custos causados pela erosão do solo na bacia. Em termos de valores médios, o custo causado pela erosão estimada na bacia atinge a magnitude de R \$ 84,54/ha por ano. Por sua vez, o custo 
causado pela erosão tolerável é de $\mathrm{R} \$ 13,76$ /ha por ano. Isso significa que o beneficio total médio de um programa de conservação que consiga restringir as perdas de solo por erosão ao seus limites máximos toleráveis é de $\mathrm{R} \$ 70,78 / \mathrm{ha}$ por ano. Isto, supondo que o único efeito externo causado pela erosão seja o aumento do custo de tratamento de água para o abastecimento urbano. Se outros custos externos existissem neste caso, o valor dos beneficios do programa conservacionista aumentaria.

Tabela Custo da erosão do solo na bacia do rio Corumbatai (em reais de dezembro de 1995), período 1985-1994.

\begin{tabular}{ccccccccc}
\hline & \multicolumn{2}{c}{ Custo interno } & \multicolumn{2}{c}{ Custo externo } & \multicolumn{2}{c}{$\begin{array}{c}\text { Custo total } \\
\text { estiferença }\end{array}$} \\
Ano & estimado & tolerável & estimado & tolerável & estimado & tolerável & tolerável \\
\hline 1985 & 17.030 .108 & 2.642 .585 & 116.539 & 106.229 & 17.146 .647 & 2.748 .814 & 14.397 .833 \\
1986 & 14.389 .069 & 1.984 .069 & 223.402 & 205.745 & 14.612 .471 & 2.189 .814 & 12.422 .657 \\
1987 & 13.741 .821 & 1.696 .787 & 97.013 & 83.214 & 13.838 .834 & 1.780 .001 & 12.058 .833 \\
1988 & 14.979 .083 & 1.867 .566 & 451.913 & 396.191 & 15.430 .996 & 2.263 .757 & 13.167 .239 \\
1989 & 13.176 .192 & 1.796 .373 & 336.816 & 304.450 & 13.513 .008 & 2.100 .823 & 11.412 .185 \\
1990 & 13.889 .258 & 2.218 .737 & 412.600 & 376.770 & 14.301 .858 & 2.595 .507 & 11.706 .351 \\
1991 & 11.638 .512 & 1.580 .523 & 567.940 & 513.710 & 12.206 .452 & 2.094 .233 & 10.112 .219 \\
1992 & 13.373 .344 & 1.737 .987 & 838.802 & 769.145 & 14.212 .146 & 2.507 .132 & 11.705 .014 \\
1993 & 13.084 .293 & 1.544 .538 & 1.312 .383 & 1.202 .301 & 14.396 .676 & 2.746 .839 & 11.649 .837 \\
1994 & 13.788 .514 & 1.468 .934 & 1.125 .775 & 1.034 .361 & 14.914 .289 & 2.503 .295 & 12.410 .994 \\
\hline Total & 139.090 .194 & 18.538 .099 & 5.483 .183 & 4.992 .116 & 144.573 .377 & 23.530 .215 & 121.043 .162 \\
Média & 13.909 .019 & 1.853 .810 & 548.318 & 499.212 & 14.457 .338 & 2.353 .022 & 12.104 .316 \\
\hline
\end{tabular}




\section{CONCLUSÕES}

O estudo gerou estimativas do custo interno (perda de produtividade e de nutrientes) e do custo operacional adicional de tratamento de água para o abastecimento urbano (um dos custos externos) que as perdas de terra por erosão causam na bacia do rio Corumbatai. Essas estimativas foram comparadas com as geradas a partir das perdas toleráveis de terra. O propósito foi o de contribuir ao entendimento das conseqüências econômicas da erosão do solo e, eventualmente, subsidiar o processo de planejamento do uso conservacionista das terras agrícolas.

Os resultados permitem concluir que, dos componentes do custo interno, o custo da perda de produtividade (depreciação do capital natural) é o dobro do custo gerado pela perda de nutrientes, apesar que ele somente atinge os solos Podzólicos.

O impacto da erosão do solo nos custos operacionais de tratamento de água é pequeno comparado aos custos internos (apenas 3,8\% do custo causado pela erosão do solo na bacia). A restrição das perdas de solo aos limites toleráveis causaria uma redução de $84 \%$ dos custos provocados pela erosão, em média.

Em relação ao desenho de políticas públicas e programas privados de conservação do solo, os resultados gerados pelo estudo sugerem que provavelmente se justifique a implantação do segundo tipo delas em áreas prioritárias da bacia. Essas áreas correspondem aos plantios de cana-de-açúcar localizados em solos podzólicos. Nessas áreas as perdas médias estimadas de terra por erosão são maiores que os limites toleráveis e, portanto, a conservação não está sendo atingida. Nelas a erosão está 
causando perdas de produtividade e, provavelmente, a conservação do solo seja econômica para os produtores. Por sua vez, a magnitude dos custos externos, medidos pelo custo adicional do tratamento de água, parece não ser suficiente para justificar, por si só, a implementação de uma política pública generalizada de conservação do solo na bacia.

Reconhece-se, contudo, que os resultados do estudo fornecem apenas uma parte das informações necessárias para o desenho e implementação de políticas públicas visando a conservação do solo. As informações complementares para determinar se a conservação é ou não econômica para os produtores são: (a) a perda de capital natural resultante da exploração contínua do solo; (b) as mudanças no uso da terra e as práticas necessárias para o controle da erosão; (c) o efeito dessas mudanças e práticas sobre a produção; (d) os custos de capital envolvidos na implementação das mudanças e práticas de conservação; (e) o efeito das mudanças sobre os custos de produção; e, (f) o efeito líquido das mudanças sobre a receita do produtor. Os itens (a), (b) e (c) requerem a participação de especialistas da área de solos.

Por sua vez, para completar a estimativa dos custos externos, seria preciso identificar quais as outras atividades econômicas, além do tratamento de água, que estão recebendo os efeitos externos da erosão do solo na bacia (por exemplo, recreação, geração de eletricidade, navegação, pesca, etc.). Uma vez identificadas estas, caberia a estimação do valor dos efeitos externos. Muito provávelmente, os outros efeitos importantes da erosão dentro da bacia seriam sobre a recreação e eutroficação. O método do custo da viajem poderia ser usado para estimar o custo em termos de recreação. $\mathrm{O}$ custo de dragagem provavelmente serveria como uma proxy para estimar o impacto da eutroficação.

Além disso, é importante indicar as principais limitações específicas do estudo. O fato de os dados usados para a obtenção das estimativas do custo da perda de produtividade corresponderem apenas a duas áreas relativamente pequenas e homogêneas 
(fazendas São Francisco e Santa Rosa II) faz com que as inferências feitas para a bacia toda devam ser consideradas cuidadosamente, em especial para os solos Latossolo Roxo e Terra Roxa Estruturada (onde a variabilidade dos rendimentos e as perdas de solo por erosão foi pequena). Futuros estudos, na mesma linha deste, deverão aprimorar as estimativas dos efeitos da erosão no rendimento das culturas, ampliando o tamanho da amostra e as variáveis explanatórias, incluindo especialmente dados sobre adubação. No caso das estimativas do custo adicional de tratamento de água, não foi possível incluir os custos de manutenção de equipamentos e instalações. Isso implica em valores subestimados para os custos de tratamento. Portanto, sugere-se, para futuros estudos, levar em conta aspectos como: os custos fixos, os custos de manutenção e os custos da eliminação de outros poluentes (como resíduos de agrotóxicos e fertilizantes). 


\section{REFERÊNCIAS BIBLIOGRÁFICAS}

AZEVEDO NETO, J.M. de. Tratamento de águas de abastecimento. São Paulo: Editora da Universidade de São Paulo, 1966. 329 p.

BABBITT, A.E.; DOLAND, J.J.; CLEASBY, J.L. Abastecimento de água. São Paulo: Edgard Blucher, 1962. 592 p.

BARBIER, E.B. The farm-level economics of soil conservation: the uplands of Java. Land Economics, v. 66, n. 2, p. 199-211, May 1990.

BASTOS FILHO, G.S. Contabilizando a erosão do solo: um ajuste ambiental para o produto bruto paulista. Piracicaba, 1995. 127 p. Dissertação (Mestrado) - Escola Superior de Agricultura "Luiz de Queiroz", Universidade de São Paulo.

BEASLEY, R.P. Erosion and sediment polution control. Ames: Iowa State University Press, 1972. 320 p.

BELLINAZZI JUNIOR, R.; BERTOLINI, D.; LOMBARDI NETO, F. A ocorrência de erosão rural no Estado de São Paulo. In: SIMPÓSIO SOBRE O CONTROLE DA ERSÃO, 2., São Paulo, 1981. Anais. São Paulo: ABGE, 1981. p. 117-37. 
BENNETT, H.H. Soil conservation. New York: McGraw-Hill, 1939. 993 p.

BERTONI, J.; LOMBARDI NETO, F. Conservação do solo. Piracicaba: Livroceres, 1985. $368 \mathrm{p}$.

BERTONI, J.; LOMBARDI NETO, F. Conservação do solo. São Paulo: Ícone, 1992. $355 \mathrm{p}$.

BRAGAGNOLO, N. Uso dos solos altamente suscetiveis à erosão. In: PAULA, V.P. de; FERREIRA, M.E.; CRUZ, M.C.P. da, ed. Solos altamente suscetíveis à erosão. Jaboticabal: FCAV-UNESP/SBCS, 1994. p. 3-16.

BUNCE, A.C. Economics of soil conservation. Ames: Iowa State College Press, 1942. $227 \mathrm{p}$.

CASTRO, O.M. Degradação do solo pela erosão. Informe Agropecuário, v. 13, n. 147, p. 64-72, mar. 1987.

CAVALCANTI, J.E.A. Impacto econômico das perdas de solo no Vale do rio São Francisco. In: CONGRESSO BRASILEIRO DE ECONOMIA E SOCIOLOGIA RURAL, 33., Curitiba, 1995. Anais. Brasilia: SOBER, 1995. v. 2, p. 1097-111.

CHAMBERS, R.G. Applied production analysis: a dual approach. Cambridge: Cambridge University Press, 1991. 331 p.

CHAVES, H.M.L. Modelagem matemática da erosão hídrica: passado, presente e futuro. Separata s.n.t. 
CHRISTENSEN, L.A.; McELYEA, D.E. Toward a general method of estimating productivity-soil depth response relationships. Journal of Soil and Water Conservation, v. 43, n. 2, p. 199-202, Mar./Apr. 1988.

CLARK, E.H.II; HAVERKAMP, J.A; CHAPMAN, W. Eroding soils: the off-farm impacts. Washington: The Conservation Foundation, 1985. 252 p.

COLACICCO, D.; OSBORN, T.; ALT, K. Economic damage from soil erosion. Journal of Soil and Water Conservation, v. 44, n. 1, p. 35-9, Jan./Feb. 1989.

CROSSON, P.; DYKE, P.; MIRANOWSKI, J.; WALKER, D. A framework for analysing the productivity costs of soil erosion in the United States. In: FOLLETT, R.F.; STEWART, B.A., ed. Soil erosion and crop productivity. Wisconsin: ASA/CSSA/SSSA, 1985. p. 481-503.

CROWDER, B.M. Economic costs of reservoir sedimentation: a regional approach to estimating crop erosion damages. Journal of Soil and Water Conservation, v. 42, n. 3, p. 194-97, May/Jun. 1987.

DEDECEK, R.A. Efeitos das perdas e deposições de camadas de solo na produtividade de um latossolo vermelho-escuro dos cerrados. Revista Brasileira de Ciência do Solo, v. 11, n. 3, p. 323-28, set./dez. 1987.

DREGNE, H.E. Historical perspective of accelerated erosion and effect on world civilization. In: SCHMIDT, B.L.; ALLMARAS, R.R.; MANNERING, J.V.; PAPENDICK, R.I., ed. Determinants of soil loss tolerance. Madison: ASA/SSSA, 1982. p.1-14. (ASA Special Publication, n. 45).

DREGNE, H.E. Erosion and soil productivity in Africa. Journal of Soil and Water Conservation, v. 46, n. 4, p. 431-36, Jul./Aug. 1990. 
FAETH, P.; REPETTO, R.; MALIK, R.P.S. et al. Off-site costs of soil erosion. In: FAETH, P. ed. Methods for economic analysis of agricultural sustainability. Geneva: World Resources Institute, 1995. p. 44-51.

FORSTER, D.L.; BARDOS, C.P.; SOUTHGATE, D.D. Soil erosion and water treatment costs. Journal of Soil and Water Conservation, v. 42, n. 5, p. 349-52, Sep./Oct. 1987.

GARDNER, K.; BARROWS, R. The impact of soil conservation investments on land prices. American Journal of Agricultural Economics, v. 67, n. 5, p. 943-7, Dec. 1985.

GUJARATI, D.N. Basic econometrics. The United States of America: McGraw-Hill, 1995. $838 \mathrm{p}$.

HALL, G.F.; DANIELS, R.B.; FOSS, J.E. Rate of soil formation and renewal in the USA. In: SCHMIDT, B.L.; ALLMARAS, R.R.; MANNERING, J.V.; PAPENDICK, R.I., ed. Determinants of soil loss tolerance. Madison: ASA/SSSA, 1982. p.2339. (ASA Special Publication, n. 45).

HARDENBERGH, W.A. Abastecimento e purificação da água. Rio de Janeiro: USAID, 1964. $466 \mathrm{p}$.

HERTZLER, G.; IBAÑEZ-MEIER, C.A.; JOLLY, R.W. User costs of soil erosion and their effect on agricultural land prices: costate variables and capitalized hamiltonians. American Journal of Agricultural Economics, v. 67, n. 5, p. 948-53, Dec. 1985.

HOLMES, T.P. The off-site impact of soil erosion on the water treatment industry. Land Economics, v. 64, n. 4, p. 356-66, Nov. 1988. 
HOLÝ, M. Erosion and environment. Great Britain: Pergamon Press, 1980. 225 p.

KERTZMAN, F.F.; RIBEIRO, F.C.; CANIL, K.; ALMEIDA, L.E.G. Erosão no estado de São Paulo: bacias hidrográficas críticas. In: SIMPÓSIO NACIONAL DE CONTROLE DA EROSÃO, 5., Bauru, 1995. Anais boletim de campo. São Paulo: ABGE, 1995. p. 221-3.

KING, D.A.; SINDEN, J.A. Influence of soil conservation on farm land values. Land Economics, v. 64, n. 3, p. 242-55, Aug. 1988.

KITAMURA, P.C.; LANZER, E.A.; ADAMS, R.I. Avaliação econômica de sistemas conservacionistas no uso dos solos agrícolas: o caso do binômio trigo-soja no Rio Grande do Sul. Revista de Economia Rural, v. 20, n. 1, p. 104-24, jan./mar. 1982.

KOFFLER, N.F. Uso das terras da bacia do rio Corumbataí em 1990. Geografia, v. 18, n.1, p. 135-50, Abr. 1993.

KOOTEN, G.C. van; WEISENSEL, W.P.; CHILANTHAMMIT, D. Valuing trade-offs between net returns and stewardchip practices: the case of soil conservation in Saskatchewan. American Journal of Agricultural Economics, v. 72, n. 1, p. 10413, Feb. 1990.

KRAUSS, H.A.; ALLMARAS, R.R. Technology masks the effects of soil erosion on wheat yields: a case study in the Whiteman County, Washington. In: SCHMIDT, B.L.; ALLMARAS, R.R.; MANNERING, J.V.; PAPENDICK, R.I., ed. Determinants of soil loss tolerance. Madison: ASA/SSSA, 1982. p. 75-86. (ASA Special Publication, n. 45). 
LOMBARDI NETO, F.; MOLDENHAUER, W.C. Erodibilidade da chuva: sua distribuição e relação com as perdas de solo em Campinas (SP). Bragantia, v. 51, n. 2, p. 189-96, jun. 1992.

McCORMACK, D.E.; YOUNG, K.K.; KIMBERLIN, L.W. Current criteria for determining soil loss tolerance. In: SCHMIDT, B.L.; ALLMARAS, R.R.; MANNERING, J.V.; PAPENDICK, R.I., ed. Determinants of soil loss tolerance. Madison: ASA/SSSA, 1982. p. 95-111. (ASA Special Publication, n. 45).

MARQUES, J.F. Efeitos da erosão do solo na geração de energia elétrica: uma abordagem da economia ambiental. São Paulo, 1995. 322 p. Tese (Doutorado) Faculdade de Economia, Administração e Contabilidade, Universidade de São Paulo.

MARTINS, L.T.P.; GALLO, Z. Industrialização, urbanização e impactos ambientais: uma refelxão sobre a bacia do rio Piracicaba. Piracicaba: Universidade Metodista de Piracicaba, 1994. Mimeo. 28 p.

MENCK, P.C.M. Avaliação econômica do controle da erosão na microbacia do ribeirão Iperó, em Araçoiaba da Serra, Estado de São Paulo. Piracicaba, 1993. 181 p. Dissertação (Mestrado) - Escola Superior de Agricultura "Luiz de Queiroz", Universidade de São Paulo.

MIRANOWSKI, J.A. Impacts of productivity loss on crop production and management in a dynamic economic model. American Journal of Agricultural Economics, v. 66, n. 1, p. 61-71, Feb. 1984

MISHAN, E.J. The postwar literature on externalities: an interpretative essay. Journal of Economic Literature, v. 9, n. 1, p. 1-28, Mar. 1971. 
NATIONAL SOIL EROSION - SOIL PRODUCTIVITY RESEARCH PLANNING COMITTEE Soil erosion effects on soil productivity: a research perspective. Journal of Soil and Water Conservation, v. 36, n. 2, p 82-90, Mar./Apr. 1981.

NICHOLSON, W. Microeconomic theory: basic principles and extensions. 3. ed. New York: Dryden, 1985. 768 p.

OLIVEIRA, J.B. de; PRADO, H. do. Levantamento pedológico semidetalhado do Estado de São Paulo. Campinas: IAC, 1984. (Boletim Técnico, n. 98).

PALMQUIST, R.B.; DANIELSON, L.E. A hedonic study of the effects of erosion control and drainage on farm land values. American Journal of Agricultural Economics, v. 71, n. 1, p. 55-62, Feb. 1989.

PIERCE, F.J.; DOWDY, R.H.; LARSON, W.E.; GRAHAM, W.A.P. Soil productivity in the Corn Belt: an assessment of erosion's long-term effects. Journal of Soil and Water Conservation, v. 39, n. 2, p. 131-36, Mar./Apr. 1984.

PIMENTEL, D.; TERHUNE, E.C.; DYSON-HUDSON, R. et al. Land degradation: effects on food and energy resources. Science, v. 194, n. 4261, p. 149-55, Oct. 1976.

POPE, C.A. III; BHIDE, S.; HEADY, E.O. Economics of conservation tillage in Iowa. Journal of Soil and Water Conservation, v. 38, n. 4, p. 370-3, Jul./Aug. 1983.

PRATO, T.; WU, S. Erosion, sediment, and economic effects of conservation compliance in an agricultural watershed. Journal of Soil and Water Conservation, v. 46, n. 3, p. 211-14, May/Jun. 1991. 
RANDALL, A. Resource economics: an economic approach to natural resource and environmental policy. 2. ed. New York: John Wiley and Sons, 1987. 434 p.

ROBERTSON, R.A.; COLLETTI, J.P. Off-site impacts of soil erosion on recreation: the case of lake Red Rock reservoir in central Iowa. Journal of soil and water conservation, v. 49, n. 6, p. 576-81, Nov./Dec. 1994.

SCHERTZ, D.L. The basis for soil loss tolerances. Journal of Soil and Water Conservation, v. 38, n. 1, p. 10-4, Jan./Feb. 1983.

SORRENSON, W.J.; MONTOYA, L.J. Implicações econômicas da erosão do solo e do uso de algumas práticas conservacionistas no Paraná. Londrina: IAPAR, 1989. 110 p. (Boletim Técnico, n. 21).

SOUTHGATE, D.; MACKE, R. The downstream benefits of soil conservation in third world hidroelectric watersheds. Land Economics, v. 65, n. 1, p. 38-48, Feb. 1989.

SPAROVEK, G.; TERAMOTO, E.R.; TORETA, D.M. et al. Erosão simulada e a produtividade da cultura do milho. Revista Brasileira de Ciência do Solo, v. 15, n. 3, p. 363-68, set./dez. 1991.

SWANSON, E.R.; MacCALLUM, D.E. Income effects of rainfall erosion control. Journal of Soil and Water Conservation, v. 24, n. 2, p. 56-9, Mar./Apr. 1969.

TISDELL, C.A. Economics of environmental conservation: economics for environmental and ecological management. Amsterdam: Elsevier, 1991. 233 p. 
VELOZ, A.; SOUTHGATE, D.; HITZHUSEN, F.; MACGREGOR, R. The economics of erosion control in a subtropical watershed: a dominican case. Land Economics, v. 61, n. 2, p. 145-55, May 1985.

VERGARA, O. Avaliação econômica das perdas de solo provocadas pela erosão hídrica. In: CONGRESSO BRASILEIRO DE ECONOMIA E SOCIOLOGIA RURAL, 29., Campinas, 1991. Anais. Brasília: SOBER, 1991. v. 1, p. 668-88.

WALKER, D.J. A damage function to evaluate erosion control economics. American Journal of Agricultural Economics, v. 64, n. 4, p. 690-98, Nov. 1982.

WISCHMEIER, W.H.; SMITH, D.D. Predicting rainfall erosion losses - a guide to conservation planning. Washington: U.S. Department of Agriculture, 1978. (Handbook n. 537). 98 p.

XU, F.; PRATO, T. Onsite erosion damages in Missouri corn production. Journal of Soil and Water Conservation, v. 50, n. 3, p. 312-6, May/Jun. 1995.

ZACHAR, D. Soil erosion. Czechoslovakia: Elsevier Scientific Publishing Company, 1982. $547 \mathrm{p}$. 


\section{A P E N D I C E 1}

Dados básicos para o cálculo do valor dos nutrientes perdidos 


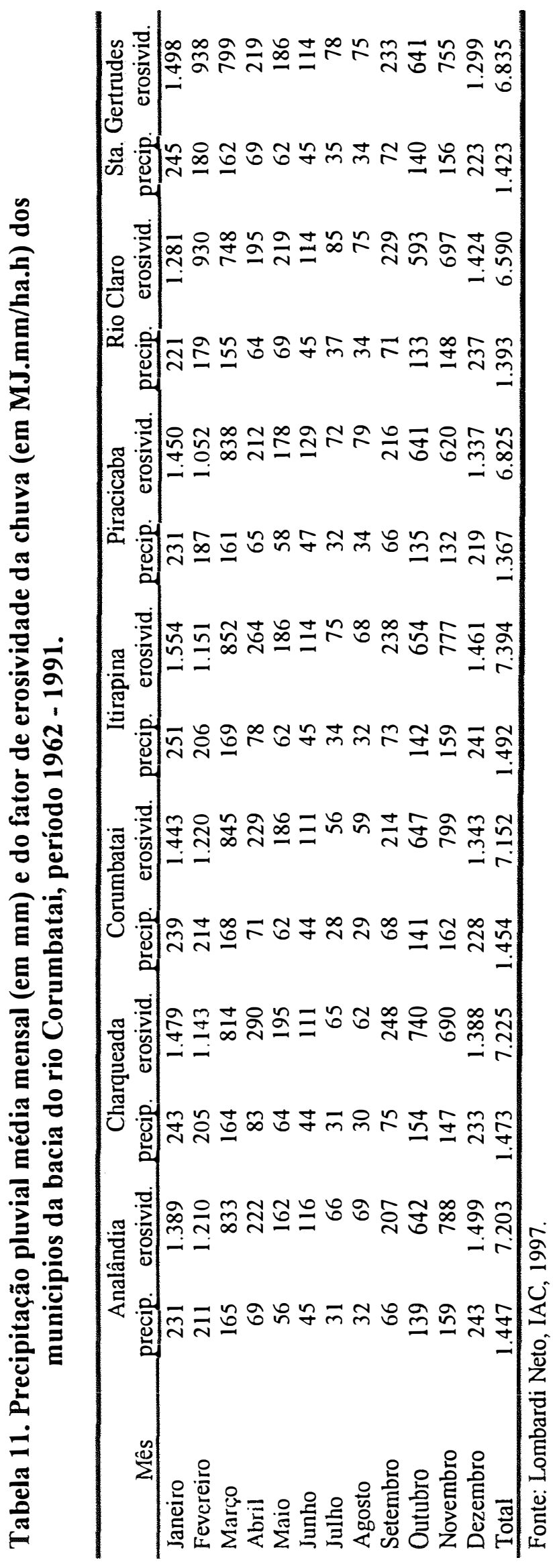


Tabela 12. Valores do fator $C$ para os distintos tipos de uso da terra na bacia do rio Corumbatai.

\begin{tabular}{cc}
\hline Tipo de uso & Fator C \\
\hline Cultura anual & 0,3207 \\
Cultura perene & 0,0871 \\
Cana-de-açúcar & 0,1063 \\
Pastagem & 0,0100 \\
Silvicultura & 0,0518 \\
Mata/capoeira & 0,0005 \\
Cerrado & 0,0040 \\
Área urbana & 1,0000 \\
Outros & 0,5000 \\
\hline
\end{tabular}

Fonte: Francisco Lombardi Neto, IAC, comunicação pessoal, 1997.

Tabela 13. Valores do fator $\mathrm{P}$ por classe de declividade na bacia do rio Corumbatai.

\begin{tabular}{cc}
\hline Classe de declividade $(\%)$ & Fator $\mathrm{P}$ \\
\hline$<2$ & 0,56 \\
2 a 5 & 0,50 \\
5 a 10 & 0,65 \\
10 a 20 & 1,00 \\
20 a 45 & 1,00 \\
$>45$ & 1,00 \\
\hline
\end{tabular}

Fonte: Francisco Lombardi Neto, IAC, comunicação pessoal, 1997. 
Tabela 14. Erodibilidade do solo e limites toleráveis de perdas para três das unidades de solo presentes na bacia do rio Corumbatai.

\begin{tabular}{lcc}
\hline \multicolumn{1}{c}{ Unidade de solo } & Erodibilidade (t.h/MJ.mm) & Perdas toleráveis (t/ha) \\
\hline Latossolo Roxo (LRe) & 0,0098 & 13,0 \\
Latossolo Roxo (LRd) & 0,0128 & 13,0 \\
Latossolo Vermelho Escuro (LE1) & 0,0167 & 12,3 \\
Latossolo Vermelho Escuro (LE2) & 0,0167 & 12,3 \\
Latossolo Vermelho Escuro (LE3) & 0,0175 & 15,0 \\
Latossolo Vermelho-Amarelo (LV1) & 0,0132 & 14,2 \\
Latossolo Vermelho-Amarelo (LV2) & 0,0132 & 14,2 \\
Latossolo Vermelho-Amarelo (LV3) & 0,0132 & 14,2 \\
Latossolo Vermelho-Amarelo (LV4) & 0,0132 & 14,2 \\
Latossolo Vermelho-Amarelo (LV5) & 0,0125 & 12,6 \\
Latossolo Vermelho-Amarelo (LV6) & 0,0246 & 12,6 \\
Latossolo Vermelho-Amarelo (LV7) & 0,0246 & 12,6 \\
Podzólico Vermelho-Amarelo (PV1) & 0,0280 & 9,9 \\
Podzólico Vermelho-Amarelo (PV2) & 0,0462 & 9,6 \\
Podzólico Vermelho-Amarelo (PV3) & 0,0462 & 9,6 \\
Podzólico Vermelho-Amarelo (PV4) & 0,0280 & 9,9 \\
Podzólico Vermelho-Amarelo (PV5) & 0,0359 & 8,6 \\
Podzólico Vermelho-Amarelo (PV6) & 0,0419 & 7,7 \\
Podzólico Vermelho-Amarelo (PV7) & 0,0462 & 9,6 \\
Podzólico Vermelho-Amarelo (PV8) & 0,0394 & 7,7 \\
Terra Roxa Estruturada (TE1) & 0,0181 & 13,4 \\
Terra Roxa Estruturada (TE2) & 0,0165 & 14,7 \\
Terra Roxa Estruturada (TE3) & 0,0202 & 12,1 \\
\hline Fonte: Lombardi Neto, IAC, 1997.
\end{tabular}

Fonte: Lombardi Neto, IAC, 1997. 
Tabela 15. Preço corrente médio mensal dos fertilizantes, em São Paulo, período 1985-1994 (na moeda correspondente/tonelada).

\begin{tabular}{|c|c|c|c|c|}
\hline mês/ano & Calcário Dolomítico & Cloreto de Potássio & Sulfato de Amônia & Superfosfato Simples \\
\hline $1 / 85$ & $41.719,00$ & $320.740,00$ & $626.580,00$ & $432.085,00$ \\
\hline $2 / 85$ & $45.890,00$ & $841.259,00$ & $727.954,00$ & $493.522,00$ \\
\hline $3 / 85$ & $50.479,00$ & $940.256,00$ & $826.039,00$ & $561.218,00$ \\
\hline $4 / 85$ & $55.528,00$ & $995.058,00$ & $879.560,00$ & $589.464,00$ \\
\hline $5 / 85$ & $61.080,00$ & $1.048 .152,00$ & $940.648,00$ & $636.536,00$ \\
\hline $6 / 85$ & $67.188,00$ & $1.096 .857,00$ & $1.043 .206,00$ & $695.414,00$ \\
\hline $7 / 85$ & $80.530,00$ & $1.273 .694,00$ & $1.179 .320,00$ & $740.806,00$ \\
\hline $8 / 85$ & $88.585,00$ & $1.463 .424,00$ & $1.265 .419,00$ & $829.429,00$ \\
\hline $9 / 85$ & $97.440,00$ & $1.444 .528,00$ & $1.354 .751,00$ & $923.086,00$ \\
\hline $1 / 85$ & $107.180,00$ & $1.571 .608,00$ & $1.472 .600,00$ & $1.023 .842,00$ \\
\hline $11 / 85$ & $117.900,00$ & $1.678 .041,00$ & $1.621 .284,00$ & $1.102 .174,00$ \\
\hline $12 / 85$ & $131.290,00$ & $1.767 .387,00$ & $1.749 .383,00$ & $1.202 .801,00$ \\
\hline $1 / 86$ & $142.000,00$ & $1.986 .784,00$ & $1.919 .858,00$ & $1.407 .729,00$ \\
\hline $2 / 86$ & 155,75 & $2.147 .571,00$ & $2.140 .920,00$ & $1.550 .842,00$ \\
\hline $3 / 86$ & 155,75 & $2.418,12$ & $1.929,74$ & $1.738,50$ \\
\hline $4 / 86$ & 155,75 & $2.418,12$ & $1.929,74$ & $1.738,50$ \\
\hline $5 / 86$ & 155,75 & $2.418,12$ & $1.929,74$ & $1.738,50$ \\
\hline $6 / 86$ & 155,75 & $2.418,12$ & $1.929,74$ & $1.738,50$ \\
\hline $7 / 86$ & 155,75 & $2.418,12$ & $1.929,74$ & $1.738,50$ \\
\hline $8 / 86$ & 155,75 & $2.418,12$ & $1.929,74$ & $1.738,50$ \\
\hline $9 / 86$ & 155,75 & $2.418,12$ & $1.929,74$ & $1.738,50$ \\
\hline $10 / 86$ & 155,75 & $2.418,12$ & $1.929,74$ & $1.738,50$ \\
\hline $11 / 86$ & 155,75 & $2.418,12$ & $1.929,74$ & $1.738,50$ \\
\hline $12 / 86$ & 155,75 & $2.418,12$ & $1.929,74$ & $1.738,50$ \\
\hline $1 / 87$ & 312,00 & $2.418,12$ & $1.929,74$ & $1.762,96$ \\
\hline $2 / 87$ & 312,00 & $2.494,77$ & $1.973,02$ & $1.859,65$ \\
\hline $3 / 87$ & 420,00 & $2.801,39$ & $2.219,20$ & $2.148,94$ \\
\hline $4 / 87$ & 400,00 & $3.494,21$ & $2.723,25$ & $2.620,57$ \\
\hline $5 / 87$ & 450,00 & $5.507,33$ & $4.276,30$ & $4.340,48$ \\
\hline $6 / 87$ & 550,00 & $7.563,05$ & $6.002,31$ & $5.674,25$ \\
\hline $7 / 87$ & 550,00 & $8.406,80$ & $6.299,75$ & $5.685,07$ \\
\hline $8 / 87$ & 575,00 & $8.844,00$ & $7.054,80$ & $6.326,87$ \\
\hline $9 / 87$ & 575,00 & $9.414,66$ & $8.005,75$ & $7.515,75$ \\
\hline $10 / 87$ & 575,00 & $10.425,00$ & $8.435,20$ & $7.636,75$ \\
\hline $11 / 87$ & 730,00 & $11.385,48$ & $9.046,68$ & $8.313,83$ \\
\hline $12 / 87$ & 828,70 & $11.378,83$ & $9.012,02$ & $8.262,42$ \\
\hline $1 / 88$ & $1.034,50$ & $14.782,16$ & $11.974,77$ & $11.022,88$ \\
\hline $2 / 88$ & $1.198,00$ & $17.428,70$ & $13.933,66$ & $13.485,53$ \\
\hline $3 / 88$ & $1.508,00$ & $20.025,84$ & $14.212,20$ & $15.886,84$ \\
\hline
\end{tabular}


Preço corrente médio mensal dos fertilizantes, em São Paulo, período 1985-1994 (na moeda correspondente/tonelada).

\begin{tabular}{|c|c|c|c|c|}
\hline $4 / 88$ & $1.714,00$ & $25.970,05$ & $20.416,18$ & $18.615,12$ \\
\hline $5 / 88$ & $1.985,00$ & $32.105,74$ & $25.064,32$ & $21.996,13$ \\
\hline $6 / 88$ & $2.351,00$ & $38.118,86$ & $29.908,70$ & $27.100,65$ \\
\hline $7 / 88$ & $3.052,00$ & $48.116,35$ & $37.524,32$ & $33.260,87$ \\
\hline $8 / 88$ & $3.970,00$ & $60.122,36$ & $46.394,75$ & $41.816,30$ \\
\hline $9 / 88$ & $4.726,00$ & $74.353,75$ & $57.369,50$ & $50.484,87$ \\
\hline $10 / 88$ & $5.838,00$ & $82.228,00$ & $62.736,16$ & $57.642,87$ \\
\hline $11 / 88$ & $8.095,00$ & $111.858,05$ & $84.611,55$ & $78.277,16$ \\
\hline $12 / 88$ & $10.525,00$ & $143.923,85$ & $94.992,12$ & $99.993,89$ \\
\hline $1 / 89$ & 15,03 & 166,44 & 114,69 & 123,38 \\
\hline $2 / 89$ & 15,03 & 180,66 & 127,13 & 133,44 \\
\hline $3 / 89$ & 15,03 & 180,66 & 127,13 & 133,44 \\
\hline $4 / 89$ & 15,03 & 212,00 & 153,00 & 142,10 \\
\hline $5 / 89$ & 18,58 & 252,61 & 163,20 & 167,00 \\
\hline $6 / 89$ & 24,39 & 299,91 & 215,84 & 188,49 \\
\hline $7 / 89$ & 39,79 & 465,25 & 359,24 & 337,05 \\
\hline $8 / 89$ & 47,25 & 692,58 & 587,59 & 487,07 \\
\hline $9 / 89$ & 66,8 & $1.107,18$ & 875,79 & 599,00 \\
\hline $10 / 89$ & 90,5 & $1.252,29$ & 949,32 & 792,84 \\
\hline $11 / 89$ & 139,69 & $1.761,30$ & $1.330,11$ & 976,94 \\
\hline $12 / 89$ & 224,92 & $2.568,80$ & $1.994,72$ & $1.222,75$ \\
\hline $1 / 90$ & 392,94 & $5.587,90$ & $3.678,40$ & $3.258,70$ \\
\hline $2 / 90$ & 590,45 & $7.771,00$ & $6.049,00$ & $4.069,00$ \\
\hline $3 / 90$ & 787,96 & $15.712,00$ & $12.106,00$ & $5.636,00$ \\
\hline $4 / 90$ & 985,47 & $17.090,00$ & $13.448,00$ & $7.523,00$ \\
\hline $5 / 90$ & $1.182,98$ & $17.090,00$ & $13.448,00$ & $7.523,00$ \\
\hline $6 / 90$ & $1.380,49$ & $18.739,00$ & $14.482,00$ & $8.682,00$ \\
\hline $7 / 90$ & $1.410,00$ & $19.648,00$ & $16.174,00$ & $11.278,00$ \\
\hline $8 / 90$ & $1.667,00$ & $23.568,00$ & $17.456,00$ & $15.058,00$ \\
\hline $9 / 90$ & $1.944,00$ & $27.722,00$ & $20.658,00$ & $16.050,00$ \\
\hline $10 / 90$ & $2.177,00$ & $30.486,00$ & $21.880,00$ & $18.762,00$ \\
\hline $11 / 90$ & $2.482,00$ & $38.798,00$ & $24.991,00$ & $20.346,00$ \\
\hline $12 / 90$ & $2.878,00$ & $47.732,00$ & $31.624,00$ & $30.005,00$ \\
\hline $1 / 91$ & $2.879,00$ & $56.052,00$ & $40.007,00$ & $31.603,00$ \\
\hline $2 / 91$ & $2.879,00$ & $56.052,00$ & $40.007,00$ & $31.603,00$ \\
\hline $3 / 91$ & $3.510,00$ & $65.320,00$ & $47.616,00$ & $41.913,00$ \\
\hline $4 / 91$ & $4.212,00$ & $69.728,00$ & $49.379,00$ & $38.010,00$ \\
\hline $5 / 91$ & $3.454,00$ & $80.677,00$ & $51.897,00$ & $39.156,00$ \\
\hline $6 / 91$ & $3.454,00$ & $80.321,00$ & $54.225,00$ & $41.143,00$ \\
\hline $7 / 91$ & $5.010,00$ & $95.131,00$ & $60.847,00$ & $46.873,00$ \\
\hline $8 / 91$ & $5.685,00$ & $110.785,00$ & $74.261,00$ & $59.413,00$ \\
\hline
\end{tabular}


Preço corrente médio mensal dos fertilizantes, em São Paulo, período 1985-1994 (na moeda correspondente/tonelada).

\begin{tabular}{|c|c|c|c|c|}
\hline $9 / 91$ & $6.346,00$ & $120.226,00$ & $85.721,00$ & $60.324,00$ \\
\hline $10 / 91$ & $7.330,00$ & $155.915,00$ & $113.126,00$ & $77.543,00$ \\
\hline $11 / 91$ & $8.796,00$ & $176.450,00$ & $121.912,00$ & $92.813,00$ \\
\hline $12 / 91$ & $11.443,00$ & $261.799,00$ & $152.466,00$ & $111.555,00$ \\
\hline $8 / 88$ & $3.970,00$ & $60.122,36$ & $46.394,75$ & $41.816,30$ \\
\hline $1 / 92$ & $15.448,00$ & $361.577,00$ & $222.065,00$ & $171.193,00$ \\
\hline $2 / 92$ & $19.773,00$ & $436.717,00$ & $279.362,00$ & $235.378,00$ \\
\hline $3 / 92$ & $24.899,00$ & $485.298,00$ & $289.614,00$ & $260.089,00$ \\
\hline $4 / 92$ & $31.118,00$ & $634.355,00$ & $389.065,00$ & $296.875,00$ \\
\hline $5 / 92$ & $37.482,00$ & $676.119,00$ & $454.501,00$ & $345.238,00$ \\
\hline $6 / 92$ & $45.996,00$ & $878.099,00$ & $558.803,00$ & $432.014,00$ \\
\hline $7 / 92$ & $56.115,00$ & $1.012 .009,00$ & $663.321,00$ & $507.670,00$ \\
\hline $8 / 92$ & $65.800,00$ & $1.226 .607,00$ & $869.986,00$ & $651.113,00$ \\
\hline $9 / 92$ & $82.376,00$ & $1.382 .126,00$ & $1.042 .184,00$ & $782.771,00$ \\
\hline $10 / 92$ & $102.850,00$ & $1.970 .653,00$ & $1.264 .526,00$ & $958.094,00$ \\
\hline $11 / 92$ & $129.591,00$ & $2.571 .778,00$ & $1.580 .531,00$ & $1.175 .280,00$ \\
\hline $12 / 92$ & $163.285,00$ & $3.071 .465,00$ & $2.021 .973,00$ & $1.423 .730,00$ \\
\hline $1 / 93$ & $211,923,00$ & $3.747 .883,00$ & $2.517 .411,00$ & $2.002 .647,00$ \\
\hline $2 / 93$ & $251.000,00$ & $4.643 .981,00$ & $3.081 .796,00$ & $2.539 .052,00$ \\
\hline $3 / 93$ & $318.772,00$ & $5.609 .403,00$ & $3.857 .863,00$ & $3.391 .628,00$ \\
\hline $4 / 93$ & $404.840,00$ & $6.741 .292,00$ & $4.955 .805,00$ & $3.745 .930,00$ \\
\hline $5 / 93$ & $526.292,00$ & $8.712 .337,00$ & $6.235 .030,00$ & $4.349 .357,00$ \\
\hline $6 / 93$ & $684.180,00$ & $11.580 .576,00$ & $8.821 .253,00$ & $6.657 .469,00$ \\
\hline $7 / 93$ & 899,70 & $17.352,86$ & $11.711,59$ & $8.699,60$ \\
\hline $8 / 93$ & $1.218,00$ & $19.207,00$ & $15.811,00$ & $11.032,00$ \\
\hline $9 / 93$ & $1.646,00$ & $28.006,00$ & $21.785,00$ & $15.938,00$ \\
\hline $10 / 93$ & $2.254,00$ & $36.183,00$ & $29.127,00$ & $20.865,00$ \\
\hline $11 / 93$ & $3.065,00$ & $45.699,00$ & $37.865,00$ & $26.254,00$ \\
\hline $12 / 93$ & $4.249,00$ & $63.615,00$ & $53.275,00$ & $36.001,00$ \\
\hline $1 / 94$ & $5.382,00$ & $86.084,00$ & $72.347,00$ & $45.625,00$ \\
\hline $2 / 94$ & $7.411,00$ & $130.473,00$ & $118.222,00$ & $79.577,00$ \\
\hline $3 / 94$ & $10.660,00$ & $169.531,00$ & $138.643,00$ & $102.767,00$ \\
\hline $4 / 94$ & $16.466,00$ & $262.692,00$ & $215.377,00$ & $152.809,00$ \\
\hline $5 / 94$ & $26.330,00$ & $376.206,00$ & $307.259,00$ & $219.416,00$ \\
\hline $6 / 94$ & 17,55 & 242,78 & 199,78 & 141,51 \\
\hline $7 / 94$ & 16,20 & 262,91 & 209,40 & 146,58 \\
\hline $8 / 94$ & 15,08 & 263,24 & 210,48 & 147,97 \\
\hline $9 / 94$ & 15,08 & 263,42 & 208,63 & 147,43 \\
\hline $10 / 94$ & 15,08 & 252,07 & 208,14 & 146,84 \\
\hline $11 / 94$ & 15,08 & 253,81 & 207,88 & 148,19 \\
\hline $12 / 94$ & 15,08 & 253,62 & 207,96 & 149,17 \\
\hline
\end{tabular}

Fonte: IEA. 
O cálculo do valor dos nutrientes perdidos junto aos sedimentos gerados pela perda de terra por erosão começa estimando-se a quantidade de nutrientes perdidos (Tabela 16), assim (o cálculo para o mês de janeiro de 1985 serve como exemplo):

Carga de sedimentos $\mathrm{x}$ teor médio de nitrogênio, potássio, cálcio, magnésio e fósforo; $250.251 \times 0,00156631=391,97 \mathrm{t}$ de nitrogênio; $250.251 \times 0,00010331=25,85 \mathrm{t}$ de potássio; $250.251 \times 0,00056643=141,75 \mathrm{t}$ de cálcio; $250.251 \times 0,00008724=21,83 \mathrm{t}$ de magnésio; $\mathrm{e}$, $250.251 \times 0,000026414=6,61 \mathrm{t}$ de fósforo.

Tabela 16. Quantidade de nutrientes perdidos nos sedimentos produzidos pela erosão do solo na bacia do rio Corumbatai, 1985.

\begin{tabular}{|c|c|c|c|c|c|c|c|}
\hline Mês & $\begin{array}{c}\text { Carga } \\
\text { sedimentos } \\
(\mathrm{t})\end{array}$ & $\begin{array}{l}\text { Nitrogênio } \\
\text { (t) }\end{array}$ & $\begin{array}{l}\text { Potássio } \\
\text { (t) }\end{array}$ & $\begin{array}{l}\text { Cálcio } \\
(\mathrm{t})\end{array}$ & $\begin{array}{l}\text { Magnésio } \\
\text { (t) }\end{array}$ & $\begin{array}{c}\text { Fósforo } \\
(\mathrm{t})\end{array}$ & $\begin{array}{l}\text { Cálcio + } \\
\text { Magnésio } \\
\text { (t) }\end{array}$ \\
\hline Janeiro & 250.251 & 391,97 & 25,85 & 141,75 & 21,83 & 6,61 & 163,58 \\
\hline Fevereiro & 191.072 & 299,28 & 19,74 & 108,23 & 16,67 & 5,05 & 124,90 \\
\hline Março & 142.678 & 223,48 & 14,74 & 80,82 & 12,45 & 3,77 & 93,27 \\
\hline Abril & 41.374 & 64,80 & 4,27 & 23,44 & 3,61 & 1,09 & 27,05 \\
\hline Maio & 55.410 & 86,79 & 5,72 & 31,39 & 4,83 & 1,46 & 36,22 \\
\hline Junho & 20.185 & 31,62 & 2,09 & 11,43 & 1,76 & 0,53 & 13,19 \\
\hline Julho & 12.913 & 20,23 & 1,33 & 7,31 & 1,13 & 0,34 & 8,44 \\
\hline Agosto & 12.159 & 19,04 & 1,26 & 6,89 & 1,06 & 0,32 & 7,95 \\
\hline Setembro & 39.999 & 62,65 & 4,13 & 22,66 & 3,49 & 1,06 & 26,15 \\
\hline Outubro & 112.974 & 176,95 & 11,67 & 63,99 & 9,86 & 2,98 & 73,85 \\
\hline Novembro & 128.197 & 200,80 & 13,24 & 72,61 & 11,18 & 3,39 & 83,79 \\
\hline Dezembro & 247.114 & 387,06 & 25,53 & 139,97 & 21,56 & 6,53 & 161,53 \\
\hline
\end{tabular}

Fonte: resultados da pesquisa.

As quantidades de nutrientes perdidos são transformadas em quantidades equivalentes de fertilizantes, dividindo-as pelo teor do nutriente (em percentagem) presente em cada fertilizante, assim:

$391,97 / 0,20=1.959,85 \mathrm{t}$ de sulfato de alumínio;

$6,61 / 0,18=36,75 \mathrm{t}$ de superfosfato simples;

$25,85 / 0,60=44,47 \mathrm{t}$ de cloreto de potássio; e,

$163,58 / 0,38=430,22 \mathrm{t}$ de calcário dolomítico. 
Tabela 17. Equivalente fertilizantes dos nutrientes perdidos na bacia do rio Corumbatai, 1985.

\begin{tabular}{lrrrr}
\hline \multicolumn{1}{c}{ Mês } & $\begin{array}{c}\text { Sulfato de amônia } \\
(\mathrm{t})\end{array}$ & $\begin{array}{c}\text { Superfosfato } \\
\text { simples } \\
(\mathrm{t})\end{array}$ & $\begin{array}{c}\text { Cloreto de Potássio } \\
(\mathrm{t})\end{array}$ & $\begin{array}{r}\text { Calcário dolomítico } \\
(\mathrm{t})\end{array}$ \\
\hline Janeiro & $1.959,85$ & 36,75 & 44,47 & 430,22 \\
Fevereiro & $1.496,39$ & 28,06 & 33,95 & 328,48 \\
Março & $1.117,39$ & 20,95 & 25,35 & 245,29 \\
Abril & 324,02 & 6,08 & 7,35 & 71,13 \\
Maio & 433,95 & 8,14 & 9,85 & 95,26 \\
Junho & 158,08 & 2,96 & 3,59 & 34,70 \\
Julho & 101,13 & 1,90 & 2,29 & 22,20 \\
Agosto & 95,22 & 1,79 & 2,16 & 20,90 \\
Setembro & 313,25 & 5,87 & 7,11 & 68,76 \\
Outubro & 884,76 & 16,59 & 20,07 & 194,22 \\
Novembro & $1.003,98$ & 18,83 & 22,78 & 220,39 \\
Dezembro & $1.935,29$ & 36,29 & 43,91 & 424,83 \\
\hline
\end{tabular}

Fonte: resultados da pesquisa.

A quantidade de cada um dos fertilizantes é multiplicada pelo respectivo preço para obter o valor das perdas de cada nutriente (Tabela 18), assim:

$1.959,85 \times 563,92=\mathrm{R} \$ 1.105 .204$ perdas de nitrogênio;

$36,75 \times 388,88=\mathrm{R} \$ 14.292$ perdas de fósforo;

$44,47 \times 288,67=\mathrm{R} \$ 12.836$ perdas de potássio; e,

$430,22 \times 37,50=R \$ 16.133$ perdas de cálcio + magnésio.

Sumando-se os quatro valores estimados obtém-se o valor dos nutrientes perdidos no mês de janeiro de 1985 (primeiro valor da última coluna da Tabela 18).

Finalmente, sumando-se os valores mensais das perdas de nutrientes obtém-se o valor anual de $\mathrm{R} \$ 5.924 .781$ que corresponde com o primeiro valor da segunda coluna da Tabela 3 (a diferença de $R \$ 4,00$ deve-se a arredondamentos).

Os valores dos nutrientes perdidos gerados com base nas perdas toleráveis de terra estimaram-se de maneira similar, sendo a única diferença os valores da carga de sedimentos. 
Tabela 18. Valor das perdas de nutrientes em termos de fertilizantes equivalentes, na bacia do rio Corumbatai, 1985.

\begin{tabular}{lrrrrr}
\hline \multicolumn{1}{c}{$\begin{array}{c}\text { Perdas } \\
\text { nitrogênio } \\
\text { Mês }\end{array}$} & \multicolumn{1}{c}{$\begin{array}{c}\text { Perdas potássio } \\
(\mathrm{R})\end{array}$} & $\begin{array}{c}\text { Perdas fósforo } \\
(\mathrm{R} \$)\end{array}$ & $\begin{array}{c}\text { Perdas cálcio } \\
\text { magnésio } \\
(\mathrm{R} \$)\end{array}$ & $\begin{array}{c}\text { Perdas } \\
\text { nutrientes } \\
(\mathrm{R} \$)\end{array}$ \\
\hline Janeiro & 1.105 .204 & 12.836 & 14.292 & 16.133 & 1.148 .465 \\
Fevereiro & 871.442 & 22.850 & 11.079 & 12.055 & 917.426 \\
Março & 646.105 & 16.687 & 8.232 & 8.659 & 679.683 \\
Abril & 199.498 & 5.121 & 2.507 & 2.767 & 209.893 \\
Maio & 244.914 & 6.192 & 3.108 & 3.486 & 257.700 \\
Junho & 98.946 & 2.360 & 1.237 & 1.398 & 103.941 \\
Julho & 59.631 & 1.461 & 702 & 895 & 62.689 \\
Agosto & 60.249 & 1.581 & 741 & 926 & 63.497 \\
Setembro & 169.753 & 4.107 & 2.169 & 2.682 & 178.711 \\
Outubro & 521.160 & 12.620 & 6.795 & 8.332 & 548.907 \\
Novembro & 651.095 & 15.290 & 8.300 & 10.402 & 685.087 \\
Dezembro & 1.015 .667 & 23.282 & 13.095 & 16.738 & 1.068 .782 \\
Total & 5.643 .664 & 124.387 & 72.257 & 84.473 & 5.924 .781 \\
\hline
\end{tabular}

Fonte: resultados da pesquisa. 


\section{A P E E D I C E 2}

Dados básicos para a determinação do valor da perda de produtividade 
Tabela 19. Dados utilizados para a estimativa do impacto da erosão do solo sobre o rendimento da cana-de-açúcar num solo Podzólico VermelhoAmarelo da fazenda São Francisco, Usina Costa Pinto, safra 1996.

\begin{tabular}{lcccccc}
\hline Variedade & Idade & Ren96(tha) & Perdas & n95 & k95 & d \\
\hline SP 70-1143 & 6 & 24,5 & 16,1 & 178,5 & 315 & 0 \\
RB 78-5148 & 3 & 85,6 & 17,8 & 176,8 & 312 & 1 \\
RB 78-5148 & 3 & 98,7 & 20,1 & 173,4 & 306 & 1 \\
SP 70-1143 & 3 & 90,2 & 21,8 & 176,8 & 312 & 0 \\
SP 70-1143 & 3 & 81,5 & 30,8 & 88,4 & 156 & 0 \\
SP 70-1143 & 3 & 81,6 & 30,8 & 90,1 & 159 & 0 \\
SP 70-1143 & 3 & 76,4 & 31,8 & 175,1 & 309 & 0 \\
SP 70-1143 & 3 & 76,8 & 31,8 & 176,8 & 312 & 0 \\
SP 70-1143 & 3 & 56,6 & 11,8 & 170,0 & 300 & 0 \\
SP 70-1143 & 3 & 88,6 & 20,8 & 178,5 & 315 & 0 \\
SP 70-1143 & 3 & 41,4 & 23,3 & 178,5 & 315 & 0 \\
SP 70-1143 & 3 & 84,7 & 20,1 & 90,1 & 159 & 0 \\
SP 70-1143 & 3 & 101,5 & 17,0 & 86,7 & 153 & 0 \\
SP 70-1143 & 3 & 89,3 & 22,6 & 175,1 & 309 & 0 \\
SP 70-1143 & 3 & 38,1 & 16,1 & 86,7 & 153 & 0 \\
SP 70-1143 & 3 & 84,5 & 21,8 & 88,4 & 156 & 0 \\
SP 70-1143 & 3 & 27,0 & 37,5 & 88,4 & 156 & 0 \\
SP 70-1143 & 3 & 81,0 & 23,3 & 83,3 & 147 & 0 \\
SP 70-1143 & 3 & 93,9 & 31,8 & 88,4 & 156 & 0 \\
SP 70-1143 & 3 & 44,9 & 34,9 & 91,8 & 162 & 0 \\
SP 70-1143 & 3 & 64,9 & 22,6 & 88,4 & 156 & 0 \\
SP 70-1143 & 3 & 69,7 & 21,8 & 85,0 & 150 & 0 \\
SP 70-1143 & 3 & 81,4 & 17,8 & 90,1 & 159 & 0 \\
SP 70-1143 & 3 & 65,1 & 30,1 & 90,1 & 159 & 0 \\
SP 70-1143 & 3 & 56,9 & 30,8 & 85,0 & 150 & 0 \\
RB 78-5148 & 2 & 82,9 & 11,9 & 126,1 & 170,1 & 1 \\
RB 78-5148 & 2 & 78,6 & 18,9 & 126,1 & 170,1 & 1 \\
RB 78-5148 & 2 & 81,8 & 13,9 & 126,1 & 170,1 & 1 \\
\hline Fonte: & & & & & \\
\end{tabular}

Fonte: Usina Costa Pinto. 
Tabela 20. Dados utilizados para a estimativa do impacto da erosão do solo sobre o rendimento da cana-de-açúcar num solo Latossolo Roxo da fazenda Santa Rosa II, Usina Costa Pinto, safra 1996.

\begin{tabular}{|c|c|c|c|c|c|c|c|c|c|}
\hline Variedade & Idade & $\begin{array}{c}\text { Ren96(t/ } \\
\text { ha) }\end{array}$ & Perdas & n95 & k95 & $\mathrm{dl}$ & d2 & d3 & $\mathrm{d} 4$ \\
\hline RB 72-454 & 2 & 92,57 & 5,45 & 126,00 & 170,10 & 1 & 0 & 0 & 0 \\
\hline SP 79-1011 & 3 & 60,06 & 5,11 & 126,00 & 164,10 & 0 & 1 & 0 & 0 \\
\hline SP 71-6163 & 7 & 63,76 & 9,11 & 125,40 & 175,89 & 0 & 0 & 1 & 0 \\
\hline SP 79-1011 & 3 & 129,08 & 3,21 & 125,40 & 163,89 & 0 & 1 & 0 & 0 \\
\hline SP 79-1011 & 3 & 103,77 & 4,25 & 127,00 & 176,45 & 0 & 1 & 0 & 0 \\
\hline SP 71-6163 & 7 & 53,92 & 5,78 & 128,00 & 44,80 & 0 & 0 & 1 & 0 \\
\hline SP 71-1406 & 3 & 95,34 & 5,45 & 128,00 & 49,55 & 0 & 0 & 0 & 0 \\
\hline SP 71-1406 & 7 & 59,73 & 5,78 & 71,80 & 25,13 & 0 & 0 & 0 & 0 \\
\hline SP 71-1406 & 3 & 40,25 & 6,09 & 125,60 & 175,96 & 0 & 0 & 0 & 0 \\
\hline SP 71-1406 & 3 & 37,52 & 5,78 & 125,60 & 175,96 & 0 & 0 & 0 & 0 \\
\hline SP 71-1406 & 3 & 54,10 & 5,45 & 125,60 & 175,96 & 0 & 0 & 0 & 0 \\
\hline SP 71-1406 & 3 & 56,85 & 5,11 & 125,60 & 175,96 & 0 & 0 & 0 & 0 \\
\hline SP 71-1406 & 3 & 59,98 & 4,75 & 125,60 & 169,96 & 0 & 0 & 0 & 0 \\
\hline SP 71-6163 & 7 & 46,59 & 5,78 & 126,00 & 170,10 & 0 & 0 & 1 & 0 \\
\hline SP 71-6163 & 7 & 52,71 & 11,06 & 126,00 & 170,10 & 0 & 0 & 1 & 0 \\
\hline SP 71-1406 & 7 & 61,21 & 5,45 & 125,20 & 169,82 & 0 & 0 & 0 & 0 \\
\hline SP 71-1406 & 7 & 43,79 & 5,78 & 125,20 & 169,82 & 0 & 0 & 0 & 0 \\
\hline SP 71-1406 & 7 & 46,59 & 5,45 & 125,20 & 169,82 & 0 & 0 & 0 & 0 \\
\hline SP 71-1406 & 7 & 39,50 & 5,78 & 125,20 & 169,82 & 0 & 0 & 0 & 0 \\
\hline SP 71-1406 & 4 & 39,11 & 7,19 & 125,20 & 169,82 & 0 & 0 & 0 & 0 \\
\hline RB 76-5418 & 4 & 67,73 & 12,21 & 125,40 & 169,89 & 1 & 0 & 0 & 0 \\
\hline RB 72-454 & 2 & 86,14 & 5,45 & 127,40 & 170,59 & 1 & 0 & 0 & 0 \\
\hline RB 72-454 & 2 & 79,41 & 8,10 & 126,20 & 176,17 & 1 & 0 & 0 & 0 \\
\hline RB 72-454 & 3 & 59,2 & 9,71 & 126,20 & 176,17 & 1 & 0 & 0 & 0 \\
\hline RB 72-454 & 3 & 63,52 & 5,78 & 0,00 & 126,00 & 1 & 0 & 0 & 0 \\
\hline RB 72-454 & 3 & 72,49 & 4,37 & 0,00 & 126,00 & 0 & 0 & 1 & 0 \\
\hline SP 71-6163 & 7 & 62,91 & 11,42 & 0,00 & 126,00 & 0 & 0 & 1 & 0 \\
\hline SP 71-6163 & 7 & 24,39 & 4,37 & 0,00 & 8,56 & 0 & 0 & 0 & 0 \\
\hline SP 71-1406 & 8 & 53,28 & 5,34 & 0,00 & 8,56 & 0 & 0 & 1 & 0 \\
\hline SP 71-6163 & 7 & 49,67 & 8,10 & 0,00 & 8,56 & 0 & 0 & 1 & 0 \\
\hline SP 71-6163 & 7 & 29,41 & 22,38 & 0,00 & 8,56 & 0 & 0 & 1 & 0 \\
\hline SP 71-6163 & 7 & 34,70 & 21,59 & 0,00 & 8,56 & 0 & 0 & 0 & 1 \\
\hline SP 79-2312 & 2 & 86,02 & 16,36 & 0,00 & 8,56 & 0 & 0 & 0 & 1 \\
\hline SP 79-2312 & 2 & 83,17 & 24,71 & 0,00 & 8,56 & 0 & 0 & 0 & 1 \\
\hline SP 79-2312 & 2 & 79,65 & 21,59 & 0,00 & 8,56 & 0 & 0 & 0 & 1 \\
\hline
\end{tabular}

Fonte: Usina Costa Pinto. 
Tabela 21. Dados utilizados para a estimativa do impacto da erosão do solo sobre o rendimento da cana-de-açúcar num solo Terra Roxa Estruturada da fazenda Santa Rosa II, Usina Costa Pinto, safra 1996.

\begin{tabular}{ccccccccccc}
\hline Variedade & Idade & Ren96(t/ha) & Perdas & N95 & K95 & dl & d2 & $\mathrm{d} 3$ & $\mathrm{~d} 4$ & $\mathrm{~d} 5$ \\
\hline SP 79-1011 & 2 & 70,23 & 8,61 & 125,6 & 169,96 & 0 & 0 & 0 & 0 & 0 \\
SP 71-1406 & 10 & 51,65 & 16,14 & 125,6 & 169,96 & 1 & 0 & 0 & 0 & 0 \\
SP 71-1406 & 9 & 54,21 & 16,14 & 125,6 & 169,96 & 1 & 0 & 0 & 0 & 0 \\
RB 76-5418 & 3 & 87,52 & 30,02 & 128,0 & 170,80 & 0 & 1 & 0 & 0 & 0 \\
SP 71-1406 & 9 & 61,67 & 15,27 & 125,6 & 169,96 & 1 & 0 & 0 & 0 & 0 \\
SP 71-1406 & 9 & 56,28 & 16,14 & 125,6 & 169,96 & 1 & 0 & 0 & 0 & 0 \\
SP 71-1406 & 9 & 41,27 & 16,37 & 0,0 & 0,00 & 1 & 0 & 0 & 0 & 0 \\
SP 71-1406 & 9 & 52,13 & 16,14 & 0,0 & 0,00 & 1 & 0 & 0 & 0 & 0 \\
SP 71-1406 & 10 & 68,50 & 15,27 & 126,0 & 170,10 & 1 & 0 & 0 & 0 & 0 \\
SP 79-1011 & 4 & 104,40 & 16,77 & 0,0 & 126,00 & 0 & 0 & 0 & 0 & 0 \\
SP 79-1011 & 4 & 68,78 & 26,85 & 0,0 & 126,00 & 0 & 0 & 0 & 0 & 0 \\
SP 79-1011 & 3 & 99,63 & 6,01 & 0,0 & 0,00 & 0 & 0 & 0 & 0 & 0 \\
SP 79-1011 & 4 & 95,30 & 6,65 & 0,0 & 126,00 & 0 & 0 & 0 & 0 & 0 \\
SP 79-1011 & 3 & 74,60 & 6,65 & 126,0 & 164,10 & 0 & 0 & 0 & 0 & 0 \\
RB 72-454 & 2 & 104,46 & 12,21 & 126,0 & 164,10 & 0 & 0 & 0 & 0 & 1 \\
SP 79-1011 & 3 & 104,87 & 15,64 & 0,0 & 126,00 & 0 & 0 & 0 & 0 & 0 \\
RB 72-454 & 3 & 115,99 & 16,37 & 126,0 & 164,10 & 0 & 0 & 0 & 0 & 1 \\
RB 72-454 & 2 & 76,76 & 15,64 & 126,0 & 164,10 & 0 & 0 & 0 & 0 & 1 \\
SP 71-1406 & 2 & 79,77 & 9,75 & 125,6 & 169,96 & 0 & 0 & 0 & 0 & 0 \\
SP 71-1406 & 9 & 78,01 & 10,17 & 125,6 & 169,96 & 0 & 0 & 0 & 0 & 0 \\
RB 76-5418 & 2 & 73,94 & 15,64 & 126,2 & 170,17 & 0 & 1 & 0 & 0 & 0 \\
RB 72-454 & 3 & 82,17 & 11,45 & 126,2 & 170,17 & 0 & 0 & 0 & 0 & 1 \\
RB 76-5418 & 2 & 78,72 & 16,14 & 0,0 & 132,00 & 0 & 1 & 0 & 0 & 0 \\
RB 72-454 & 3 & 80,38 & 11,80 & 0,00 & 126,00 & 0 & 0 & 0 & 0 & 1 \\
RB 72-454 & 3 & 83,72 & 10,63 & 0,0 & 126,00 & 0 & 0 & 0 & 0 & 1 \\
SP 71-6163 & 7 & 43,60 & 16,37 & 125,8 & 176,03 & 0 & 0 & 1 & 0 & 0 \\
SP 71-6163 & 7 & 25,13 & 16,14 & 125,8 & 176,03 & 0 & 0 & 1 & 0 & 0 \\
SP 79-2312 & 2 & 77,22 & 31,65 & 0,0 & 8,56 & 0 & 0 & 0 & 1 & 0 \\
SP 79-2312 & 2 & 101,90 & 12,00 & 0,0 & 8,56 & 0 & 0 & 0 & 1 & 0 \\
\hline
\end{tabular}

Fonte: Usina Costa Pinto. 
Tabela 22. Preço médio anual da cana-de-açúcar na região de Piracicaba, período 1985-1994.

\begin{tabular}{lll}
\hline Ano & Preço (R\$ dez. 95/t) \\
\hline 1985 & 31,046579 \\
1986 & 26,761068 \\
1987 & 25,549464 \\
1988 & 24,729521 \\
1989 & 21,766494 \\
1990 & 20,212042 \\
1991 & 17,777726 \\
1992 & 20,156447 \\
1993 & 19,874530 \\
1994 & 20,997444 \\
\hline
\end{tabular}

Fonte: Associação dos Fornecedores de Cana de Piracicaba. 
Da Tabela 4 tem-se que, para os solos podzólicos da área do estudo, o rendimento da cana-de-açúcar tem a forma:

$$
R=139,0676-17,8048 I-0,0197 P^{2} ;
$$

$\frac{\partial R}{\partial P}=-0,0394 P$.

Avaliando-se esse efeito ao nível médio de perdas de terra toleráveis para os solos podzólicos $(9,17 \mathrm{t} / \mathrm{ha})$, obtém-se:

$$
-0,0394(9,17)=-0,3613 \mathrm{t} / \mathrm{ha} \text {. }
$$

Nos solos podzólicos da bacia ocupados com cana-de-açúcar a perda média estimada de terra por erosão é 61,37 t/ha. Subtraindo dela a média do limite tolerável $(9,17)$ obtém-se um valor de 52,2 t/ha. Para esse valor médio de perda adicional de terra (além do limite tolerável) na bacia, a perda de produtividade é:

$$
-0,3613 \times 52,2=18,86 \mathrm{t} / \mathrm{ha} \text {. }
$$

Multiplicando-se 18,86 vezes o preço médio anual (Tabela 21) da tonelada de cana gera-se o valor da perda de produtividade. Por exemplo para 1985:

$$
18,86 \times 31,05=\mathrm{R} \$ 585,60 / \mathrm{ha} \text {. }
$$

Por sua vez, ao se multiplicar o valor da perda de produtividade vezes a área de solos podzólicos com cana, em 1985, gera-se o valor anual da perda de produtividade:

$$
585,60 \times 18.966=\mathrm{R} \$ 11.106 .490,
$$

que se aproxima do valor apresentado na terceira coluna da Tabela 5 correspondente a 1985. A diferença é devida a arredondamentos.

A mecânica do cálculo foi a mesma para os outros anos da série analisada. 


\section{A P E N D I C E 3}

Dados das estações de tratamento de água e cálculo do custo adicional 


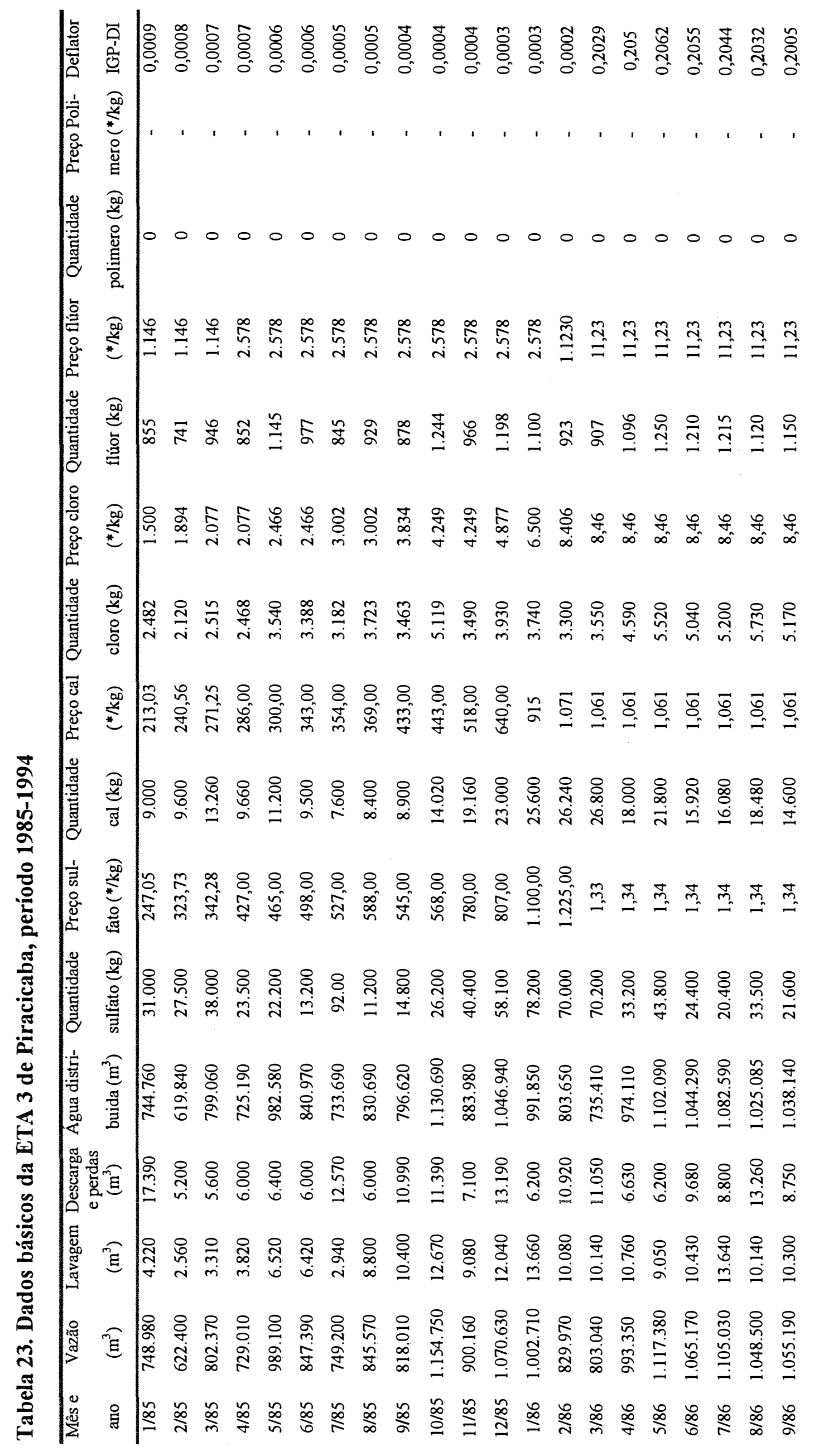




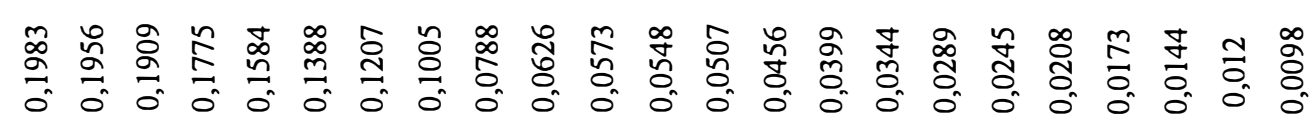

00000000000000000000000

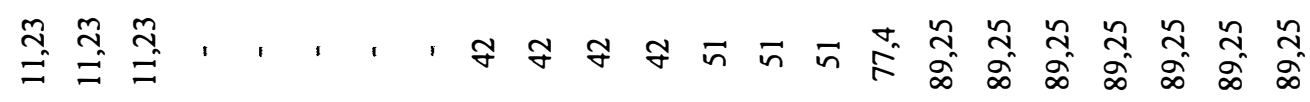

윰

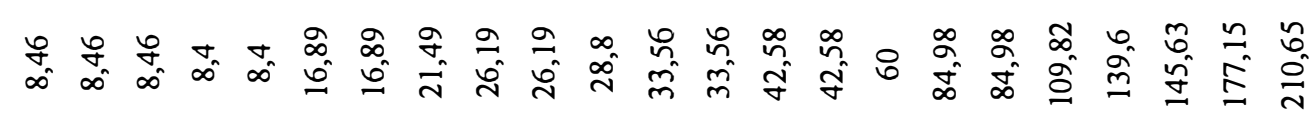

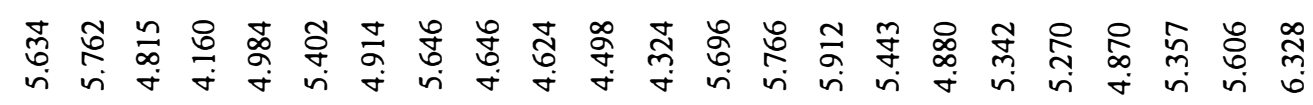

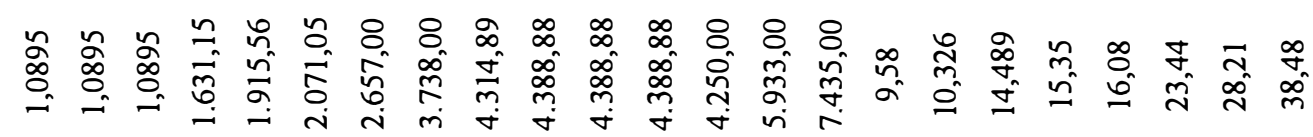

\&

๖

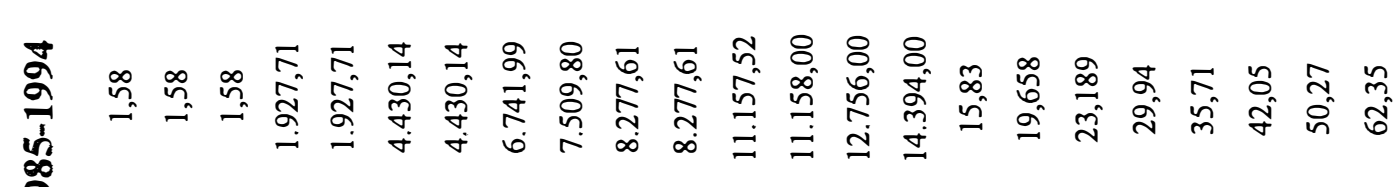

을 号

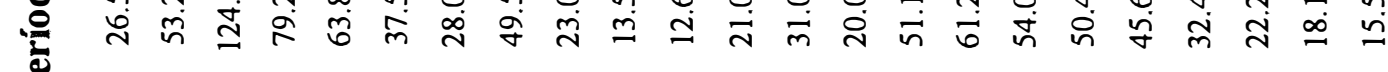

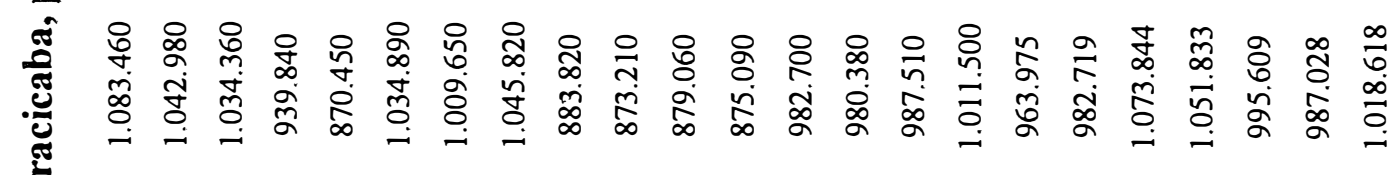

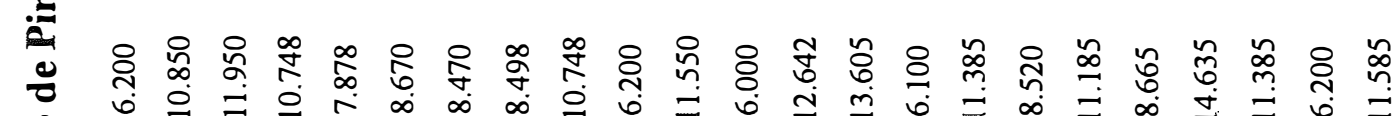

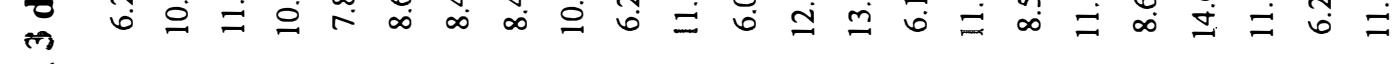

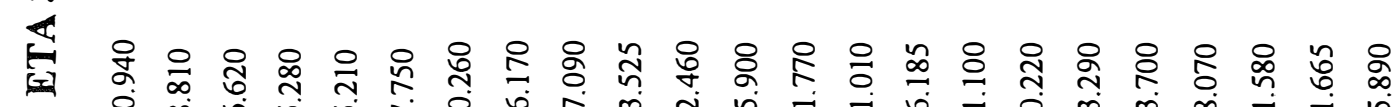

r 0 向

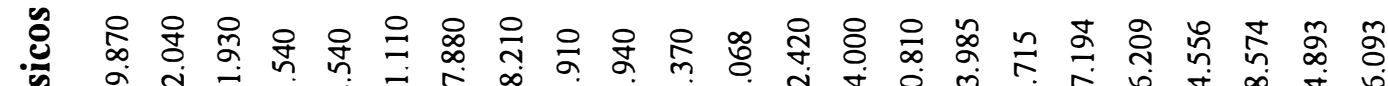

氙

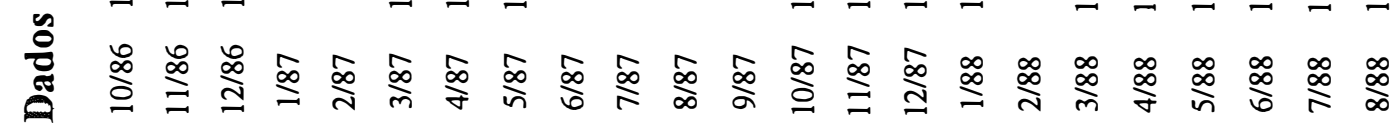




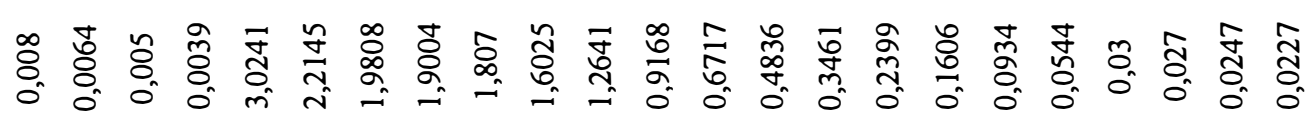

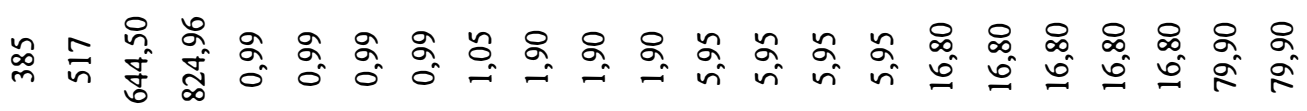

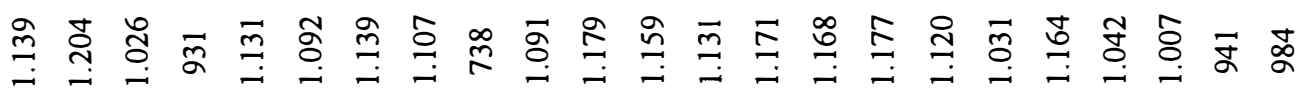

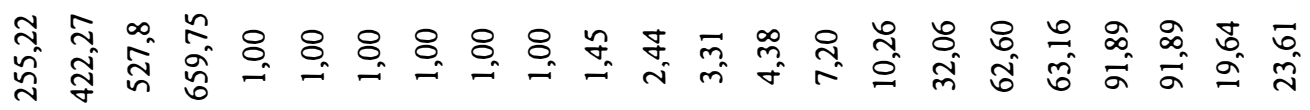

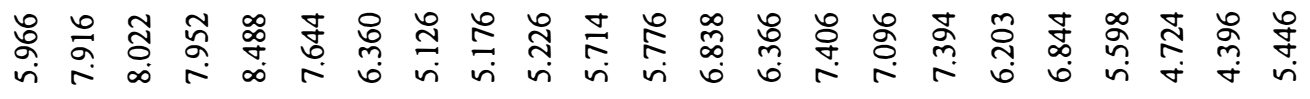

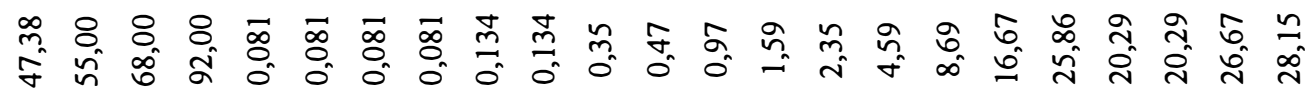

\&

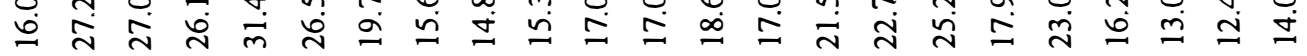

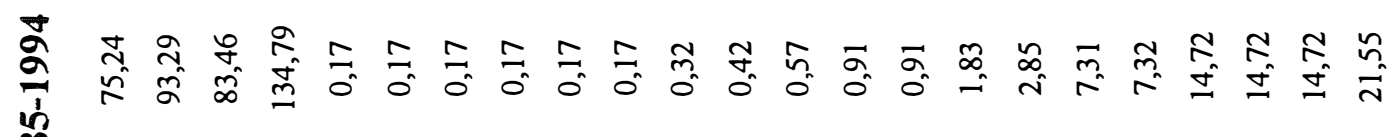

융 \& \& \& \& 8 \& 产

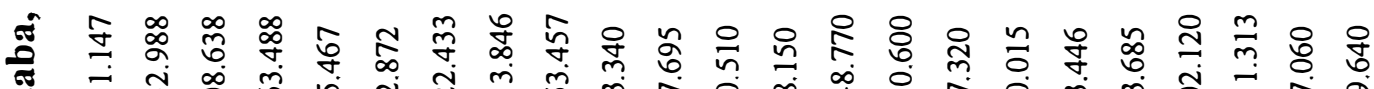

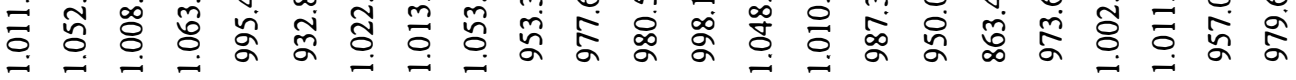

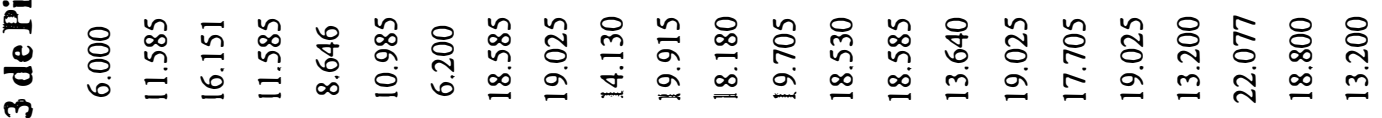

년

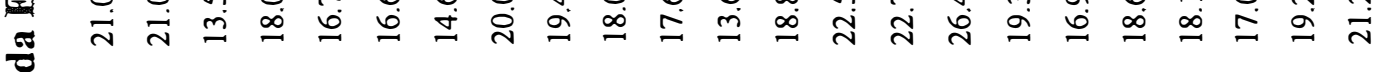

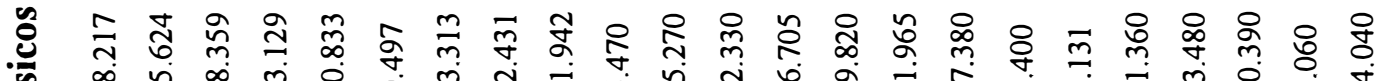

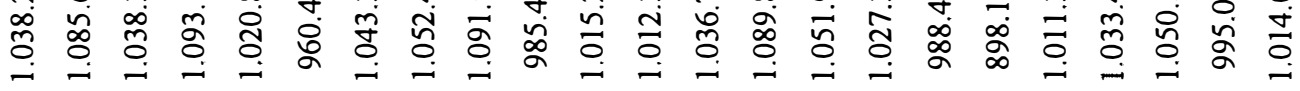

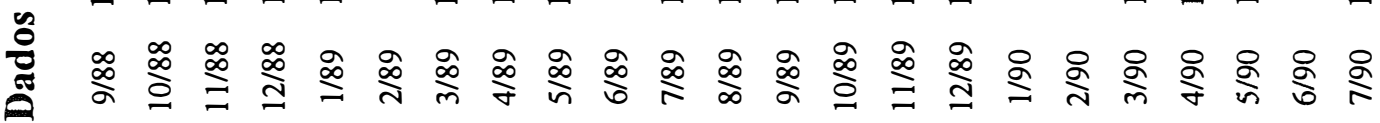




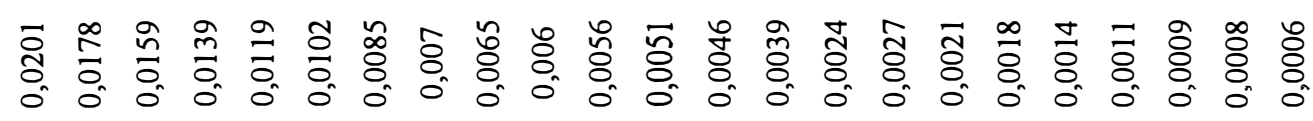

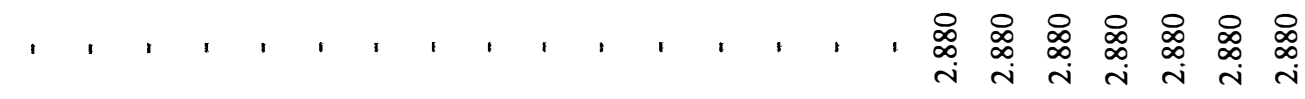

$000000000000000000 \tilde{N}=00$

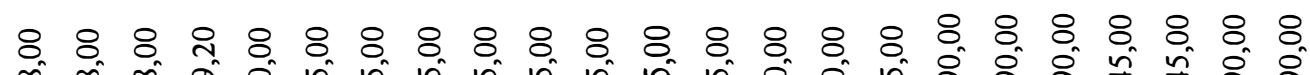

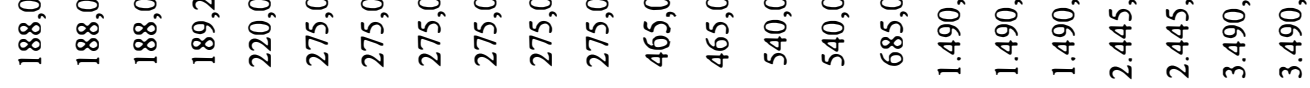

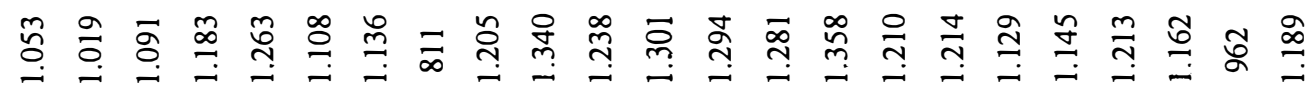

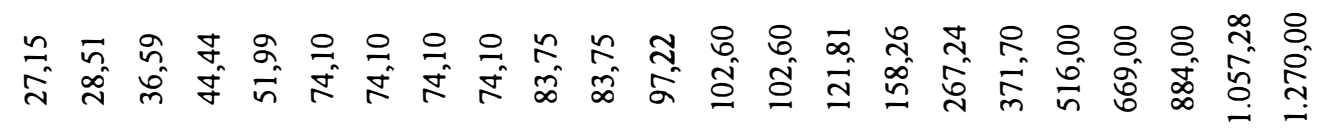

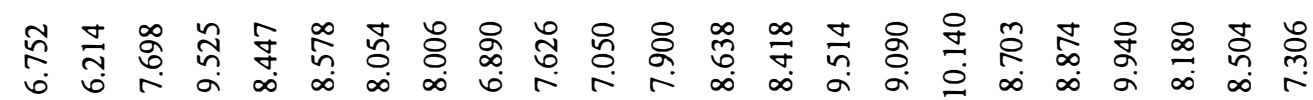

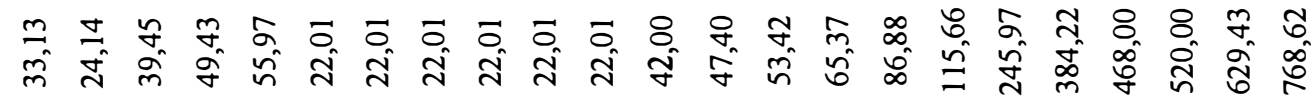

\& \& 규 \& ๒

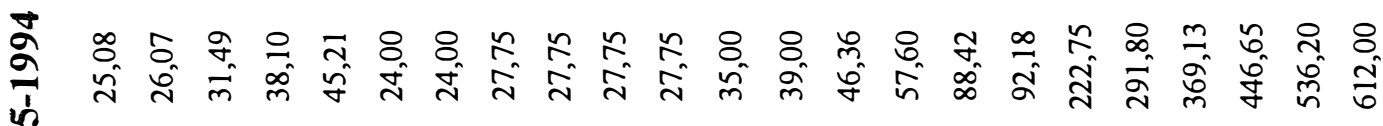

¿ \&

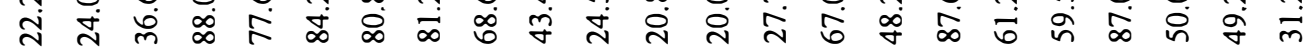

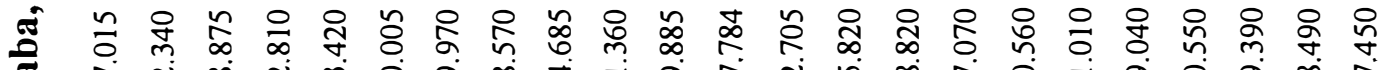
正

สิర

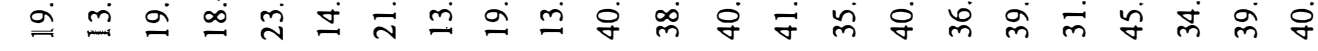

융 \&

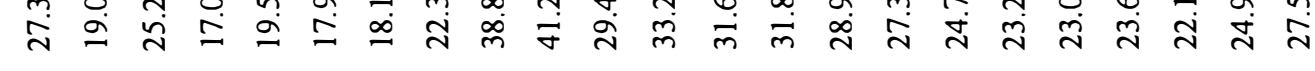
앙 \& m

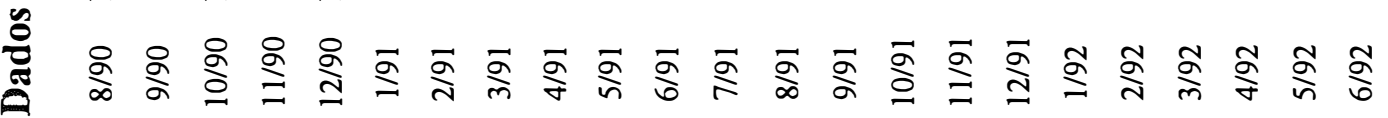




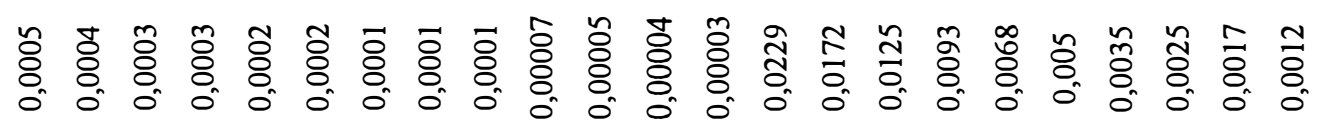

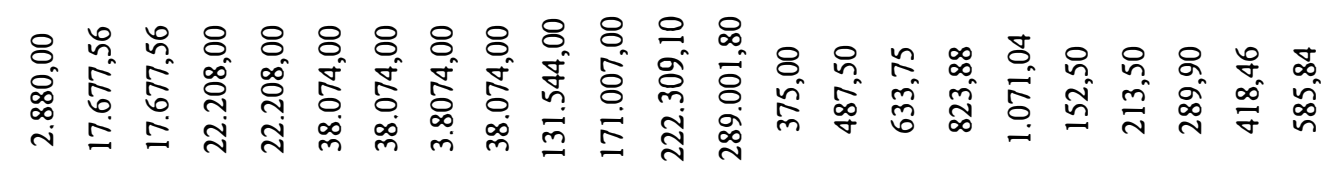

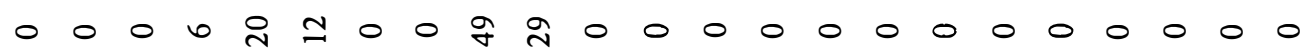

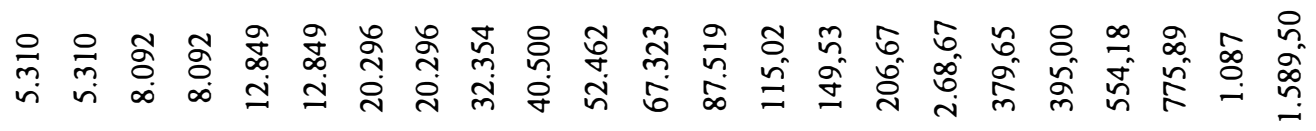

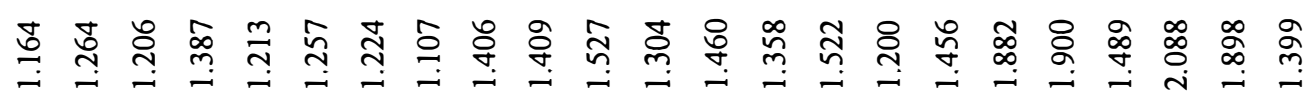

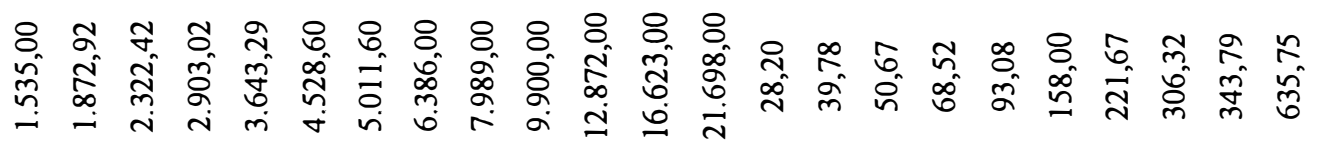

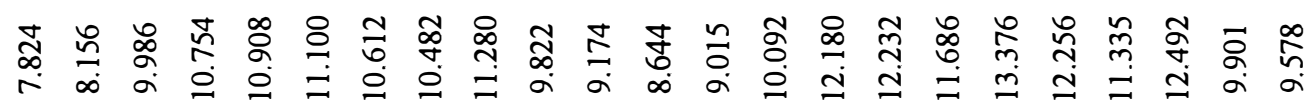

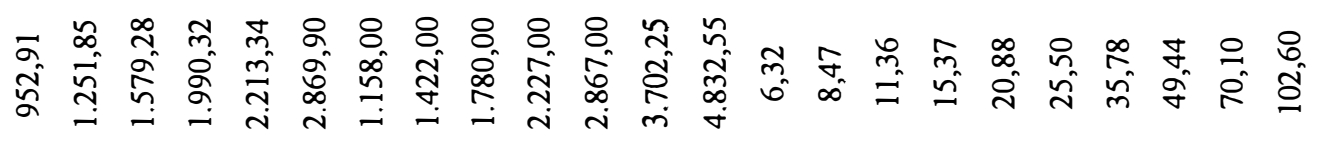

\&ి 윰

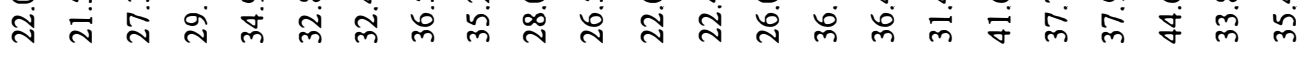

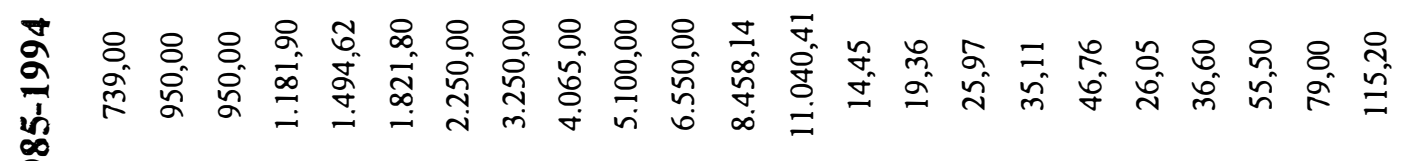

ஓ \& \& \&

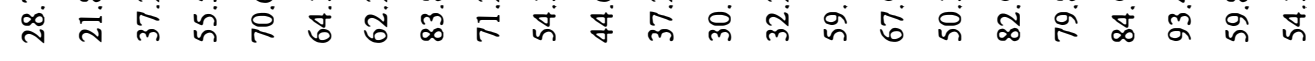

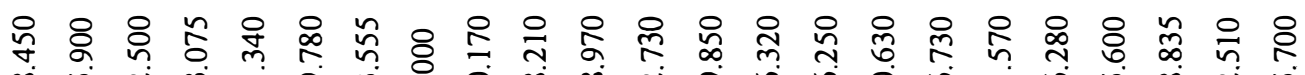

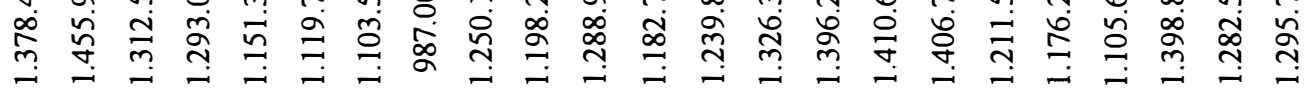

\&

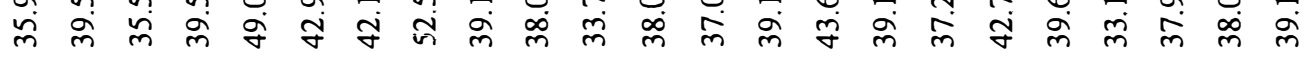

క్ష त

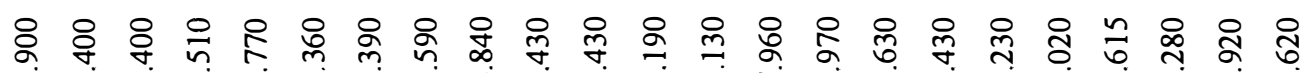

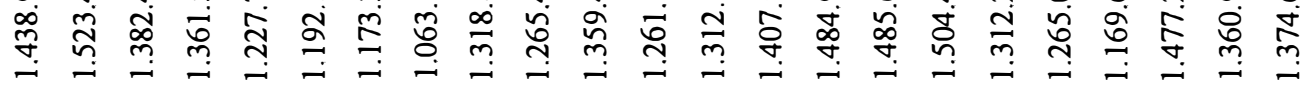

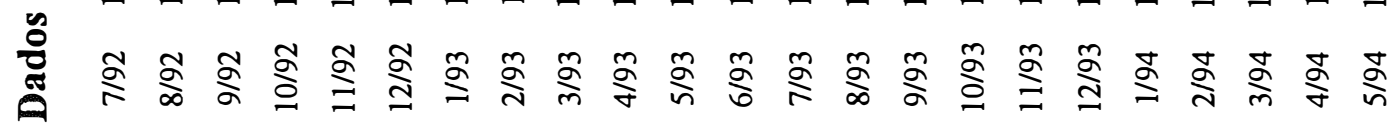




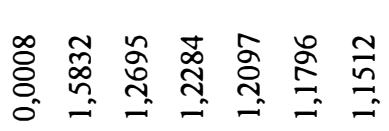

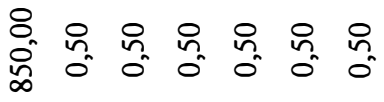

$000000=$

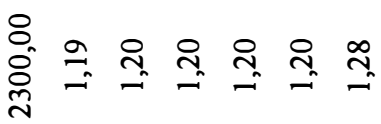

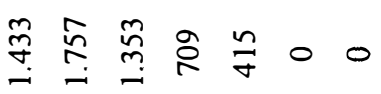

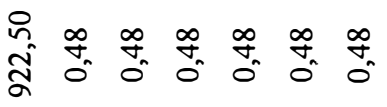

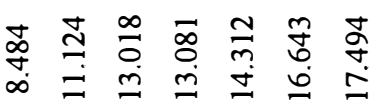

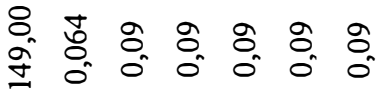

\& \& \& \& 용 \&

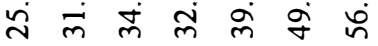

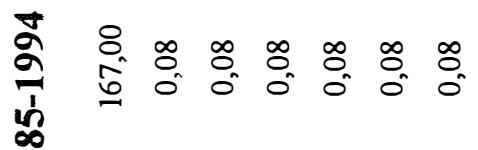

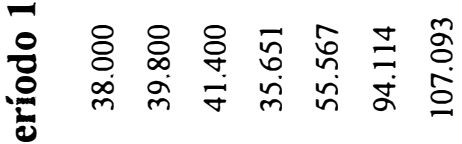

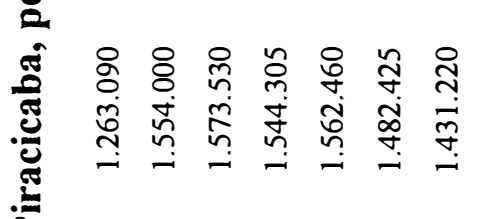

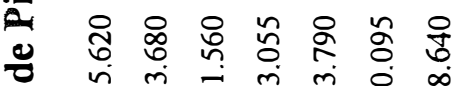

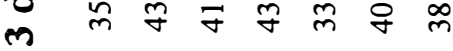

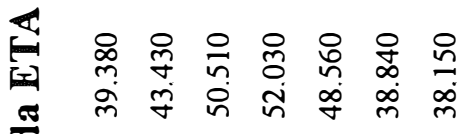

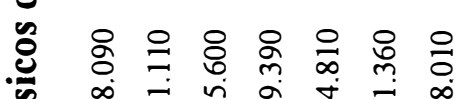

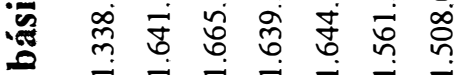

苛 
Tabela 24. Dados básicos da ETA 1 de Rio Claro, período 1985-1994

\begin{tabular}{|c|c|c|c|c|c|}
\hline $\begin{array}{l}\text { Mês e } \\
\text { ano }\end{array}$ & $\begin{array}{l}\text { Vazão } \\
\text { (m3) }\end{array}$ & $\begin{array}{l}\text { Quantidade } \\
\text { sulfato }(\mathrm{kg})\end{array}$ & $\begin{array}{l}\text { Quantidade } \\
\text { cal (kg) }\end{array}$ & $\begin{array}{l}\text { Quantidade } \\
\text { cloro }(\mathrm{kg})\end{array}$ & $\begin{array}{l}\text { Quantidade } \\
\text { flúor (kg) }\end{array}$ \\
\hline $1 / 85$ & 1.045 .896 & 37.200 & 10.840 & 941 & 3.850 \\
\hline $2 / 85$ & 999.770 & 30.600 & 9.640 & 898 & 3.400 \\
\hline $3 / 85$ & 1.109 .304 & 34.200 & 11.960 & 1.022 & 4.600 \\
\hline $4 / 85$ & 1.014 .624 & 30.000 & 10.380 & 964 & 4.000 \\
\hline $5 / 85$ & 1.015 .688 & 17.400 & 9.120 & 983 & 4.000 \\
\hline $6 / 85$ & 952.056 & 12.600 & 7.200 & 883 & 3.200 \\
\hline $7 / 85$ & 1.009 .894 & 12.600 & 8.720 & 936 & 2.400 \\
\hline $8 / 85$ & 1.094 .364 & 14.400 & 6.740 & 983 & 4.000 \\
\hline 9/85 & 1.044 .493 & 19.200 & 8.780 & 943 & 3.250 \\
\hline $10 / 85$ & 1.151 .892 & 16.200 & 6.440 & 1.009 & 3.600 \\
\hline $11 / 85$ & 1.125 .980 & 18.600 & 6.200 & 971 & 3.150 \\
\hline $12 / 85$ & 1.109 .592 & 20.400 & 6.740 & 1.024 & 4.100 \\
\hline $1 / 86$ & 1.115 .352 & 27.700 & 9.210 & 1.036 & 4.400 \\
\hline $2 / 86$ & 963.802 & 24.000 & 7.580 & 906 & 2.800 \\
\hline $3 / 86$ & 1.038 .700 & 3.5400 & 9.400 & 1.011 & 3.200 \\
\hline $4 / 86$ & 1.024 .848 & 26.400 & 10.690 & 1.021 & 3.200 \\
\hline $5 / 86$ & 994.680 & 16.800 & 8.320 & 1.004 & 3.300 \\
\hline $6 / 86$ & 996.876 & 13.200 & 6.780 & 1.020 & 3.200 \\
\hline $7 / 86$ & 1.048 .788 & 9.600 & 6.040 & 1.035 & 3.200 \\
\hline $8 / 86$ & 1.009 .756 & 13.800 & 6.780 & 1.039 & 3.600 \\
\hline 9/86 & 1.063 .512 & 16.200 & 7.800 & 1.028 & 3.600 \\
\hline $10 / 86$ & 1.111 .500 & 17.400 & 7.260 & 1.043 & 3.750 \\
\hline $11 / 86$ & 1.097 .496 & 25.800 & 9.550 & 1.120 & 3.600 \\
\hline $12 / 86$ & 1.057 .572 & 43.350 & 11.180 & 1.118 & 4.000 \\
\hline $1 / 87$ & 1.093 .968 & 36.000 & 89.000 & 8.900 & 3.850 \\
\hline $2 / 87$ & 995.760 & 26.400 & 6.960 & 6.960 & 3.000 \\
\hline $3 / 87$ & 1.079 .604 & 21.600 & 5.940 & 5.940 & 2.400 \\
\hline $4 / 87$ & 950.328 & 16.200 & 5.200 & 5.200 & 3.600 \\
\hline $5 / 87$ & 923.039 & 22.200 & 6.660 & 6.660 & 3.200 \\
\hline $6 / 87$ & 874.396 & 12.000 & 5.040 & 5.040 & 2.400 \\
\hline $7 / 87$ & 982.540 & 10.200 & 4.680 & 4.680 & 3.400 \\
\hline $8 / 87$ & 978.156 & 9.600 & 4.280 & 4.280 & 2.800 \\
\hline
\end{tabular}


Dados básicos da ETA 1 de Rio Claro, período 1985-1994

\begin{tabular}{|c|c|c|c|c|c|}
\hline 9/87 & 941.112 & 13.200 & 4.760 & 4.760 & 2.800 \\
\hline $10 / 87$ & 1.029 .708 & 19.350 & 5.660 & 5.660 & 2.200 \\
\hline $11 / 87$ & 1.032 .156 & 26.100 & 6.030 & 6.030 & 2.750 \\
\hline $12 / 87$ & 1.041 .047 & 31.200 & 5.960 & 5.960 & 1.350 \\
\hline $1 / 88$ & 1.060 .166 & 34.800 & 5.780 & 1.105 & 0 \\
\hline $2 / 88$ & 943.344 & 28.600 & 5.360 & 1.035 & 0 \\
\hline $3 / 88$ & 1.056 .203 & 38.800 & 5.540 & 1.135 & 0 \\
\hline $4 / 88$ & 972.973 & 26.400 & 5.200 & 1.127 & 0 \\
\hline $5 / 88$ & 992.500 & 22.800 & 5.520 & 1.168 & 2.550 \\
\hline $6 / 88$ & 893.483 & 15.000 & 5.240 & 1.106 & 2.800 \\
\hline $7 / 88$ & 1.012 .680 & 10.800 & 4.520 & 1.220 & 2.100 \\
\hline $8 / 88$ & 1.059 .717 & 9.600 & 4.660 & 1.239 & 3.300 \\
\hline $9 / 88$ & 1.069 .848 & 10.800 & 5.140 & 1.189 & 2.800 \\
\hline $10 / 88$ & 1.003 .500 & 28.200 & 8.040 & 1.220 & 3.050 \\
\hline $11 / 88$ & 972.818 & 8.620 & 8.620 & 1.188 & 700 \\
\hline $12 / 88$ & 1.077 .192 & 30.600 & 9.280 & 1.263 & 1.600 \\
\hline $1 / 89$ & 1.035 .577 & 36.600 & 8.860 & 1.313 & 0 \\
\hline $2 / 89$ & 930.204 & 32.400 & 7.440 & 1.209 & 0 \\
\hline $3 / 89$ & 1.001 .952 & 22.800 & 5.500 & 1.396 & 0 \\
\hline $4 / 89$ & 981.540 & 15.600 & 5.120 & 1.356 & 0 \\
\hline $5 / 89$ & 961.992 & 15.000 & 5.120 & 1.364 & 1.600 \\
\hline $6 / 89$ & 893.700 & 16.200 & 8.990 & 1.286 & 3.250 \\
\hline $7 / 89$ & 940.573 & 13.200 & 7.400 & 1.293 & 4.000 \\
\hline $8 / 89$ & 941.364 & 23.400 & 10.240 & 1.368 & 4.400 \\
\hline $9 / 89$ & 924.198 & 23.400 & 8.300 & 1.321 & 3.600 \\
\hline $10 / 89$ & 1.009 .620 & 23.400 & 8.800 & 1.344 & 4.000 \\
\hline $11 / 89$ & 1.003 .896 & 25.800 & 7.840 & 1.370 & 2.150 \\
\hline $12 / 89$ & 1.065 .204 & 37.800 & 10.020 & 1.594 & 2.150 \\
\hline $1 / 90$ & 977.940 & 42.000 & 9.600 & 1.573 & 2.150 \\
\hline $2 / 90$ & 920.736 & 30.000 & 7.980 & 7.980 & 0 \\
\hline $3 / 90$ & 995.798 & 34.400 & 8.980 & 8.980 & 0 \\
\hline $4 / 90$ & 930.924 & 25.800 & 8.160 & 8.160 & 0 \\
\hline $5 / 90$ & 939.564 & 18.600 & 7.640 & 7.640 & 3.150 \\
\hline $6 / 90$ & 897.048 & 11.400 & 6.180 & 6.180 & 1.050 \\
\hline $7 / 90$ & 980.784 & 13.800 & 7.640 & 7.640 & 2.400 \\
\hline
\end{tabular}




\section{Dados básicos da ETA 1 de Rio Claro, período 1985-1994}

\begin{tabular}{|c|c|c|c|c|c|}
\hline $8 / 90$ & 1.008 .244 & 15.600 & 8.280 & 8.280 & 0 \\
\hline 9/90 & 933.660 & 19.200 & 8.800 & 8.800 & 0 \\
\hline $10 / 90$ & 1.053 .180 & 30.600 & 10.440 & 10.440 & 1.200 \\
\hline $11 / 90$ & 1.052 .964 & 33.600 & 11.380 & 11.380 & 800 \\
\hline $12 / 90$ & 1.085 .220 & 33.000 & 9.400 & 9.400 & 4.000 \\
\hline $1 / 91$ & 1.272 .672 & 30.600 & 9.840 & 2.190 & 4.000 \\
\hline $2 / 91$ & 960.336 & 40.800 & 8.980 & 2.040 & 3.700 \\
\hline $3 / 91$ & 1.014 .660 & 39.000 & 9.680 & 2.282 & 4.400 \\
\hline $4 / 91$ & 1.042 .416 & 33.000 & 9.800 & 2.053 & 3.150 \\
\hline $5 / 91$ & 1.012 .248 & 25.000 & 11.500 & 2.309 & 1.850 \\
\hline $6 / 91$ & 963.433 & 18.000 & 8.900 & 2.204 & 3.000 \\
\hline $7 / 91$ & 991.080 & 16.200 & 7.420 & 2.280 & 4.450 \\
\hline $8 / 91$ & 1.062 .416 & 15.000 & 8.120 & 2.297 & 5.000 \\
\hline $9 / 91$ & 1.019 .088 & 19.200 & 9.760 & 2.184 & 5.600 \\
\hline $10 / 91$ & 1.042 .380 & 38.400 & 17.400 & 2.143 & 4.000 \\
\hline $11 / 91$ & 1.084 .824 & 31.800 & 13.900 & 2.076 & 2.900 \\
\hline $12 / 91$ & 1.064 .724 & 37.200 & 16.860 & 2.573 & 0 \\
\hline $1 / 92$ & 1.042 .452 & 39.600 & 17.160 & 2.435 & 0 \\
\hline $2 / 92$ & 1.019 .448 & 38.400 & 14.700 & 2.271 & 2.400 \\
\hline $3 / 92$ & 1.061 .100 & 34.200 & 10.780 & 2.730 & 2.450 \\
\hline $4 / 92$ & 994.104 & 32.400 & 15.500 & 2.621 & 1.900 \\
\hline $5 / 92$ & 996.948 & 28.800 & 16.000 & 2.838 & 0 \\
\hline $6 / 92$ & 965.376 & 21.600 & 14.720 & 2.671 & 2.700 \\
\hline $7 / 92$ & 1.000 .512 & 21.600 & 14.680 & 2.775 & 2.250 \\
\hline $8 / 92$ & 1.006 .128 & 21.000 & 12.300 & 3.071 & 1.400 \\
\hline $9 / 92$ & 947.563 & 22.200 & 10.800 & 2.240 & 1.800 \\
\hline $10 / 92$ & 1.025 .090 & 29.400 & 12.640 & 2.398 & 2.400 \\
\hline $11 / 92$ & 993.204 & 47.400 & 12.720 & 3.020 & 2.400 \\
\hline $12 / 92$ & 1.030 .284 & 49.800 & 15.100 & 2.911 & 1.450 \\
\hline $1 / 93$ & 1.026 .072 & 42.000 & 14.900 & 3.176 & 0 \\
\hline $2 / 93$ & 887.094 & 34.800 & 12.800 & 2.774 & 0 \\
\hline $3 / 93$ & 1.073 .152 & 36.600 & 15.220 & 3.342 & 900 \\
\hline $4 / 93$ & 1.007 .676 & 26.400 & 13.560 & 3.196 & 1.850 \\
\hline $5 / 93$ & 1.004 .751 & 25.200 & 11.180 & 4.611 & 2.150 \\
\hline $6 / 93$ & 962.630 & 20.400 & 10.260 & 4.657 & 900 \\
\hline
\end{tabular}


Dados básicos da ETA 1 de Rio Claro, período 1985-1994

\begin{tabular}{cccccc}
$7 / 93$ & 1.010 .124 & 15.600 & 8.380 & 4.427 & 2.400 \\
$8 / 93$ & 988.253 & 18.600 & 8.080 & 3.636 & 1.800 \\
$9 / 93$ & 989.820 & 30.000 & 13.280 & 3.831 & 2.100 \\
$10 / 93$ & 1.048 .392 & 37.800 & 15.740 & 3.800 & 2.100 \\
$11 / 93$ & 1.056 .744 & 31.200 & 14.320 & 3.990 & 1.800 \\
$12 / 93$ & 1.049 .252 & 28.200 & 15.140 & 4.062 & 2.500 \\
$1 / 94$ & 995.770 & 36.600 & 16.280 & 4.482 & 1.250 \\
$2 / 94$ & 949.932 & 39.000 & 15.720 & 4.458 & 0 \\
$3 / 94$ & 1.025 .859 & 32.400 & 15.480 & 4.881 & 1.500 \\
$4 / 94$ & 955.766 & 24.600 & 14.840 & 4.704 & 3.850 \\
$5 / 94$ & 990.720 & 24.000 & 15.320 & 4.822 & 3.500 \\
$6 / 94$ & 941.724 & 20.400 & 12.560 & 3.993 & 3.700 \\
$7 / 94$ & 985.896 & 16.800 & 10.920 & 4.268 & 4.000 \\
$8 / 94$ & 1.060 .625 & 16.800 & 9.420 & 4.344 & 2.400 \\
$9 / 94$ & 1.054 .944 & 22.800 & 14.660 & 4.596 & 1.300 \\
$10 / 94$ & 943.668 & 27.600 & 14.080 & 4.143 & 2.400 \\
$11 / 94$ & 988.020 & 35.400 & 15.940 & 4.251 & 1.200 \\
$12 / 94$ & 1.084 .514 & 40.200 & 16.040 & 4.630 & 1.000 \\
\hline
\end{tabular}

Fonte: DAAE 
Tabela 25. Dados básicos da ETA 2 de Rio Claro, período 1985-1994

\begin{tabular}{|c|c|c|c|c|c|}
\hline $\begin{array}{l}\text { Mês e } \\
\text { ano }\end{array}$ & $\begin{array}{l}\text { Vazão } \\
\text { (m3) }\end{array}$ & $\begin{array}{l}\text { Quantidade } \\
\text { sulfato }(\mathrm{kg})\end{array}$ & $\begin{array}{l}\text { Quantidade } \\
\text { cal (kg) }\end{array}$ & $\begin{array}{l}\text { Quantidade } \\
\text { cloro }(\mathrm{kg})\end{array}$ & $\begin{array}{l}\text { Quantidade } \\
\text { flúor }(\mathrm{kg})\end{array}$ \\
\hline $1 / 85$ & 110.650 & 11.950 & 4.040 & 154 & 0 \\
\hline $2 / 85$ & 99.240 & 10.050 & 2.780 & 153 & 0 \\
\hline $3 / 85$ & 99.440 & 7.450 & 2.380 & 163 & 0 \\
\hline $4 / 85$ & 110.260 & 6.950 & 2.600 & 166 & 0 \\
\hline $5 / 85$ & 104.580 & 5.600 & 2.040 & 152 & 0 \\
\hline $6 / 85$ & 96.320 & 4.150 & 1.680 & 139 & 0 \\
\hline $7 / 85$ & 102.619 & 4.600 & 1.940 & 138 & 0 \\
\hline $8 / 85$ & 128.030 & 4.600 & 2.530 & 157 & 0 \\
\hline $9 / 85$ & 108.760 & 4.365 & 1.880 & 156 & 0 \\
\hline $10 / 85$ & 126.300 & 4.750 & 1.880 & 186 & 0 \\
\hline $11 / 85$ & 118.070 & 5.200 & 2.420 & 164 & 0 \\
\hline $12 / 85$ & 116.320 & 6.250 & 3.100 & 168 & 0 \\
\hline $1 / 86$ & 117.240 & 7.000 & 2.900 & 2.900 & 0 \\
\hline $2 / 86$ & 106.190 & 9.250 & 5.640 & 5.640 & 0 \\
\hline $3 / 86$ & 105.090 & 7.750 & 2.860 & 2.860 & 0 \\
\hline $4 / 86$ & 111.610 & 5.050 & 2.760 & 2.760 & 0 \\
\hline $5 / 86$ & 118.710 & 6.730 & 3.380 & 3.380 & 0 \\
\hline $6 / 86$ & 100.670 & 5.200 & 3.060 & 3.060 & 0 \\
\hline $7 / 86$ & 123.630 & 6.700 & 3.640 & 3.640 & 0 \\
\hline $8 / 86$ & 105.920 & 6.000 & 3.160 & 3.160 & 0 \\
\hline $9 / 86$ & 103.900 & 4.850 & 3.300 & 3.300 & 0 \\
\hline $10 / 86$ & 126.890 & 6.450 & 3.880 & 3.880 & 0 \\
\hline $11 / 86$ & 127.980 & 9.150 & 4.720 & 4.720 & 0 \\
\hline $12 / 86$ & 129.660 & 11.800 & 5.040 & 5.040 & 0 \\
\hline $1 / 87$ & 146.520 & 8.700 & 4.780 & 192,5 & 0 \\
\hline $2 / 87$ & 140.920 & 7.600 & 3.580 & 175,1 & 0 \\
\hline $3 / 87$ & 201.960 & 10.800 & 5.140 & 241,1 & 0 \\
\hline $4 / 87$ & 328.420 & 14.750 & 7.500 & 238,5 & 0 \\
\hline $5 / 87$ & 355.940 & 17.650 & 7.920 & 282,7 & 0 \\
\hline $6 / 87$ & 322.720 & 11.750 & 5.560 & 248,2 & 0 \\
\hline $7 / 87$ & 392.660 & 13.600 & 7.500 & 281,4 & 0 \\
\hline $8 / 87$ & 386.000 & 8.800 & 6.140 & 217,6 & 0 \\
\hline $9 / 87$ & 354.960 & 8.750 & 5.180 & 256,6 & 0 \\
\hline $10 / 87$ & 493.720 & 14.300 & 8.100 & 410,3 & 0 \\
\hline
\end{tabular}


Dados básicos da ETA 2 de Rio Claro, período 1985-1994

\begin{tabular}{|c|c|c|c|c|c|}
\hline $11 / 87$ & 476.560 & 15.400 & 8.300 & 478,8 & 0 \\
\hline $12 / 87$ & 506.160 & 20.050 & 8.120 & 539,6 & 0 \\
\hline $1 / 88$ & 535.780 & 24.000 & 7.000 & 528,4 & 0 \\
\hline $2 / 88$ & 462.580 & 19.900 & 6.180 & 499,1 & 0 \\
\hline $3 / 88$ & 378.720 & 23.650 & 6.840 & 528,2 & 0 \\
\hline $4 / 88$ & 320.040 & 16.100 & 4.720 & 412,4 & 0 \\
\hline $5 / 88$ & 229.460 & 12.000 & 4.460 & 523,4 & 0 \\
\hline $6 / 83$ & 388.800 & 12.300 & 5.440 & 816 & 0 \\
\hline $7 / 88$ & 424.040 & 12.500 & 4.600 & 753,7 & 0 \\
\hline $8 / 88$ & 552.560 & 12.700 & 4.400 & 594,7 & 0 \\
\hline $9 / 88$ & 549.310 & 12.400 & 4.040 & 505,7 & 0 \\
\hline $10 / 88$ & 554.000 & 17.900 & 6.400 & 738,6 & 0 \\
\hline $11 / 88$ & 550.080 & 18.850 & 4.900 & 756,6 & 0 \\
\hline $12 / 88$ & 516.000 & 15.850 & 5.910 & 646,5 & 0 \\
\hline $1 / 89$ & 366.800 & 21.400 & 5.440 & 411,9 & 0 \\
\hline $2 / 89$ & 367.960 & 17.610 & 4.660 & 604,5 & 0 \\
\hline $3 / 89$ & 552.960 & 20.980 & 6.420 & 810,8 & 0 \\
\hline $4 / 89$ & 496.720 & 16.060 & 5.760 & 772,2 & 0 \\
\hline $5 / 89$ & 615.300 & 14.020 & 5.060 & 720,5 & 0 \\
\hline $6 / 89$ & 526.110 & 11.000 & 4.100 & 615,5 & 0 \\
\hline $7 / 89$ & 597.600 & 13.860 & 4.560 & 692,4 & 0 \\
\hline $8 / 89$ & 573.840 & 16.080 & 6.020 & 535,0 & 0 \\
\hline $9 / 89$ & 423.000 & 18.320 & 5.480 & 518,3 & 0 \\
\hline $10 / 89$ & 585.360 & 18.200 & 5.340 & 700,5 & 0 \\
\hline $11 / 89$ & 519.840 & 22.260 & 5.580 & 561,0 & 0 \\
\hline $12 / 89$ & 516.420 & 26.600 & 5.900 & 689,2 & 0 \\
\hline $1 / 90$ & 468.360 & 29.580 & 5.980 & . 698 & 0 \\
\hline $2 / 90$ & 531.260 & 18.560 & 4.960 & 751,5 & 0 \\
\hline $3 / 90$ & 587.520 & 25.020 & 5.340 & 950,5 & 0 \\
\hline $4 / 90$ & 510.048 & 16.560 & 4.720 & 842,5 & 0 \\
\hline $5 / 90$ & 529.600 & 13.920 & 4.540 & 859,2 & 0 \\
\hline $6 / 90$ & 438.840 & 12.640 & 4.400 & 819,2 & 0 \\
\hline $7 / 90$ & 445.180 & 12.280 & 4.580 & 661,5 & 0 \\
\hline $8 / 90$ & 493.920 & 12.880 & 4.620 & 753,0 & 0 \\
\hline $9 / 90$ & 472.960 & 13.660 & 4.540 & 805,0 & 0 \\
\hline $10 / 90$ & 575.200 & 19.620 & 6.360 & 921,8 & 0 \\
\hline $11 / 90$ & 466.560 & 21.440 & 5.620 & 929,5 & 0 \\
\hline
\end{tabular}


Dados básicos da ETA 2 de Rio Claro, período 1985-1994

\begin{tabular}{|c|c|c|c|c|c|}
\hline $12 / 90$ & 503.640 & 19.480 & 5.940 & 884,5 & 0 \\
\hline $1 / 91$ & 468.720 & 22.240 & 5.700 & 869,5 & 0 \\
\hline $2 / 91$ & 417.600 & 24.200 & 5.460 & 761,0 & 0 \\
\hline $3 / 91$ & 472.680 & 29.540 & 7.460 & 814,5 & 0 \\
\hline $4 / 91$ & 463.720 & 23.600 & 6.960 & 1080,5 & 0 \\
\hline $5 / 91$ & 461.520 & 19.880 & 7.640 & $1.156,0$ & 0 \\
\hline $6 / 91$ & 446.200 & 17.100 & 6.760 & $1.144,5$ & 0 \\
\hline $7 / 91$ & 479.660 & 17.760 & 6.680 & $1.227,5$ & 2.650 \\
\hline $8 / 91$ & 566.200 & 16.880 & 6.320 & $1.310,0$ & 3.750 \\
\hline $9 / 91$ & 625.360 & 17.820 & 7.200 & $1.179,0$ & 2.150 \\
\hline $10 / 91$ & 636.120 & 25.780 & 8.380 & $1.293,5$ & 3.750 \\
\hline $11 / 91$ & 714.960 & 23.780 & 7.940 & $1.541,5$ & 3.600 \\
\hline $12 / 91$ & 670.022 & 29.520 & 9.760 & $1.585,7$ & 0 \\
\hline $1 / 92$ & 671.890 & 27.040 & 8.720 & $1.505,0$ & 0 \\
\hline $2 / 92$ & 588.400 & 24.140 & 8.500 & $1.414,0$ & 4.920 \\
\hline $3 / 92$ & 610.024 & 25.980 & 8.600 & 1.512 & 2.460 \\
\hline $4 / 92$ & 567.080 & 23.600 & 9.040 & 1.447 & 3.120 \\
\hline $5 / 92$ & 545.040 & 23.920 & 8.520 & $1.527,5$ & 0 \\
\hline $6 / 92$ & 554.800 & 19.680 & 7.860 & $1.352,5$ & 4.020 \\
\hline $7 / 92$ & 565.560 & 20.520 & 7.600 & $2.242,0$ & 2.280 \\
\hline $8 / 92$ & 522.520 & 18.360 & 6.880 & $1.445,0$ & 2.280 \\
\hline $9 / 92$ & 518.520 & 19.440 & 6.680 & $1.434,5$ & 2.880 \\
\hline $10 / 92$ & 572.200 & 25.520 & 8.460 & $1.467,5$ & 2.820 \\
\hline $11 / 92$ & 610.240 & 33.240 & 10.720 & $1.685,0$ & 2.580 \\
\hline $12 / 92$ & 709920 & 36920 & 12040 & $2.105,0$ & 1.320 \\
\hline $1 / 93$ & 701640 & 39040 & 12320 & 1959,5 & 0 \\
\hline $2 / 93$ & 605.880 & 44.660 & 12.660 & $2.050,0$ & 0 \\
\hline $3 / 93$ & 683.640 & 34.790 & 10.780 & $2.178,0$ & 1.320 \\
\hline $4 / 93$ & 584.640 & 29.100 & 11.160 & $1.804,0$ & 1.800 \\
\hline $5 / 93$ & 624.960 & 30.740 & 10.000 & $1.328,0$ & 2.100 \\
\hline $6 / 93$ & 591.274 & 27.220 & 10.140 & $2.060,0$ & 400 \\
\hline $7 / 93$ & 642.200 & 24.780 & 10.120 & $1.810,0$ & 2.350 \\
\hline $8 / 93$ & 646.890 & 25.000 & 10.920 & $1.582,0$ & 2.200 \\
\hline $9 / 93$ & 660.960 & 27.860 & 9.540 & $1.773,0$ & 1.950 \\
\hline $10 / 93$ & 690.120 & 30.440 & 9.500 & $2.405,0$ & 2.150 \\
\hline $11 / 93$ & 716.040 & 26.360 & 8.640 & $2.502,0$ & 2.050 \\
\hline $12 / 93$ & 763.650 & 37.760 & 10.480 & $4.041,0$ & 1.400 \\
\hline
\end{tabular}


Dados básicos da ETA 2 de Rio Claro, período 1985-1994

\begin{tabular}{cccccc}
$1 / 94$ & 722.520 & 34.760 & 9.860 & $3.162,0$ & 1.300 \\
$2 / 94$ & 709.560 & 33.280 & 10.160 & $3.381,0$ & 0 \\
$3 / 94$ & 740.880 & 32.040 & 12.640 & $3.460,0$ & 1.050 \\
$4 / 94$ & 726.840 & 23.720 & 11.740 & 3.324 & 2.100 \\
$5 / 94$ & 758.160 & 21.440 & 9.510 & $3.228,0$ & 1.100 \\
$6 / 94$ & 732.240 & 18.200 & 11.600 & $3.390,0$ & 1.700 \\
$7 / 94$ & 764.640 & 17.480 & 9.140 & $3.248,0$ & 2.200 \\
$8 / 94$ & 787.400 & 16.300 & 9.280 & $3.422,0$ & 1.500 \\
$9 / 94$ & 759.240 & 15.080 & 7.500 & $3.146,0$ & 1.800 \\
$10 / 94$ & 786.240 & 22.400 & 9.000 & $2.751,0$ & 1.500 \\
$11 / 94$ & 752.520 & 27.520 & 8.800 & $2.302,0$ & 1.800 \\
$12 / 94$ & 798.120 & 31.420 & 9.740 & $2.798,0$ & 1.800 \\
\hline
\end{tabular}

Fonte: DAAE 
Tabela 26. Preço médio mensal da energía elétrica pago pela ETA 3 de Piracicaba (em reais de dezembro de 1995 por $\mathrm{kw} / \mathrm{h}$ )

\begin{tabular}{cccccccc}
\hline Mês & Preço & Mês & Preço & Mês & Preço & Mês & Preço \\
\hline $1 / 85$ & 0,176219 & $1 / 88$ & 0,085110 & $1 / 91$ & 0,177650 & $1 / 94$ & 0,337923 \\
$2 / 85$ & 0,172331 & $2 / 88$ & 0,177352 & $2 / 91$ & 0,216743 & $2 / 94$ & 0,313944 \\
$3 / 85$ & 0,210166 & $3 / 88$ & 0,158556 & $3 / 91$ & 0,203163 & $3 / 94$ & 0,287580 \\
$4 / 85$ & 0,206964 & $4 / 88$ & 0,222772 & $4 / 91$ & 0,197796 & $4 / 94$ & 0,425714 \\
$5 / 85$ & 0,195435 & $5 / 88$ & 0,307120 & $5 / 91$ & 0,177499 & $5 / 94$ & 0,395716 \\
$6 / 85$ & 0,144733 & $6 / 88$ & 0,249077 & $6 / 91$ & 0,185305 & $6 / 94$ & 0,099648 \\
$7 / 85$ & 0,217034 & $7 / 88$ & 0,243943 & $7 / 91$ & 0,185570 & $7 / 94$ & 0,078701 \\
$8 / 85$ & 0,202048 & $8 / 88$ & 0,288127 & $8 / 91$ & 0,179907 & $8 / 94$ & 0,071438 \\
$9 / 85$ & 0,200118 & $9 / 88$ & 0,277392 & $9 / 91$ & 0,174577 & $9 / 94$ & 0,074667 \\
$10 / 85$ & 0,223343 & $10 / 88$ & 0,272616 & $10 / 91$ & 0,168393 & $10 / 94$ & 0,083809 \\
$11 / 85$ & 0,189286 & $11 / 88$ & 0,225051 & $11 / 91$ & 0,179360 & $11 / 94$ & 0,068552 \\
$12 / 85$ & 0,243544 & $12 / 88$ & 0,218652 & $12 / 91$ & 0,214912 & $12 / 94$ & 0,066684 \\
$1 / 86$ & 0,174403 & $1 / 89$ & 0,211474 & $1 / 92$ & 0,210028 & & \\
$2 / 86$ & 0,174139 & $2 / 89$ & 0,215002 & $2 / 92$ & 0,204963 & & \\
$3 / 86$ & 0,209299 & $3 / 89$ & 0,219321 & $3 / 92$ & 0,220630 & & \\
$4 / 86$ & 0,206531 & $4 / 89$ & 0,235058 & $4 / 92$ & 0,285073 & & \\
$5 / 86$ & 0,171144 & $5 / 89$ & 0,229577 & $5 / 92$ & 0,251662 & & \\
$6 / 86$ & 0,156647 & $6 / 89$ & 0,208385 & $6 / 92$ & 0,226557 & & \\
$7 / 86$ & 0,159224 & $7 / 89$ & 0,210207 & $7 / 92$ & 0,240880 & & \\
$8 / 86$ & 0,150904 & $8 / 89$ & 0,200999 & $8 / 92$ & 0,282375 & & \\
$9 / 86$ & 0,159104 & $9 / 89$ & 0,211026 & $9 / 92$ & 0,280558 & & \\
$10 / 86$ & 0,151839 & $10 / 89$ & 0,207854 & $10 / 92$ & 0,263135 & & \\
$11 / 86$ & 0,143830 & $11 / 89$ & 0,231759 & $11 / 92$ & 0,241127 & & \\
$12 / 86$ & 0,142500 & $12 / 89$ & 0,238929 & $12 / 92$ & 0,236508 & & \\
$1 / 87$ & 0,123656 & $1 / 90$ & 0,201406 & $1 / 93$ & 0,287438 & & \\
$2 / 87$ & 0,113305 & $2 / 90$ & 0,246099 & $2 / 93$ & 0,223576 & & \\
$3 / 87$ & 0,097118 & $3 / 90$ & 0,235089 & $3 / 93$ & 0,237698 & & \\
$4 / 87$ & 0,130347 & $4 / 90$ & 0,251183 & $4 / 93$ & 0,308654 & & \\
$5 / 87$ & 0,127057 & $5 / 90$ & 0,234454 & $5 / 93$ & 0,335815 & & \\
$6 / 87$ & 0,141164 & $6 / 90$ & 0,208053 & $6 / 93$ & 0,360735 & & \\
$7 / 87$ & 0,211283 & $7 / 90$ & 0,199551 & $7 / 93$ & 0,379438 & & \\
$8 / 87$ & 0,192386 & $8 / 90$ & 0,168471 & $8 / 93$ & 0,415566 & & \\
$9 / 87$ & 0,189314 & $9 / 90$ & 0,162724 & $9 / 93$ & 0,412997 & & \\
$10 / 87$ & 0,158666 & $10 / 90$ & 0,188391 & $10 / 93$ & 0,305596 & & \\
$11 / 87$ & 0,190146 & $11 / 90$ & 0,180692 & $11 / 93$ & 0,308848 & & \\
$12 / 87$ & 0,160209 & $12 / 90$ & 0,182219 & $12 / 93$ & 0,312166 & & \\
\hline
\end{tabular}

Fonte: SEMAE 
Tabela 27. Preço da mão-de-obra pago pela ETA 3 de Piracicaba (em reais de dezembro de 1995 por mês)

\begin{tabular}{cccccccc}
\hline Mês & Preço & Mês & Preço & Mês & Preço & Mês & Preço \\
\hline $1 / 85$ & $1.287,84$ & $1 / 88$ & $1.726,58$ & $1 / 91$ & $1.455,44$ & $1 / 94$ & $1.536,48$ \\
$2 / 85$ & $1.041,15$ & $2 / 88$ & $1.384,12$ & $2 / 91$ & $2.084,30$ & $2 / 94$ & $2.703,33$ \\
$3 / 85$ & $1.178,43$ & $3 / 88$ & $1.420,39$ & $3 / 91$ & $2.516,59$ & $3 / 94$ & 708,44 \\
$4 / 85$ & 916,39 & $4 / 88$ & $1.553,57$ & $4 / 91$ & $2.884,86$ & $4 / 94$ & 533,37 \\
$5 / 85$ & $1.460,73$ & $5 / 88$ & $1.661,58$ & $5 / 91$ & $2.831,33$ & $5 / 94$ & 595,73 \\
$6 / 85$ & $1.234,34$ & $6 / 88$ & $1.219,46$ & $6 / 91$ & $2.934,28$ & $6 / 94$ & 589,09 \\
$7 / 85$ & $1.282,98$ & $7 / 88$ & $1.628,41$ & $7 / 91$ & $2.435,62$ & $7 / 94$ & 585,16 \\
$8 / 85$ & $1.222,52$ & $8 / 88$ & $1.340,57$ & $8 / 91$ & $2.379,29$ & $8 / 94$ & 617,65 \\
$9 / 85$ & $1.000,71$ & $9 / 88$ & 906,23 & $9 / 91$ & $2.305,25$ & $9 / 94$ & $1.184,31$ \\
$10 / 85$ & 986,81 & $10 / 88$ & $1.382,83$ & $10 / 91$ & $2.700,42$ & $10 / 94$ & $2.903,04$ \\
$11 / 85$ & $1.167,28$ & $11 / 88$ & $1.639,07$ & $11 / 91$ & $2.367,36$ & $11 / 94$ & 804,51 \\
$12 / 85$ & $1.134,89$ & $12 / 88$ & $2.209,58$ & $12 / 91$ & $3.289,15$ & $12 / 94$ & $1.991,43$ \\
$1 / 86$ & $1.812,75$ & $1 / 89$ & $2.293,15$ & $1 / 92$ & $1.557,85$ & & \\
$2 / 86$ & $1.341,42$ & $2 / 89$ & $2.784,34$ & $2 / 92$ & $2.371,18$ & & \\
$3 / 86$ & $1.527,56$ & $3 / 89$ & $3.390,82$ & $3 / 92$ & $2.449,09$ & & \\
$4 / 86$ & $1.450,44$ & $4 / 89$ & $3.762,34$ & $4 / 92$ & $2.333,40$ & & \\
$5 / 86$ & $1.419,51$ & $5 / 89$ & $3.729,19$ & $5 / 92$ & $3.046,85$ & & \\
$6 / 86$ & $1.453,01$ & $6 / 89$ & $3.430,95$ & $6 / 92$ & $2.704,59$ & & \\
$7 / 86$ & $1.562,04$ & $7 / 89$ & $3.215,69$ & $7 / 92$ & $2.692,03$ & & \\
$8 / 86$ & $1.359,07$ & $8 / 89$ & $2.597,36$ & $8 / 92$ & $2.743,26$ & & \\
$9 / 86$ & $1.715,24$ & $9 / 89$ & $1.794,33$ & $9 / 92$ & $2.879,59$ & & \\
$10 / 86$ & $1.629,73$ & $10 / 89$ & $2.997,64$ & $10 / 92$ & $2.790,76$ & & \\
$11 / 86$ & $1.807,98$ & $11 / 89$ & $3.251,19$ & $11 / 92$ & $3.148,14$ & & \\
$12 / 86$ & $1.624,61$ & $12 / 89$ & $2.604,63$ & $12 / 92$ & $4.183,54$ & & \\
$1 / 87$ & $1.553,67$ & $1 / 90$ & 696,47 & $1 / 93$ & $2.586,39$ & & \\
$2 / 87$ & $2.050,89$ & $2 / 90$ & $2.115,14$ & $2 / 93$ & $2.525,51$ & & \\
$3 / 87$ & $1.922,16$ & $3 / 90$ & $2.414,02$ & $3 / 93$ & $2.961,84$ & & \\
$4 / 87$ & $1.668,23$ & $4 / 90$ & $2.026,84$ & $4 / 93$ & $3.244,06$ & & \\
$5 / 87$ & $1.713,97$ & $5 / 90$ & $2.295,52$ & $5 / 93$ & $2.691,40$ & & \\
$6 / 87$ & $1.261,11$ & $6 / 90$ & $2.607,02$ & $6 / 93$ & $2.853,94$ & & \\
$7 / 87$ & $1.489,41$ & $7 / 90$ & $2.657,20$ & $7 / 93$ & $2.418,42$ & & \\
$8 / 87$ & $1.327,24$ & $8 / 90$ & $2.937,30$ & $8 / 93$ & $2.566,42$ & & \\
$9 / 87$ & $1.597,51$ & $9 / 90$ & $2.578,67$ & $9 / 93$ & $2.913,09$ & & \\
$10 / 87$ & $1.546,66$ & $10 / 90$ & $3.198,92$ & $10 / 93$ & $2.346,48$ & & \\
$11 / 87$ & $1.502,13$ & $11 / 90$ & $2.672,50$ & $11 / 93$ & $2.531,40$ & & \\
$12 / 87$ & $1.231,93$ & $12 / 90$ & $7.264,08$ & $12 / 93$ & $4.804,76$ & & \\
\hline
\end{tabular}


Tabela 28. Estimativa da média mensal do custo operacional de tratamento de água na ETA 3 (em logaritmo neperiano), sem levar em conta a carga de sedimentos, 1985.

\begin{tabular}{lccc}
\hline \multicolumn{1}{c}{ Variável } & Coeficiente estimado & Valor médio 1985 (ln) & Produto \\
\hline Intercepto & $-14,6084$ & & \\
Água distribuída (A) & 1,963388 & 6,725541 & 13,2048 \\
Carga de sedimentos (Y) & 0,072224 & & \\
Preço do sulfato de alumínio (ps) & $-2,368055$ & 5,564280 & $-13,1765$ \\
Preço do cal (pc) & 1,501110 & 5,241512 & 7,8681 \\
Preço do cloro (pcl) & $-0,778417$ & 5,015914 & $-3,9045$ \\
Salário (sal) & 5,684321 & 4,301873 & 24,4532 \\
Preço da eletricidade (ele) & $-3,038958$ & 6,061105 & $-18,4194$ \\
pspc & 0,066256 & 14,584690 & 0,9663 \\
pspcl & 0,308029 & 13,955620 & 4,2987 \\
pssal & $-0,169327$ & 11,968190 & $-2,0265$ \\
psele & 0,266964 & 16,866530 & 4,5028 \\
pcpcl & 0,112853 & 13,145370 & 1,4835 \\
pcsal & 0,024636 & 11,273600 & 0,2777 \\
pcele & $-0,451735$ & 15,885680 & $-7,1761$ \\
pclsal & $-0,344384$ & 10,790480 & $-3,7161$ \\
pclele & $-0,111972$ & 15,200530 & $-1,7020$ \\
salele & 0,298680 & 13,035860 & 3,8936 \\
psA & 0,226717 & 37,420700 & 8,4839 \\
pcA & $-0,131108$ & 35,250280 & $-4,6216$ \\
pclA & 0,152329 & 33,738970 & 5,1394 \\
salA & $-0,714093$ & 28,943450 & $-20,6683$ \\
eleA & 0,466155 & 40.768370 & 19,0044 \\
Dummy & $-0,3248$ & & \\
Dummyl & 0,1266 & & 18,1654 \\
Sub-total & & & \\
\hline
\end{tabular}

Fonte: resultados da pesquisa.

Ao subtotal de 18,1654 foi-lhe subtraído o intercepto $(-14,6084)$ e a Dummy $(-0,3248)$, resultando num valor de 3,2322. Esse valor de 3,2322 vai para a Tabela 28 como uma constante na coluna de custo mensal sem carga de sedimento (Y).

Os valores da coluna de carga de sedimentos da Tabela 28 foram multiplicados pelo coeficiente estimado $(0,072224)$. O produto obtido, para cada mês, foi adicionado aos valores da coluna custo mensal sem carga de sedimento da Tabela 27. Ao total de cada mês foi aplicado o antilog para se obter a estimativa do custo mensal em $\mathrm{R} \$$ de dezembro de 1995. O exemplo para o mês de janeiro serve como ilustração: 
$5,522 \times 0,072224=0,3988 ; 3,2322+0,3987=3,6310 ;$ antilog de $3,6310=R \$$ $37.750,54$.

Tabela 29. Estimativa do custo adicional mensal de tratamento de água causado pela carga de sedimentos na ETA 3, 1985.

\begin{tabular}{lcccccc}
\hline \multicolumn{1}{c}{$\begin{array}{c}\text { Custo mensal } \\
\text { sem carga } \\
\text { Mês }\end{array}$} & $\begin{array}{c}\text { Carga } \\
\text { sedimento }\end{array}$ & $\begin{array}{c}\text { sedimentos } \\
(\mathrm{ln})\end{array}$ & $\begin{array}{c}\text { Custo mensal } \\
(\mathrm{R} \$ \text { dez./95) }\end{array}$ & $\begin{array}{c}\text { Água tratada } \\
\left(\mathrm{m}^{3}\right)\end{array}$ & $\begin{array}{c}\text { Custo } \\
\left(\mathrm{R} \$ \mathrm{~m}^{3}\right)\end{array}$ & $\begin{array}{c}\text { Custo } \\
\text { adicional } \\
\left(\mathrm{RS} / \mathrm{m}^{3}\right)\end{array}$ \\
\hline Janeiro & 3.2322 & 5,52 & $37.750,16$ & 748.980 & 0,0504 & 0,0145 \\
Fevereiro & 3.2322 & 5,25 & $37.021,64$ & 622.400 & 0,0595 & 0,0236 \\
Março & 3.2322 & 4,96 & $36.248,89$ & 802.370 & 0,0452 & 0,0093 \\
Abril & 3.2322 & 3,72 & $33.148,59$ & 729.010 & 0,0455 & 0,0096 \\
Maio & 3.2322 & 4,01 & $33.855,35$ & 989.100 & 0,0342 & $-0,0017$ \\
Junho & 3.2322 & 3,00 & $31.474,07$ & 847.390 & 0,0371 & 0,0013 \\
Julho & 3.2322 & 2,56 & $30.474,83$ & 749.200 & 0,0407 & 0,0048 \\
Agosto & 3.2322 & 2,50 & $30.342,69$ & 845.570 & 0,0359 & 0,0000 \\
Setembro & 3.2322 & 3,69 & $33.067,77$ & 818.010 & 0,0404 & 0,0045 \\
Outubro & 3.2322 & 4,73 & $35.642,88$ & 1.154 .750 & 0,0309 & $-0,0050$ \\
Novembro & 3.2322 & 4,85 & $35.969,78$ & 900.160 & 0,0400 & 0,0041 \\
Dezembro & 3.2322 & 5,51 & $37.715,78$ & 1.070 .630 & 0,0352 & $-0,0007$ \\
\hline
\end{tabular}

Fonte: resultados da pesquisa.

Dividindo-se o custo operacional mensal por a quantidade de água tratada em cada mês obtém-se o custo operacional de tratamento por $\mathrm{m}^{3}$, assim:

$37.750,54 / 748.980=\mathrm{R} \$ 0,0504 / \mathrm{m}^{3}$.

Subtraindo o custo $/ \mathrm{m}^{3}$ correspondente ao mês de agosto do custo $/ \mathrm{m}^{3}$ de cada um dos outros meses do ano, obtém-se o custo adicional $/ \mathrm{m}^{3}$ causado pela erosão do solo, assim:

$0,0504-0,0359=\mathrm{R} \$ 0,0145 / \mathrm{m}^{3}$.

Multiplicando-se o custo adicional $/ \mathrm{m}^{3}$ vezes a quantidade de água tratada obtém-se o custo adicional mensal:

$0,0145 \times 748.980=R \$ 10.873,76$. 
Tabela 30. Estimativa do custo adicional mensal de tratamento de água nas três ETAs da bacia do rio Corumbatai, 1985.

\begin{tabular}{lrrrrr}
\hline \multicolumn{1}{c}{ Mês } & $\begin{array}{c}\text { Custo adicional } \\
\text { mensal ETA 3 } \\
(\mathrm{R} \$ \text { dez./95 })\end{array}$ & $\begin{array}{c}\text { Vazão ETA 1 } \\
\left(\mathrm{m}^{3}\right)\end{array}$ & $\begin{array}{c}\text { Custo adicional } \\
\text { mensal ETA 1 } \\
(\mathrm{R} \$ \text { dez./95 })\end{array}$ & $\begin{array}{r}\text { Vazão ETA 2 } \\
\left(\mathrm{m}^{3}\right)\end{array}$ & $\begin{array}{c}\text { Custo adicional } \\
\text { mensal ETA 2 } \\
(\mathrm{RS} \mathrm{dez./95)}\end{array}$ \\
\hline Janeiro & $10.873,76$ & 1.045 .896 & $15.165,49$ & 110.650 & $1.604,43$ \\
Fevereiro & $14.687,44$ & 999.770 & $23.594,57$ & 99.240 & $2.342,06$ \\
Março & $7.456,65$ & 1.109 .304 & $10.316,53$ & 99.440 & 924,79 \\
Abril & $6.988,79$ & 1.014 .624 & $9.740,39$ & 110.260 & $1.058,50$ \\
Maio & $-1.637,51$ & 1.015 .688 & $-1.726,67$ & 104.580 & $-177,79$ \\
Junho & $1.066,32$ & 952.056 & $1.237,67$ & 96.320 & 125,22 \\
Julho & $3.590,54$ & 1.009 .894 & $4.847,49$ & 102.619 & 492,57 \\
Agosto & 0,26 & 1.094 .364 & - & 128.030 & - \\
Setembro & $3.714,29$ & 1.044 .493 & $4.700,22$ & 108.760 & 489,42 \\
Outubro & $-5.794,17$ & 1.151 .892 & $-5.759,46$ & 126.300 & $-631,50$ \\
Novembro & $3.668,44$ & 1.125 .980 & $4.616,52$ & 118.070 & 484,09 \\
Dezembro & $-702,71$ & 1.109 .592 & $-776,71$ & 116.320 & $-81,42$ \\
Total & $43.911,89$ & & $65.956,04$ & & $6.630,37$ \\
\hline
\end{tabular}

Fonte: resultados da pesquisa.

$\mathrm{O}$ custo adicional mensal para as ETAs 1 e 2 obteve-se multiplicando o custo adicional $/ \mathrm{m}^{3}$ da ETA 3 (última coluna da Tabela 28 ) vezes a vazão das respectivas ETAs. Por exemplo, para o mês de janeiro:

$0,0145 \times 1.045 .896=\mathrm{R} \$ 15.165,49 ; \mathrm{e}$,

$0,0145 \times 110.650=\mathrm{R} \$ 1.604,43$, para as ETAs 1 e 2, respectivamente.

Finalmente, somado o custo adicional mensal através dos meses do ano obtémse o custo adicional anual de $R \$ 43.911,89$ para a ETA 3; $R \$ 65.956,04$ para a ETA 1; e, R\$6.630,37 para a ETA 2 .

Somando o custo adicional anual através das três ETAs gera-se a estimativa do custo adicional anual para a bacia toda:

$43.911,89+65.956,04+6.630,37=\mathrm{R} \$ 116.498$ que corresponde ao primeiro valor da segunda coluna da Tabela 8 (ano de 1985). A diferença de $\mathrm{R} \$ 41$ deve-se ao diferente número de cassas decimais utilizadas nos cálculos. 
Os valores para o custo adicional causado pelas perdas de terra toleráveis foram calculados da mesma forma, mudando-se unicamente os valores da carga de sedimentos. 